\title{
Article \\ An Extended Entropic Model for Cohesive Sediment Flocculation in a Piecewise Varied Shear Environment
}

\author{
Zhongfan Zhu ${ }^{1, *(D)}$ and Jie Dou ${ }^{2}$ D \\ 1 Beijing Key Laboratory of Urban Hydrological Cycle and Sponge City Technology, College of Water Sciences, \\ Beijing Normal University, Beijing 100875, China \\ 2 Three Gorges Research Center for Geo-Hazards, Ministry of Education, China University of Geosciences, \\ Wuhan 430074, China; douj888@gmail.com \\ * Correspondence: zhuzhongfan1985@bnu.edu.cn; Tel.: +86-10-5880-2739
}

Citation: Zhu, Z.; Dou, J. An Extended Entropic Model for Cohesive Sediment Flocculation in a Piecewise Varied Shear Environment. Entropy 2021, 23, 1263. https:// doi.org/10.3390/e23101263

Academic Editor: Raúl Alcaraz

Received: 26 August 2021

Accepted: 25 September 2021

Published: 28 September 2021

Publisher's Note: MDPI stays neutral with regard to jurisdictional claims in published maps and institutional affiliations.

Copyright: (c) 2021 by the authors. Licensee MDPI, Basel, Switzerland. This article is an open access article distributed under the terms and conditions of the Creative Commons Attribution (CC BY) license (https:// creativecommons.org/licenses/by/ $4.0 /)$.

\begin{abstract}
In this study, an extended model for describing the temporal evolution of a characteristic floc size of cohesive sediment particles when the flocculation system is subject to a piecewise varied turbulent shear rate was derived by the probability methods based on the Shannon entropy theory following Zhu (2018). This model only contained three important parameters: initial and steady-state values of floc size, and a parameter characterizing the maximum capacity for floc size increase (or decay), and it can be adopted to capture well a monotonic pattern in which floc size increases (or decays) with flocculation time. Comparison with 13 literature experimental data sets regarding floc size variation to a varied shear rate showed the validity of the entropic model with a high correlation coefficient and few errors. Furthermore, for the case of tapered shear flocculation, it was found that there was a power decay of the capacity parameter with the shear rate, which is similar to the dependence of the steady-state floc size on the shear rate. The entropic model was further parameterized by introducing these two empirical relations into it, and the finally obtained model was found to be more sensitive to two empirical coefficients that have been incorporated into the capacity parameter than those in the steady-state floc size. The proposed entropic model could have the potential, as an addition to existing flocculation models, to be coupled into present mature hydrodynamic models to model the cohesive sediment transport in estuarine and coastal regions.
\end{abstract}

Keywords: cohesive sediment; flocculation; entropy; piecewise varied shear; model

\section{Introduction}

Cohesive sediment is composed of water, fine-grained sediments (such as silt and clay), and organic matter [1-4], and it can absorb some pollutants (such as heavy metals) and nutrients on its surface due to a short-range electrochemical attraction [5-7]. When some cohesive sediments are transported into rivers, lakes, reservoirs, and estuarine and coastal waters, they are aggregated due to a particle-particle attractive force, forming some flocs of varied sizes; however, they also experience a breakage impact in the turbulent flow when the flow shear exceeds their inherent strengths [8-10]. Flocs are greatly different from primary particles (i.e., the basic element of which a porous floc is comprised) in terms of larger sizes, more porous structures, and faster-settling velocities [4,11-13]. Therefore, studying the flocculation characteristic of cohesive sediment particles is of importance since it plays an essential role in affecting the water quality change, ecosystem function evolution, and bio-geochemical cycle process in some aquatic environments [4,14-17].

Flocculation of cohesive particles is not only limited to cohesive sediment science. In other research areas, such as sanitary engineering, water treatment works, and colloidal science, particle flocculation is an essential element in some dynamic processes, and related studies regarding its mechanism are always a research focus [18-29]. Especially, the temporal evolution of the floc size distribution of cohesive particles in a turbulent fluid has been investigated by many researchers via theoretical formulation [2,9,30-32], numerical 
simulation [33-39], and experimental observation [6,23,26,40] in many disciplines. At present, there are three kinds of deterministic flocculation models in the literature, as summarized by Shen et al. (2015) [37]. The first kind is the Lagrangian flocculation model originally proposed by Winterwerp (1998) [9] and its modified versions [2,28,31,32]. The second kind of flocculation model is the population balance model (PBM) $[10,34,36-38,41]$, which is based on a classic equation originally by Smoluchowski (1918) [34,42-44]. The third kind of flocculation model is based on the lattice Boltzmann method [37,39,45].

In contrast to the above deterministic models, there has also been a kind of flocculation model in a stochastic form based on some probability knowledge [46-48]. By considering a sequence of stochastic aggregation and breakup events among particles, Maggi (2008) formulated a stochastic Lagrangian model to describe the flocculation of suspended cohesive sediment flocs in water [46]. This model can be adopted to reflect floc mobility within the population size spectrum in terms of a stochastic perspective. Different from Son and Hsu (2009) [30], Shin et al. (2015) dealt with the floc breakup term of the Winterwerp model to be a stochastic variable, and the modified model can reproduce the floc size spectrum well for different water-sediment conditions [47]. Zhu (2018) derived a simple and explicit expression for floc size variation in a fixed flow shear environment based on the entropy concept. Recently, Shen et al. (2021) developed a quasi-Monte Carlo model to predict the temporal evolution of floc size distribution of cohesive sediment in aquatic environments, and its validity has been tested by comparing with known simple analytical solutions and two series of laboratory experimental data [48].

These models have provided a tool to predict the floc size distribution (or characteristic floc size) in a constant turbulent shear environment. However, different from a laboratory experiment where a simple flow shear condition has been easily controlled [28,49-51], hydrodynamic conditions in natural waters are always complicated [17,52-56]. For example, it could include many cycles of a high and low shear condition, which leads to a complicated variation of floc size distribution. Some in situ observations have shown that floc size distribution is sensitive to the change of flow shear rate in a tidal estuary, deltas, and coastal regions [52,53,55,57]. Eisma and $\operatorname{Li}(2019)$ and Braithwaite et al. (2012) observed an obvious difference in floc size distribution among the slack, ebb, and flood parts of a tidal cycle in the estuary $[28,58,59]$. In river mouths, some measurements have also shown that river input condition reshapes the floc size distribution in waters $[28,55,60]$. In the wastewater treatment, sanitary engineering, and colloidal science fields, the flocs are often subject to cycles of high and low shearing conditions to maximize the flocculation efficiency and optimize the separation effect [22,24]. Thus, for these engineering circumstances, attention should be paid to the performance of flocculation models for cohesive particle flocculation under a piecewise varied shearing condition in terms of accuracy and efficiency.

In this study, we attempted to extend the work of Zhu (2018) and proposed a simple flocculation model of cohesive particles in a consecutive varied shear environment using the entropic model. Different from existing flocculation models, the entropic model contains a small number of input parameters and calibrated parameters, and it might be an attractive choice for tracing the floc size variation in a complicated hydrodynamic condition. Entropy, as a measure of uncertainty associated with the system, originates from the thermodynamic subject and is widely applied to various research fields [61]. In hydraulic engineering, Chiu (1987) was the first to derive the one-dimensional longitudinal velocity distribution along the vertical direction in an open channel using the entropy concept [62]. Since then, some researchers have adopted the entropy method based on the probability to deal with some classic hydraulic engineering problems. They include velocity distribution in open channels or a canopy open channel flow $[63,64]$, suspended sediment concentration distribution [65], boundary shear stress in circular and trapezoidal channels [66], infiltration process in unsaturated soils [67], flow duration curve [68], sediment graph [69], rating curve [70], and velocity-dip position in an open channel [71]. In these works, the entropic method showed its potential to tackle the engineering problems as an addition to existing deterministic models. 
The paper is arranged as follows. Starting from a single-step flocculation model, Section 2 formulates a multi-step model for flocculation of cohesive particles subject to a piecewise varied shear using the Shannon entropy concept. Section 3 tests the model accuracy by comparing it with 13 experimental data sets regarding floc size variation in a varied shear condition from the literature. Two important parameters that have been incorporated into the model, the steady-state floc size and the maximum capacity for floc size growth (or decay) and the sensitivity of the entropic model to some empirical parameters, as well as an application of the entropic model in engineering practices, are also analyzed in Section 4. Finally, Section 5 presents some concluding remarks.

\section{Multi-Step Entropic Model for Sediment Flocculation}

The turbulent flow environment where sediment flocculation develops is often characterized by the flow shear rate $G$ (its unit is $\mathrm{s}^{-1}$ ). It is defined as $G=\sqrt{\varepsilon / v}$, where $\varepsilon$ is the turbulent dissipation rate of flow and $v$ is the kinematic viscosity of the fluid, as employed by some studies $[9,10,21,23,26-28,40,72]$.

Since the flocculation model for a constant shear environment is the basis for the flocculation model formulation for a piecewise varied shear condition, a constant shearinduced flocculation model using the entropy method is presented firstly in the following.

\subsection{Flocculation Model for a Constant Flow Shear Environment}

2.1.1. Floc Size Growth toward the Steady State at a Constant Shear Rate

As shown in Figure 1, the sediment flocculation system experiences a rapidly increasing phase, a subsequently slowly increasing phase, and finally a steady state in terms of the characteristic size of the floc population (always characterized by its median size of floc population, $L$ ) with flocculation time $t$, given a constant flow shear environment (i.e., constant $G$ ). The application of the Shannon entropic method to the flocculation process includes the following steps: definition of Shannon entropic function, specification of constraint condition, maximization of entropic function, calculation of Lagrange multiplier, hypothesis on a cumulative distribution function, and finally derivation of flocculation model, as presented in Zhu (2018) [73]. To avoid repetition, the results for flocculation expression are only presented here in this study, and specific mathematical derivations regarding it can be found in Zhu (2018) [73] in more detail.

By the Shannon entropy method, floc size $L(t)$ can be obtained as:

$$
L(t)=L_{s}-\left(L_{s}-L_{0}\right) \exp \left[-\frac{L_{s}-L_{0}}{M}\left(t-t_{0}\right)\right]
$$

where $L_{0}$ and $L_{s}$ are the initial value and the steady-state value of floc size, respectively, $M$ is the proposed maximum capacity for floc size growth (its unit is equal to the multiplication of units of floc size and flocculation time), and $t_{0}$ is the initial time at which flocculation starts. It can be seen from Equation (1) that floc size growth approaches its steady state almost after a flocculation time point $t_{0}+3 M /\left(L_{s}-L_{0}\right)$ for a given flocculation system, and, in other words, the proposed parameter $M$ determines the rapidity with which the steady state is approached. In the work of Zhu (2018) [73], Equation (1) was presented to agree with existing experimental data sets well, and the parameter $M$ is a monotonic function of the flow shear rate $G$, which will be mentioned in Section 4.1.

\subsubsection{Floc Size Decay toward Another Steady State at a Higher Constant Shear Rate}

When the flocculation system is suddenly subject to a stronger shear, floc size will make a corresponding response. As flocculation time progresses, floc size experiences a rapidly decreasing phase and a slowly decreasing phase before entering another steady state, as shown by some laboratory experiments [18-20,22-24,27,74]. As illustrated in Figure 2, we can also derive an entropic flocculation model for this case, which is similar to that mentioned in Section 2.1.1. 


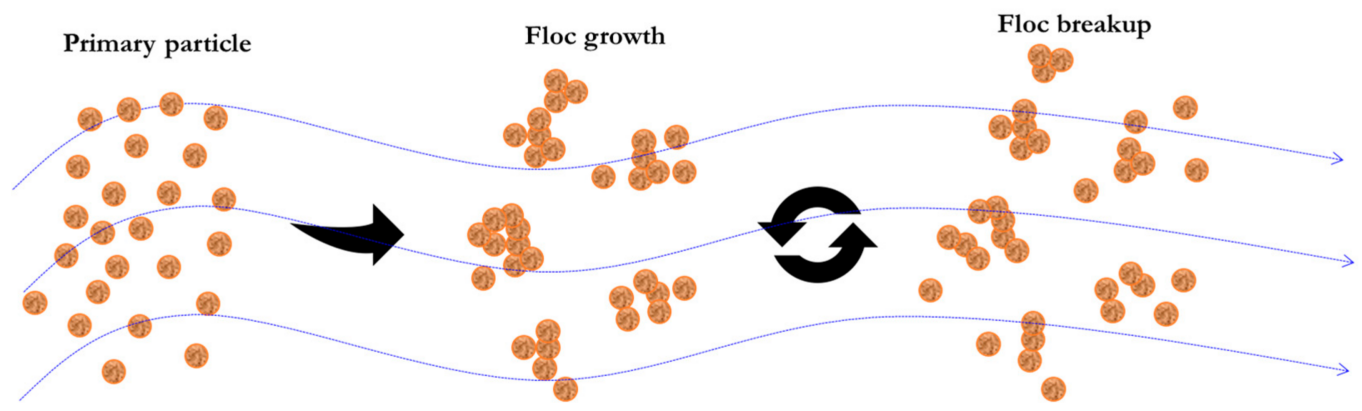

(a)

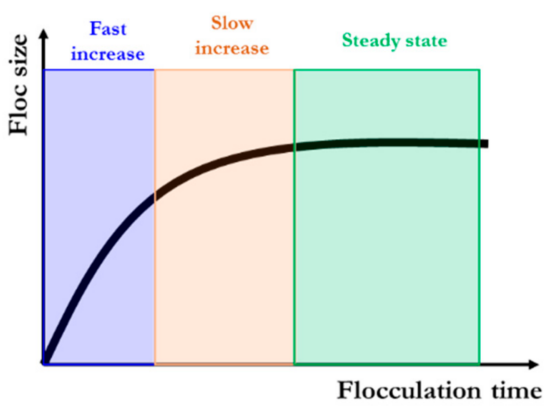

(b)

Figure 1. Schematic of particle flocculation in a constant shear rate (partly redrawn based on Zhu (2018) [73]): (a) floc variation; (b) floc size variation with flocculation time.

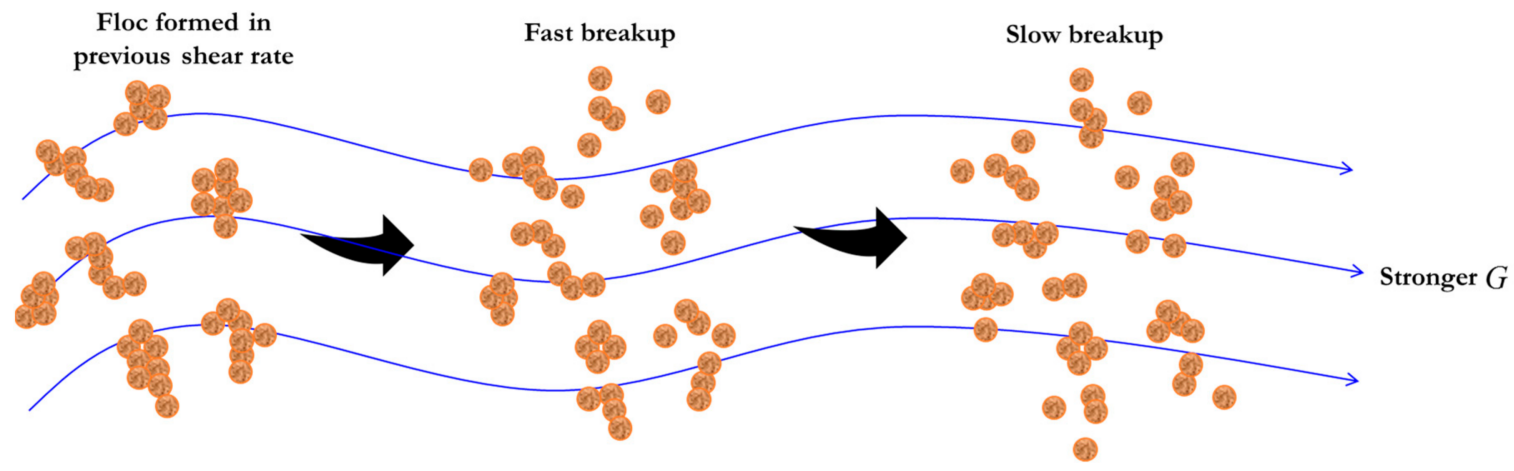

(a)
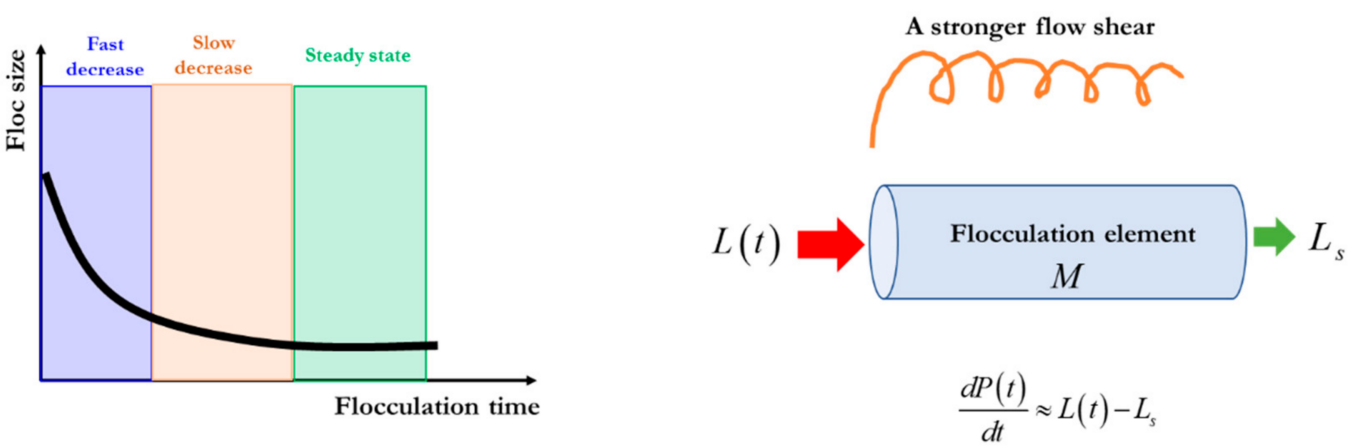

(b)

Figure 2. Schematic of floc size decay subject to a stronger flow shear: (a) floc variation; (b) floc size variation with flocculation time and flocculation element. 
The Shannon entropy function $H(L)$ of floc size during stronger shear-induced flocculation can be written in the following form [62]:

$$
H(L)=-\int_{L_{s}}^{L_{0}} f(L)[\ln f(L)] d L
$$

where $f(L)$ is the probability density function, and the probability law becomes:

$$
\int_{L_{s}}^{L_{0}} f(L) d L=1
$$

where $L_{s}<L_{0}$. Furthermore, the Lagrangian function $\Lambda$ is constructed by

$$
\Lambda=-\int_{L_{s}}^{L_{0}} f(L)[\ln f(L)] d L+\lambda\left[\int_{L_{s}}^{L_{0}} f(L) d L-1\right]
$$

where $\lambda$ is the Lagrange multiplier. Taking its derivative to $f(L)$ and defining it to be zero can still have:

$$
f(L)=\exp (\lambda-1)
$$

Integrating it from the steady-state value $L_{S}$ to arbitrary value $L$ can yield $F(L)$ in the following form:

$$
F(L)=\left(L-L_{S}\right) \exp (\lambda-1)
$$

Choose a small flocculation element at a certain flocculation time $t$ (as shown in Figure $2 \mathrm{~b}$ ) with its input being floc size $L(t)$ and its output being approximated by its steady-state value $L_{s}$. Here, the parameters $P$ and $M$ denote the cumulative quantity and the maximum capacity for floc size decay, respectively. The mass conservation equation for the flocculation element becomes

$$
\frac{d P(t)}{d t} \approx L(t)-L_{s}
$$

Further, the cumulative distribution function of floc size in the space domain could be hypothesized to be 1 minus the ratio of the cumulative quantity of floc size decay to the maximum capacity, i.e.,

$$
F(L)=1-\frac{P}{M}
$$

which means the cumulative distribution function monotonically increases from null to unity as flocculation time progresses from the initial time to infinity, and all of the values of flocculation time $t$ between $t_{0}$ and $\infty$ are equally likely.

Substituting Equation (5) into Equation (3) can have: $\exp (\lambda-1)=1 /\left(L_{0}-L_{s}\right)$. Combining it with Equations (6)-(8) can yield the following analytical expression for floc size $L(t)$ after using the initial condition $\left(L=L_{0}\right.$ at $\left.t=t_{0}\right)$ :

$$
L(t)=L_{s}+\left(L_{0}-L_{s}\right) \exp \left[-\frac{L_{0}-L_{s}}{M}\left(t-t_{0}\right)\right]
$$

It can be seen that Equations (1) and (9) are a little different in terms of the numerator term in the exponential function. Thus, they can be generalized to be:

$$
L(t)=L_{s}-\left(L_{s}-L_{0}\right) \exp \left[-\frac{\left|L_{s}-L_{0}\right|}{M}\left(t-t_{0}\right)\right]
$$

\subsection{Flocculation Model for a Piecewise Varied Shear}

When the flocculation system is subject to a piecewise varied shear, floc size is inferred to show a piecewise exponential increase (or decrease) behavior with flocculation time $[18,20,22,23,27,28]$. Figure $3 a-d$ schematically shows four different types of floc size 
variation to various types of piecewise varied shear environments, which is similar to a sediment accumulation effect in reservoirs, dams, and river channels [75,76]. They include a piecewise increasing flow shear, a piecewise decreasing flow shear, sequenced flow shear (e.g., low shear $\rightarrow$ high shear $\rightarrow$ low shear), and consecutive cycled flow shear (e.g., low shear $\rightarrow$ high shear $\rightarrow$ low shear $\rightarrow$ high shear $\ldots$ ).
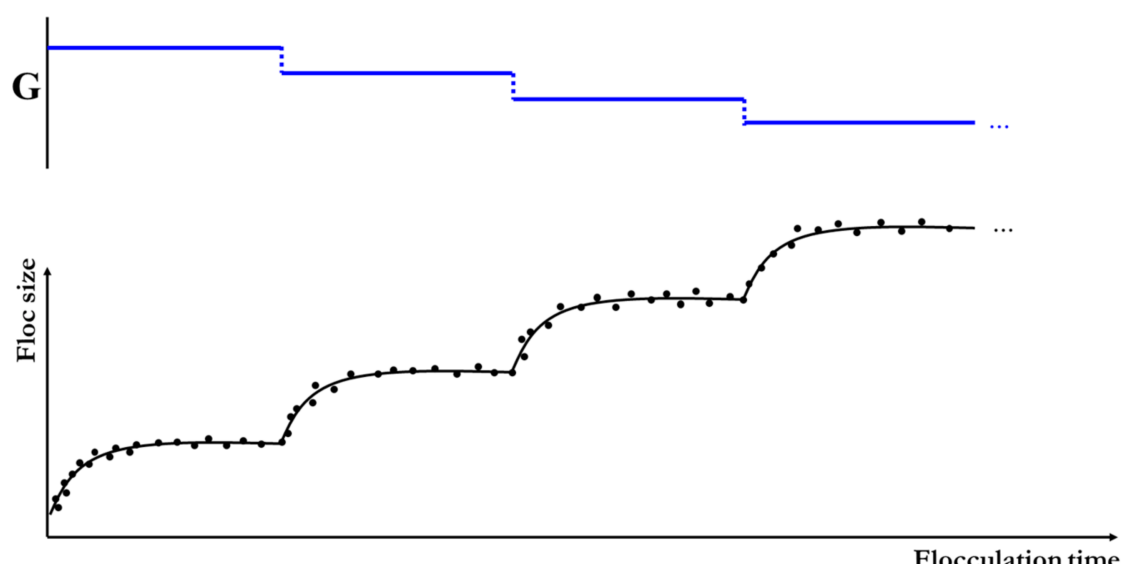

(a)
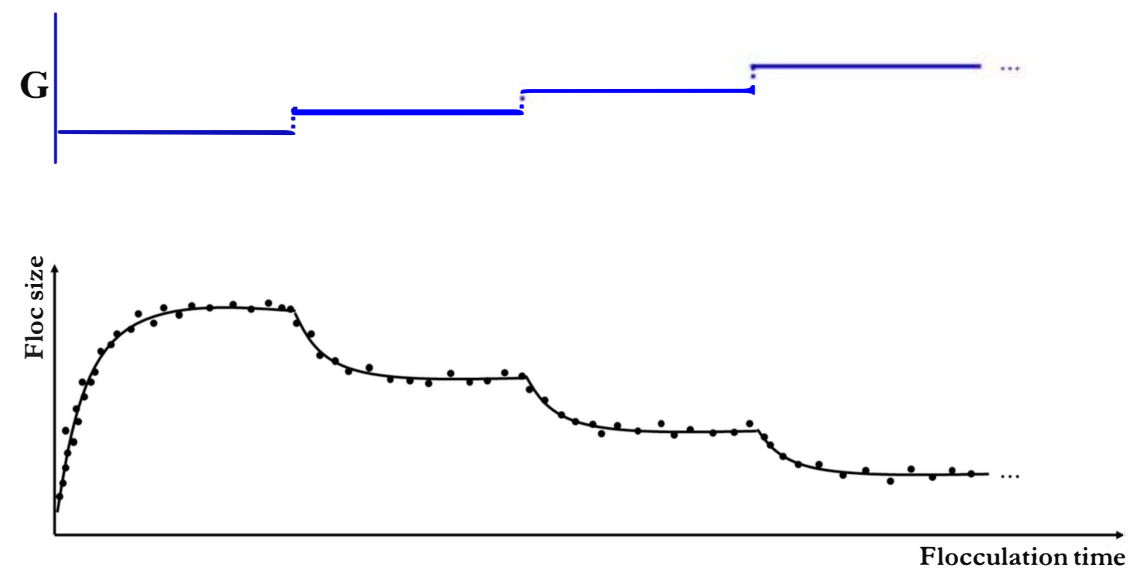

(b)
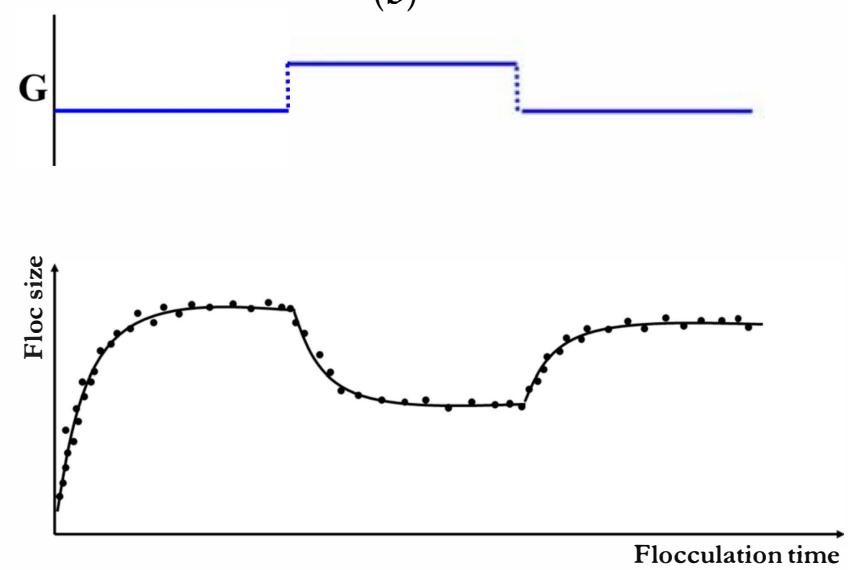

(c)

Figure 3. Cont. 

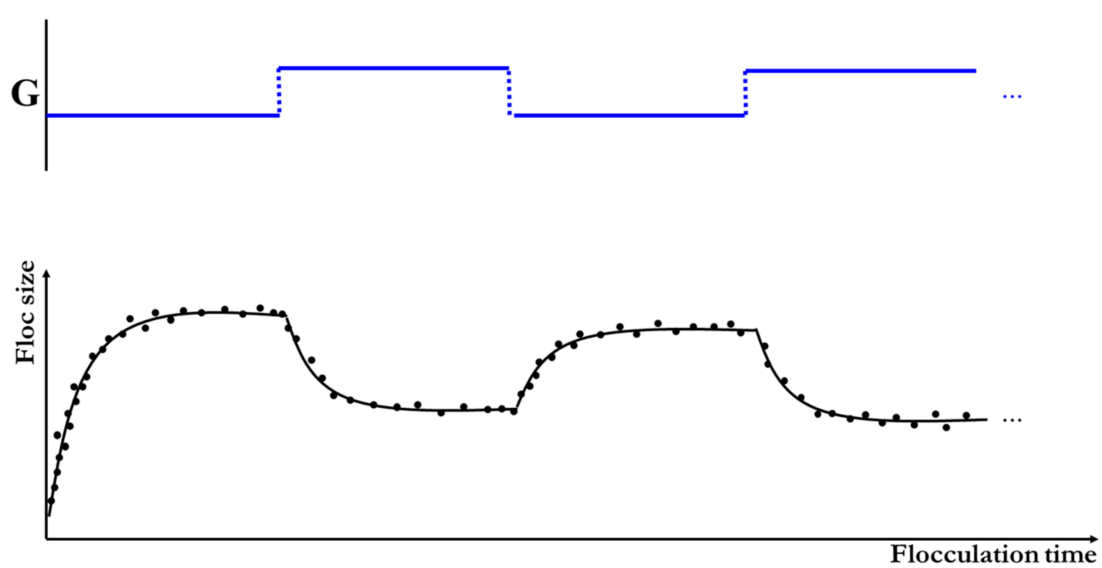

(d)

Figure 3. Floc size variation subject to a piecewise varied shear rate: (a) a piecewise increasing shear; (b) a piecewise decreasing shear; (c) sequenced flow shear (low shear $\rightarrow$ high shear $\rightarrow$ low shear); (d) consecutive cycled flow shear (low shear $\rightarrow$ high shear $\rightarrow$ low shear $\rightarrow$ high shear ... ).

For each type of piecewise varied shear, Equation (10) still holds for each stage where the flow shear rate is a constant. Consider a $n$-step shear procedure: $G=G_{i}$ at $t_{i-1} \leq t<t_{i}$, $i=1,2, \ldots n$, where $G_{1}, G_{2}, \ldots, G_{n}$ are piecewise values of the shear rate, and $t_{0}, t_{1}, \ldots, t_{n}$ are piecewise time nodes. For the $i$-th flocculation period, the temporal evolution of floc size $L_{i}(t)$ can be described by Equation (10). However, $L_{s}$ in Equation (10) should be substituted by $L_{s, i}$, the steady-state value of floc size in the $i$-step flocculation period, $L_{1}$ by $L_{i-1}$, a floc size value at $t=t_{i-1}$, and $M$ by $M_{i}$ corresponding to a constant $G_{i}$ period, respectively. Therefore, Equation (10) can be recast in the following form:

$$
L_{i}(t)=L_{s, i}-\left(L_{s, i}-L_{i-1}\right) \exp \left[-\frac{\left|L_{s, i}-L_{i-1}\right|}{M_{i}}\left(t-t_{i-1}\right)\right]
$$

For example, for three piecewise shear schedules, $G=G_{1}, G_{2}, G_{3}$ at $t_{0} \leq t \leq t_{1}$, $t_{1} \leq t \leq t_{2}$, and $t_{2} \leq t \leq t_{3}$, respectively, Equation (11) can be expanded into the following recursive formula for floc size variation:

$$
\left\{\begin{array}{c}
L_{1}(t)=L_{s, 1}-\left(L_{s, 1}-L_{0}\right) \exp \left[-\frac{\left|L_{s, 1}-L_{0}\right|}{M_{1}}\left(t-t_{0}\right)\right] \\
L_{2}(t)=L_{s, 2}-\left[L_{s, 2}-L_{1}\left(t_{1}\right)\right] \exp \left[-\frac{\left|L_{s, 2}-L_{1}\left(t_{1}\right)\right|}{M_{2}}\left(t-t_{1}\right)\right] \\
L_{3}(t)=L_{s, 3}-\left[L_{s, 3}-L_{2}\left(t_{2}\right)\right] \exp \left[-\frac{\left|L_{s, 3}-L_{2}\left(t_{2}\right)\right|}{M_{3}}\left(t-t_{2}\right)\right]
\end{array}\right.
$$

which can be adopted to predict the temporal evolution of floc size in a three piecewise shear environment provided the values of $L_{s, 1}, L_{s, 2}, L_{s, 3}$ and $M_{1}, M_{2}, M_{3}$ are known prior.

\section{Test with Experimental Data}

\subsection{Performance Evaluation of the Model}

To evaluate the accuracy of the proposed entropic model with experimental data points, an error analysis was performed in this study, including the following three statistical parameters:

(1) Correlation coefficient $R^{2}$ between the observed data points and the modeled data points;

(2) The average relative error $(R E)$ between the observed data points and the modeled data, which is calculated as follows: $\frac{1}{N} \sum_{i=1}^{N} \frac{\left|y_{O i}-y_{M i}\right|}{y_{O i}}$, where $y_{O i}$ and $y_{M i}$ are the observed data and the modeled data, and $N$ is the total number of data points; 
(3) The root mean square error (RMSE) between the observed data points and the modeled data points: $R M S E=\sqrt{\frac{1}{N} \sum_{i=1}^{N}\left(y_{O i}-y_{M i}\right)^{2}}$.

\subsection{Comparison with Experimental Data Sets in the Literature}

Experimental data sets regarding floc size variation in a varied flow shear environment are collected as much as possible in the literature, covering different flocculation materials and various flocculation environments in many subjects. They include three experimental data sets in the cohesive sediment field, Burban et al. (1989) [50], Keyvani and Strom (2014) [28], and Tsai et al. (1987) [77]; eight experimental data sets in the water treatment field, Biggs et al. (2003) [18], Chaignon et al. (2002) [27], Gregory (2004) [19], Nan et al. (2016) [20], Slavik et al. (2012) [22], Wu et al. (2019) [29], Xu and Gao (2012) [74], and $\mathrm{Xu}$ et al. (2010) [24]; and two experimental data sets in the colloidal science field, Spicer et al. (1998) [23] and Wu and van de Ven (2009) [25].

\subsubsection{Cohesive Sediment Field}

The effect of flow shear on the flocculation dynamic of fine-grained sediments in freshwater was studied in the experiment of Tsai et al. (1987) [77]. The sediments were collected from the Detroit River inlet of Lake Erie, and the Couette viscometer was adopted to generate the turbulence environment. Shear stresses were set to be 1,2 , and 4 dynes $/ \mathrm{cm}^{2}$, corresponding to shear rates of 100,200, and $400 \mathrm{~s}^{-1}$, and sediment concentrations ranged from 50, 100, 400, and $800 \mathrm{mg} / \mathrm{L}$. In this experiment, floc size distribution as a function of flocculation time was recorded. Experimental observations showed that the steady-state floc size decreased with shear stress and that they increased with sediment concentration.

Using the same flocculation apparatus as those in Tsai et al. (1987) [77], Burban et al. (1989) [50] investigated experimentally and theoretically the effects of salinity, fluid shear rate, and sediment concentration on the flocculation of fine-grained sediment from the Detroit River. The adopted shear rates were from 100 to $600 \mathrm{~s}^{-1}$, whereas the sediment concentration covered from 10 to $800 \mathrm{mg} / \mathrm{L}$. Experimental data regarding floc size distributions as a function of flocculation time were obtained. Based on experimental results, physical mechanisms regarding the impact of salinity, fluid shear, and sediment concentration on the aggregation and breakup of cohesive sediment were analyzed in their work.

A laboratory study of Keyvani and Strom (2014) [28] focused on the effects of repeated exposure to multiple cycles of high and low shearing conditions on the growth pattern and the steady-state size of mud flocs. The flocculation material was a $50 \mathrm{mg} / \mathrm{L}$ mixture of kaolinite and montmorillonite clay, whereas a 13-L mixing chamber $(27.5 \mathrm{~cm} \times 27.5 \mathrm{~cm} \times 25 \mathrm{~cm})$ with a rotating paddle as well as a high-resolution imaging system formed an environment for the flocculation observation. The flocs were allowed to grow until an equilibrium was reached at a shear rate of $35 \mathrm{~s}^{-1}$, and they were broken down with a strong turbulent shear of $400 \mathrm{~s}^{-1}$. This procedure was repeated seven times in their experiment, and the characteristics of the floc population (floc size distribution, floc circularity index, and floc number variation) were measured and analyzed. Their observations demonstrated that initial particle size distributions play little role in the steady-state floc size, whereas it plays an important role in the flow growth rate. The flocs become also slightly stronger and less reactive with repeated cycles of growth and breakup.

Figures 4-6 show comparisons of the proposed entropic model (Equation (11)) with experimental data of Tsai et al. (1987) [77], Burban et al. (1989) [50], and Keyvani and Strom (2014) [28], respectively. Table 1 presents these comparison results. In this table, the second through fifth columns present the experimental conditions adopted in these experiments, including flocculation material, turbulence-generated apparatus, flocculation conditions, and the adopted shear rates, respectively. The values of $L_{0}$ and $L_{S}$ in the sixth and seventh columns were obtained from experimental data. Fitting effects of the entropic model for these experimental results, including the calculated values of $R^{2}, R E, R M S E$, are listed in the last three columns, as well as the values $M$ in the eighth column. 


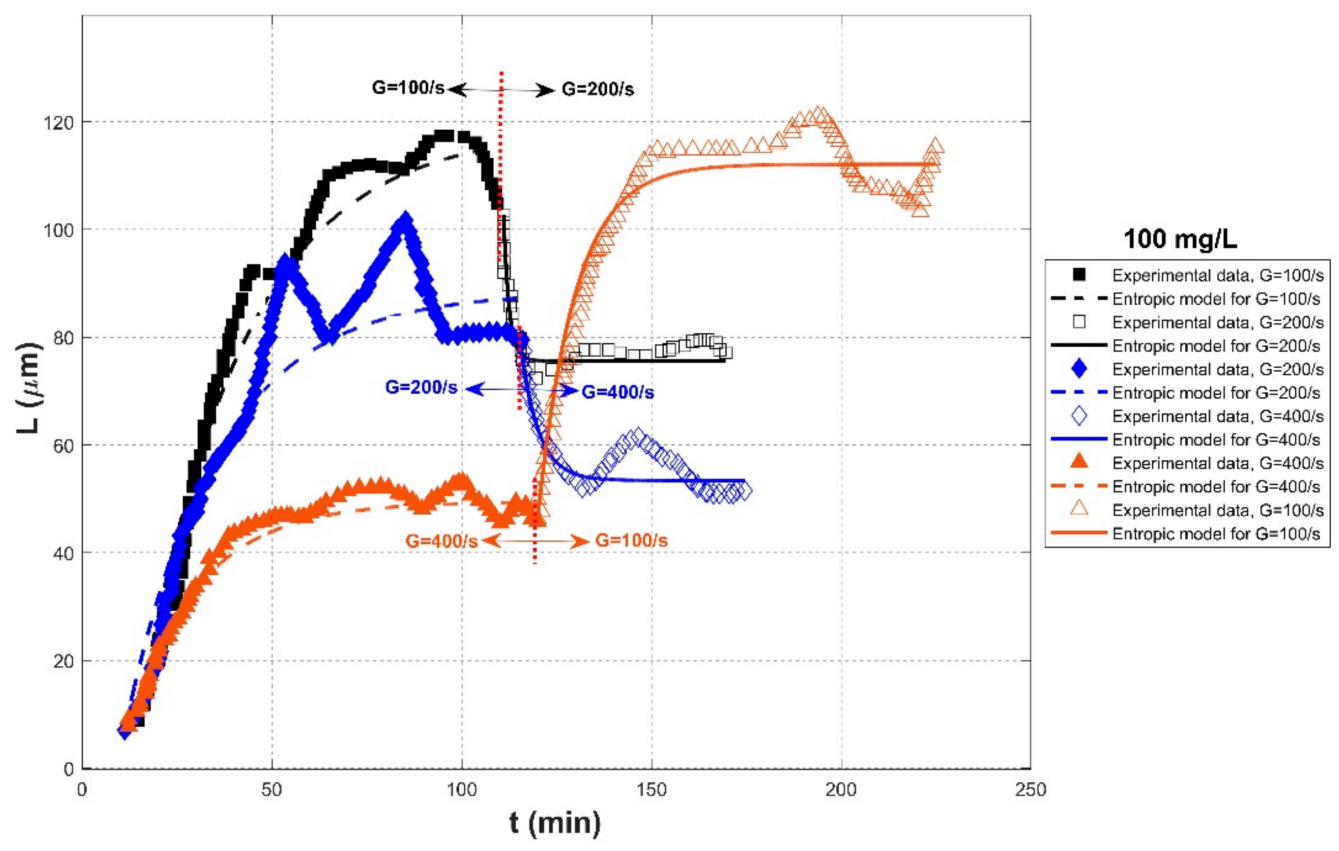

(a)

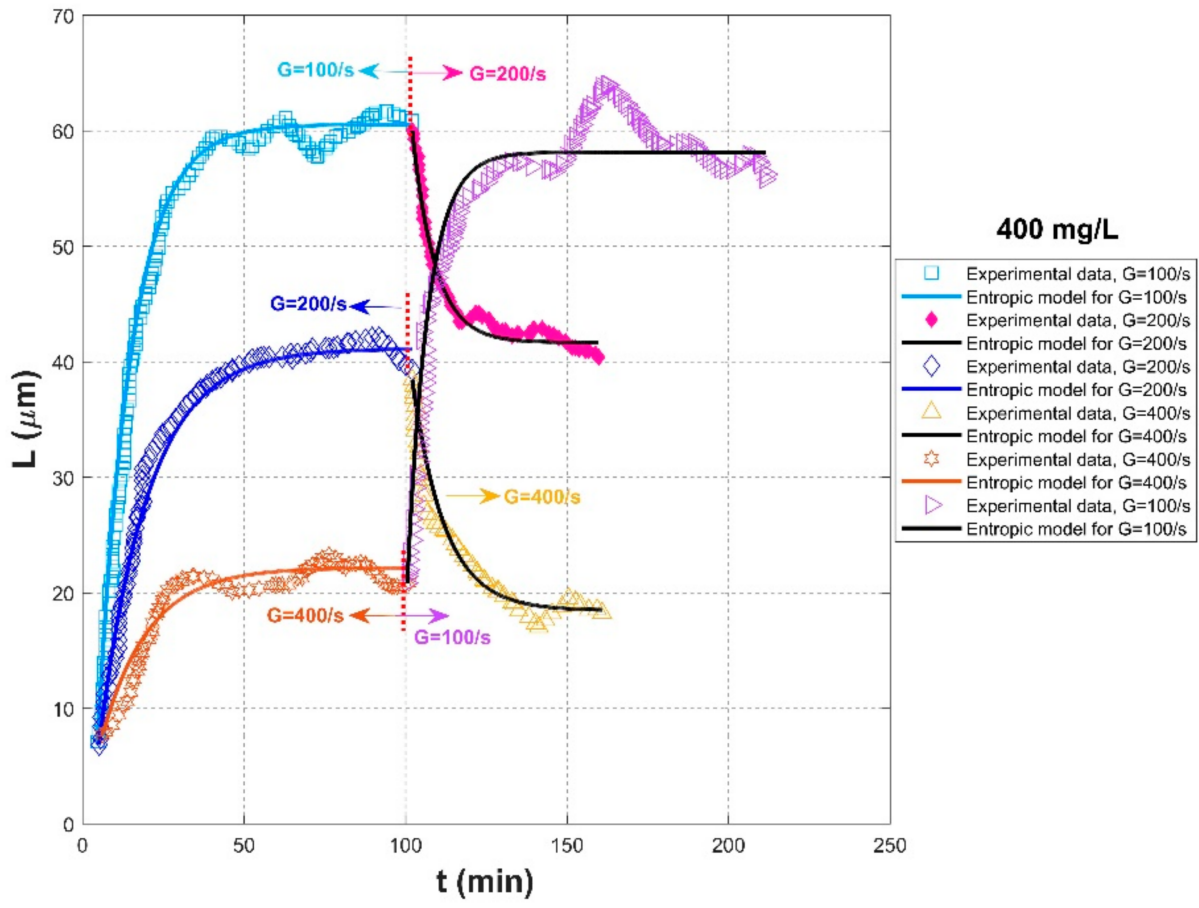

(b)

Figure 4. Comparison of the entropic model with experimental data points of Tsai et al. (1987) [77]: (a) $100 \mathrm{mg} / \mathrm{L}$ floc concentration; (b) $400 \mathrm{mg} / \mathrm{L}$ floc concentration. 


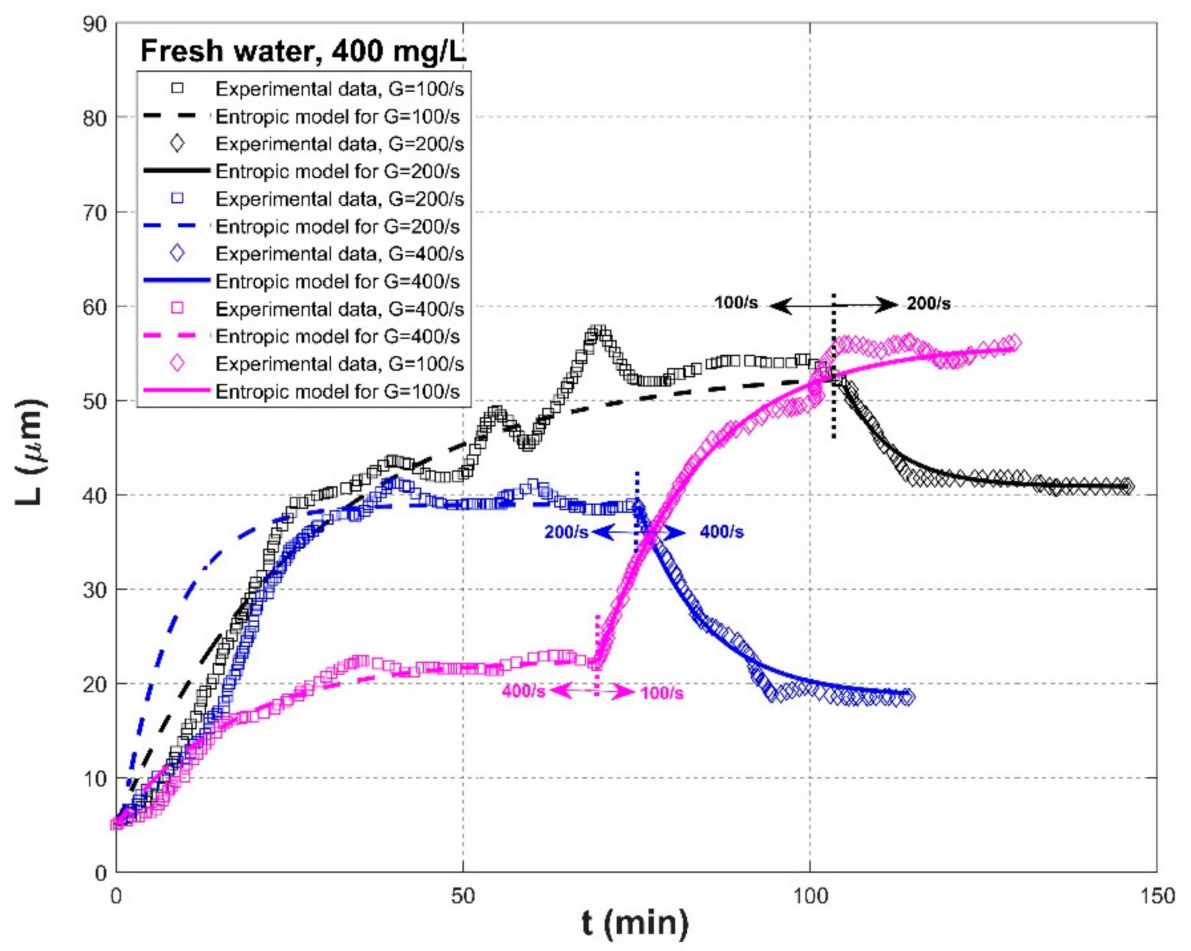

(a)

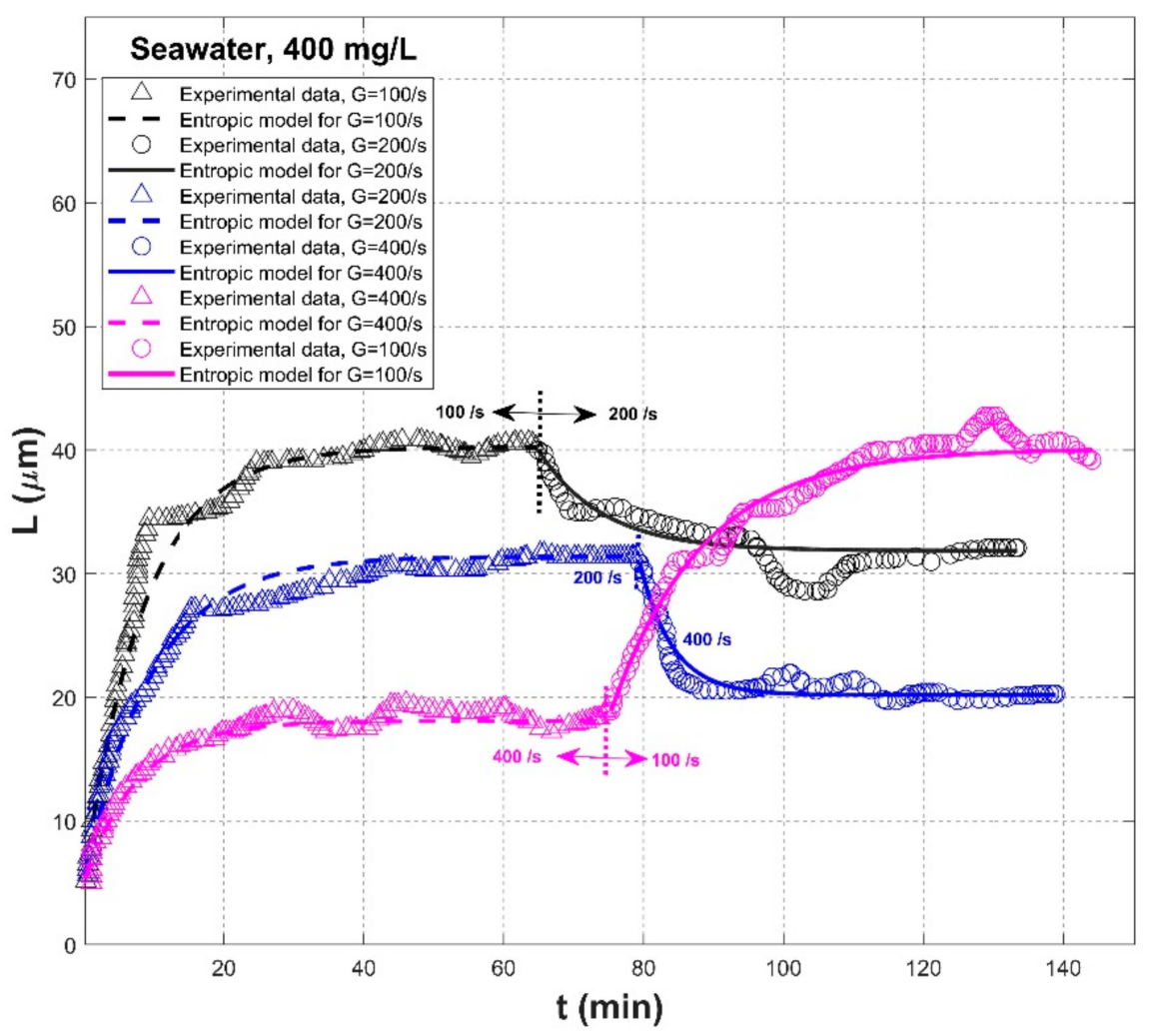

(b)

Figure 5. Comparison of the entropic model with experimental data points of Burban et al. (1989) [50]: (a) fresh water at a concentration of $400 \mathrm{mg} / \mathrm{L}$; (b) seawater at a concentration of $400 \mathrm{mg} / \mathrm{L}$. 


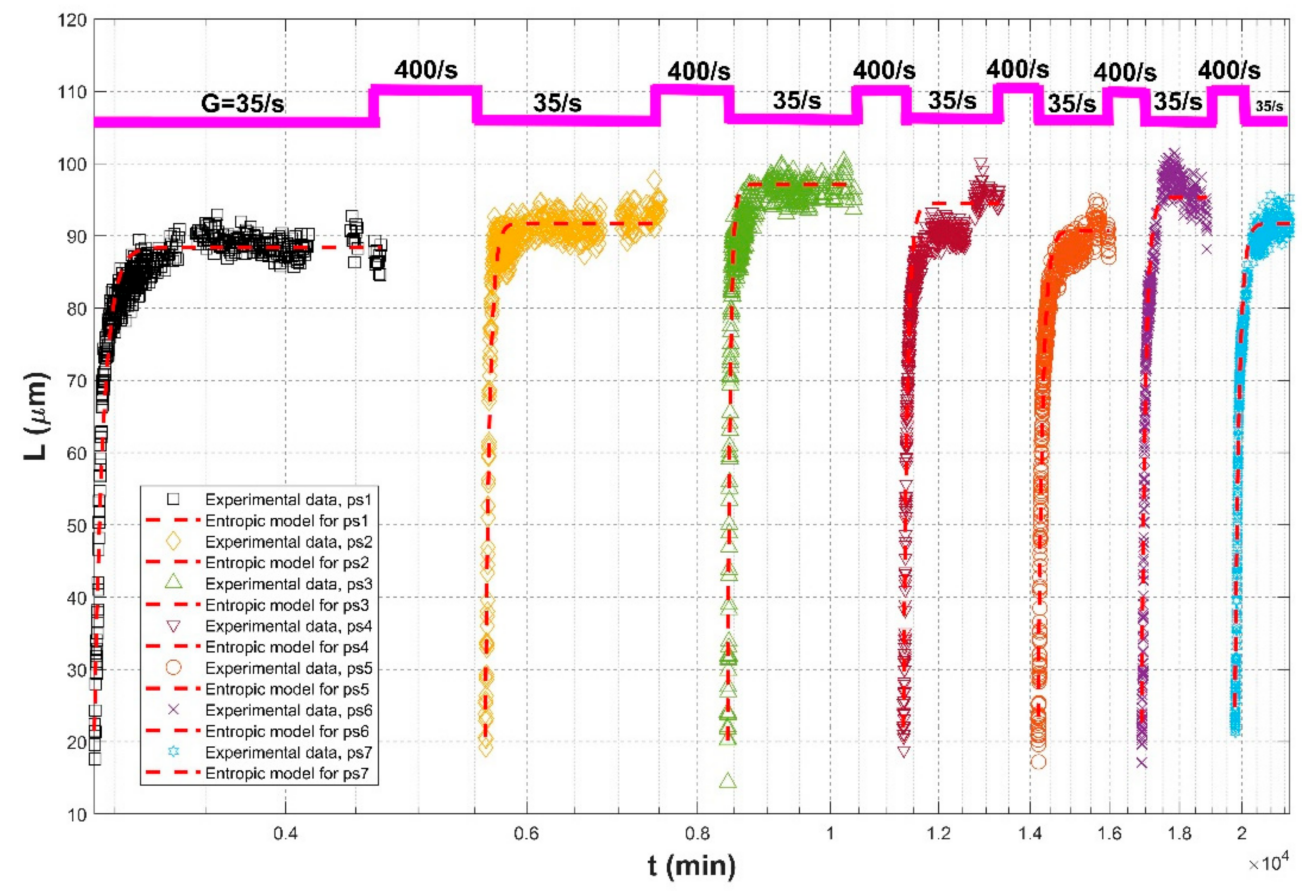

Figure 6. Comparison of the entropic model with experimental data points of Keyvani and Strom (2014) [28]. Here ps 1 refers to prior shear 1, etc., ps 7 refers to prior shear 7.

Figure 7 shows the Taylor diagram of calculated correlation coefficients and relative errors for all of the cases. It can be seen that the entropic model can fit most experimental data sets with a high correlation coefficient above 0.9 and a relative error below 0.1 . As presented in the last row of Table 1, the average values of $R^{2}, R E$, and $R M S E$ for all experimental data are $0.9453,0.0595,2.8560$, respectively. The largest deviation in Figure 7 comes from the comparison of the entropic model with experiment data points of $G=200 \mathrm{~s}^{-1}$ in the case of freshwater flocculation in Burban et al. (1989), as shown by the blue color in Figure 5a. The reason is that the floc size experienced a slow growth process before reaching the steady state, for which the model did not track it well. Additionally, a large relative error can be seen from Figure $5 \mathrm{a}$ for $G=200 \mathrm{~s}^{-1}$ in the case of $100 \mathrm{mg} / \mathrm{L}$ sediment concentration in Tsai et al. (1987) and from Figure 6a for $G=100 \mathrm{~s}^{-1}$ in the case of fresh water flocculation in Burban et al. (1989) since there was a strong data scatter that may have been due to measurement uncertainties. Additionally, the entropic model seemed to work better with seawater sediment flocculation by comparing Figure $5 \mathrm{a}, \mathrm{b}$, which might be attributed to a smaller data scatter for seawater sediment flocculation relative to freshwater sediment.

As shown by Figures $4 a, b$ and $5 a, b$, an abrupt change of the shear rate triggered the flocculation system that had already reached an equilibrium to evolve toward another equilibrium, for which the entropic model can be also applicable. In Figure 6, due to a lack of experimental data regarding floc breakage at a high shear rate $G$ of $400 \mathrm{~s}^{-1}$, the entropic model could only fit those flow growth data; although some data were crowding in each period, an agreement between the proposed model and original experimental points was still noticeable.

\subsubsection{Water Treatment Field}

Using local, activated sludge samples from a wastewater treatment plant in Maxeville, France, the flocculation experiment of Chaignon et al. (2002) [27] focused on the effect of cycled-shear conditions on the evolution of average floc size. Sludge flocculation occurred in a 1-L baffled reactor $(90 \mathrm{~mm} \times 150 \mathrm{~mm}$ ) with a $15 \mathrm{~mm} \times 54 \mathrm{~mm}$ blade, and an adjustable-speed motor was set to provide a large shear rate range from 135 to $370 \mathrm{~s}^{-1}$. Two experimental conditions including raw sludge of $35 \mathrm{mg} / \mathrm{L}$ and sludge spiked with $20 \mathrm{wt} \%$ of aquatic particles were monitored and compared in their study. 
In Biggs et al. (2003) [18], activated sludge collected from a wastewater treatment plant in Australia was adopted to carry out the flocculation experiment in a 1.2-L baffled batch vessel with a flat six-blade impeller. Malvern Mastersizer/E instrument was used to measure the real-time floc size variation. Two groups of experimental procedures were arranged to investigate the effect of shear history on floc size. They included a procedure (E1), a shear process with $G=19.4 \mathrm{~s}^{-1}$ for $85 \mathrm{~min}$ (floc aggregation), $G=113 \mathrm{~s}^{-1}$ for 35 min (floc breakup), and $G=19.4 \mathrm{~s}^{-1}$ again for floc re-growth; and another cycling shear procedure (E2), two consecutive step changes in the shear rate $G$ between 19.4 and $113 \mathrm{~s}^{-1}$.

Flocculation of kaolin suspension $(50 \mathrm{mg} / \mathrm{L})$ from London tap water in a stirred jar was investigated in Gregory (2004) [19]. Three kinds of coagulants were added into the suspension, including alum and two commercial poly aluminum chloride (PACl) products, XL-1: $r^{\prime}=1.9,5.1$ wt. $\%$ Al and XL-9: $r^{\prime}=2.1,4.6$ wt. \%, where $r^{\prime}(=\mathrm{OH} / \mathrm{Al})$ denotes the different degrees of neutralization. In this study, the flocculation index (dimensionless) of the suspension instead of floc size distribution, which is an empirical index of floc size, was monitored by an optical measurement system. The adopted shear rate procedures were (1) $G=11 \mathrm{~s}^{-1}$ for $600 \mathrm{~s}$, followed by $G=340 \mathrm{~s}^{-1}$ for $60 \mathrm{~s}$ and again $G=11 \mathrm{~s}^{-1}$, and (2) $G=23 \mathrm{~s}^{-1}$ followed by a stronger $G=520 \mathrm{~s}^{-1}$ and a returning $G=23 \mathrm{~s}^{-1}$. Their experimental results showed that $\mathrm{PACl}$ yields gave larger flocs than with alum. For the alum coagulant, floc breakage was not fully reversible; however, for the case of polyDADMAC (a high-charge, low-molecular-weight cationic polyelectrolyte) added into the suspension, floc breakage after experiencing a strong shear condition reduced to the original one before a high shear rate to a large degree.

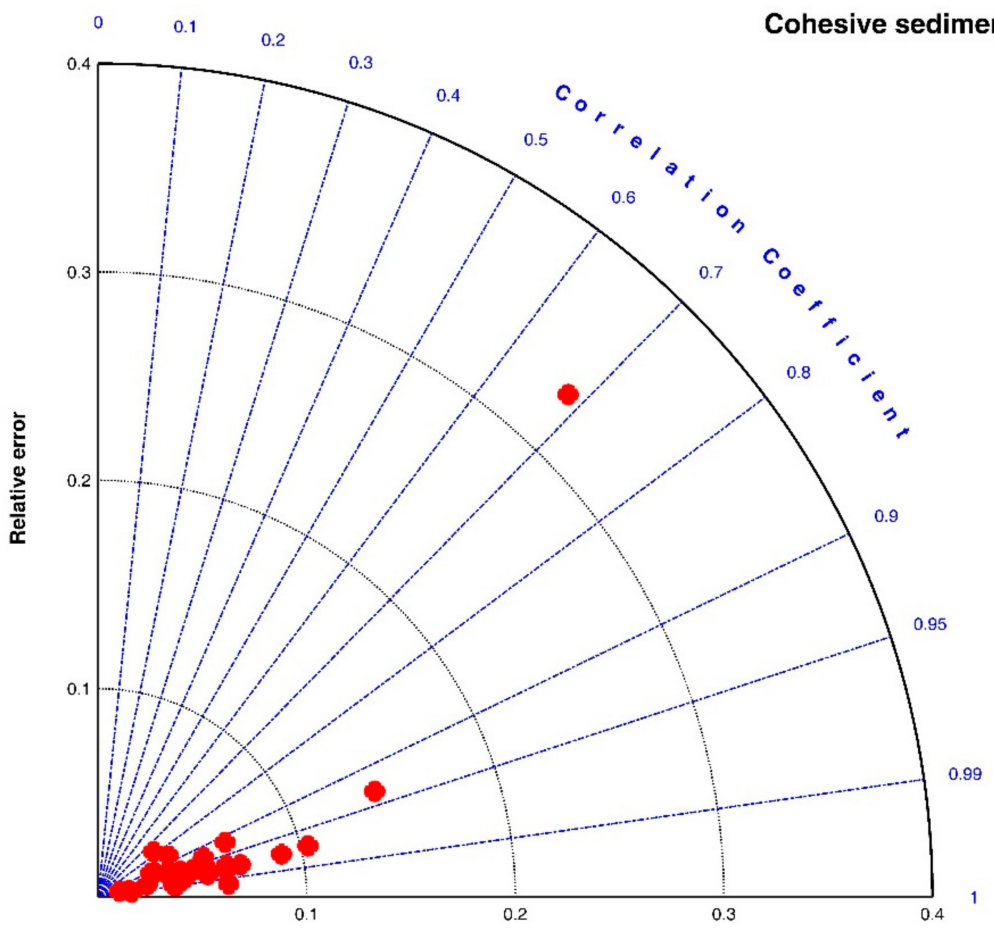

Figure 7. Taylor diagram of calculated correlation coefficients $R^{2}$ and relative errors $R E$ for experimental cases in the cohesive sediment field. 


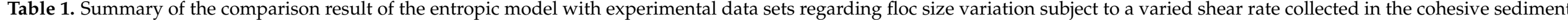
field. The last row shows the average values of statistical errors.

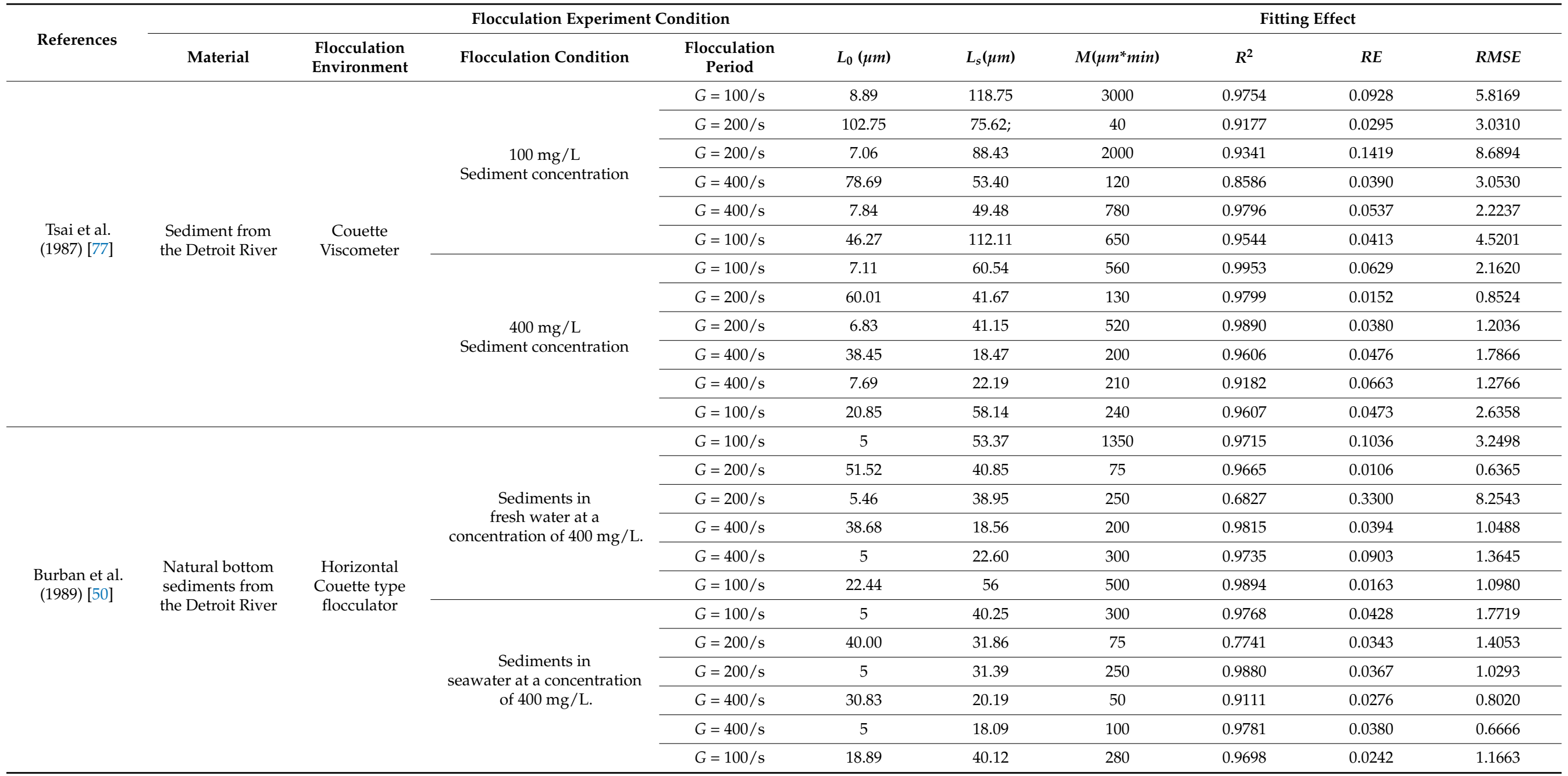


Table 1. Cont

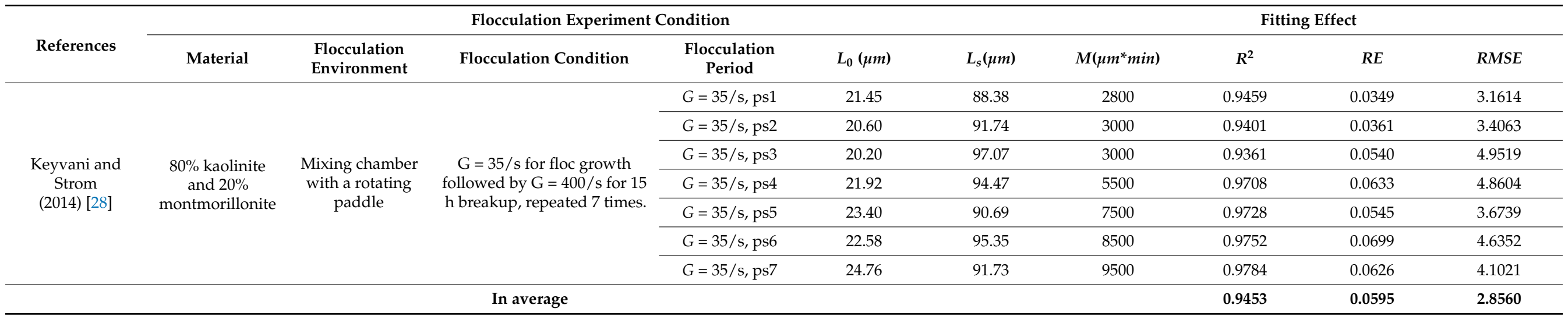


Xu et al. (2010) [24] performed a series of flocculation experiments to study the effects of varied shear rates and solution $\mathrm{pH}$ on aggregation and breakage of humic acid flocs in 1-L cylindrical plexiglass beakers using a conventional Jar-test apparatus. Two kinds of coagulants, poly aluminum chloride (PAC) and the $\mathrm{Al}_{13} \mathrm{O}_{4}(\mathrm{OH})_{24}{ }^{7+}\left(\mathrm{Al}_{13}\right)$ polymer, were added into the suspension, and the floc size distribution was monitored timely using a laser diffraction instrument (Malvern Mastersizer 2000). Since some authors have asserted that a global shear rate in the jar does not represent the flow shear condition for determining floc size distribution, the stirring speed $r$ was directly adopted to characterize the shear condition in their study. The stirring speed ranged from $40 \mathrm{rpm}$ for floc growth to $200 \mathrm{rpm}$ for floc breakage, and there were two groups of shear procedures: (1) $r=40 \mathrm{rpm}$ for floc growth $\rightarrow$ different stirring rates for breakup $\rightarrow r=40 \mathrm{rpm}$ for floc regrowth, and (2) $r=40 \mathrm{rpm}$ for floc growth $\rightarrow r=200 \mathrm{rpm}$ for breakup with $\mathrm{pH}=5,7,9 \rightarrow r=40 \mathrm{rpm}$ for floc regrowth. Experimental results demonstrated that the flocs formed by $\mathrm{Al}_{13}$ polymer were weaker than those of $\mathrm{PAC}$, whereas $\mathrm{Al}_{13}$ polymer showed a better recoverability than PAC. Additionally, the $\mathrm{pH}$ of the solution had an impact on floc size and floc recoverability. Furthermore, Xu and Gao (2012) [74] focused on the three kinds of Al-based coagulants, including alum, $\mathrm{PACl}$, and $\mathrm{PACl}-\mathrm{Al}_{\mathrm{b}}$, on the floc formation, breakage, and re-growth profiles of humic acid flocs. In this study, three shear rates were adopted for floc breakage: $G=34.6,87.8$, and $223.5 \mathrm{~s}^{-1}$, and $G=10.1 \mathrm{~s}^{-1}$ was fixed for floc formation and floc regrowth. The impact of floc breakage for $5 \mathrm{~min}$ and $10 \mathrm{~min}$ at a fixed $G=87.8 \mathrm{~s}^{-1}$ on the floc size profile was also compared in their experiment.

Effects of shear stress and increases in $\mathrm{pH}$ on the evolution of the Fe-dissolved organic matter (DOM) and Al-DOM flocs in raw water were identified in the experimental study of Slavik et al. (2012) [22]. The flocculation test was performed in 2-L beakers with baffles, and floc size was monitored using an improved light transmission technique with dynamic extinction measurement. Four shear rates were adopted: $G=40,500,1000$, and $1500 \mathrm{~s}^{-1}$. Three experimental cases were included: (1) $G=40 \mathrm{~s}^{-1}$ for floc growth $\rightarrow G=500,1000$, and $1500 \mathrm{~s}^{-1}$ for floc breakage $\rightarrow G=40 \mathrm{~s}^{-1}$ again for floc re-growth; (2) $G=40 \mathrm{~s}^{-1}$ for floc growth with five cycles of a $60 \mathrm{~s}$ strong shear rate of $G=1000 \mathrm{~s}^{-1}$ followed by a weak shear rate of $5 \mathrm{~min}$ at $G=40 \mathrm{~s}^{-1}$; and (3) adding the shear rate at $G=1000 \mathrm{~s}^{-1}$ for $1 \mathrm{~min}$ and increasing $\mathrm{pH}$ by 0.5 . In their study, the authors adopted a relative floc size (its dimension was \%) with the average maximum floc size at the steady state to characterize the floc aggregation and floc breakup behaviors.

Nan et al. (2016) [20] investigated the effect of shear rate in three stages (before floc breakage, during floc breakage, and after floc breakage) on the re-growth properties of flocs using a non-intrusive optical sampling and an imaging treatment system. Kaolin clay was collected as flocculation material in a rectangular tank reactor $(150 \mathrm{~mm} \times 150 \mathrm{~mm})$ stirred with an R1342-type impeller (50 $\mathrm{mm}$ in diameter), and the coagulant was Polyaluminum chloride ( $\mathrm{PACl}$ ) with a basicity value of $75 \%$. In this study, three shear procedures were provided: (1) $G=7.7,12.8,18.7$, and $27.4 \mathrm{~s}^{-1}$ for floc growth $\rightarrow G=113.7 \mathrm{~s}^{-1}$ of $1 \mathrm{~min}$ for floc breakage $\rightarrow G=18.7 \mathrm{~s}^{-1}$ for floc re-growth; (2) $G=18.7 \mathrm{~s}^{-1}$ for floc growth $\rightarrow$ $G=86.5,113.7,143.2$, and $175.2 \mathrm{~s}^{-1}$ of $1 \mathrm{~min}$ for floc breakage $\rightarrow G=18.7 \mathrm{~s}^{-1}$ for floc re-growth; and (3) $G=18.7 \mathrm{~s}^{-1}$ for floc growth $\rightarrow G=113.7 \mathrm{~s}^{-1}$ of $1 \mathrm{~min}$ for floc breakage $\rightarrow G=7.7,12.8,18.7$, and $27.4 \mathrm{~s}^{-1}$ for floc re-growth. Additionally, coagulations of humic acid, phosphate, or kaolin particles with alum and $\mathrm{PACl}$ as coagulants were investigated in $\mathrm{Wu}$ et al. (2019) [29]. The adopted equipment was Flocculator ZR4-2, and the floc size was measured timely using a laser diffraction instrument and a PDA 3000 in the jar test. In their experiment, two cases were extracted, including (1) $G=23 \mathrm{~s}^{-1}$ for alum floc formation, followed by $G=184 \mathrm{~s}^{-1}$ of $1 \mathrm{~min}$ or $10 \mathrm{~min}$ for floc breakage and $G=23 \mathrm{~s}^{-1}$ for floc regrowth and (2) effect of a change in $\mathrm{pH}(\mathrm{pH}=5$ and 7) on the re-growth of broken alum-kaolin flocs at breakage stage $\left(G=23 \mathrm{~s}^{-1} \rightarrow G=184 \mathrm{~s}^{-1}\right.$ of $\left.1 \mathrm{~min} \rightarrow G=23 \mathrm{~s}^{-1}\right)$.

Comparisons of the proposed entropic model (Equation (11)) with experimental results of Chaignon et al. (2002) [27], Biggs et al. (2003) [18], Gregory (2004) [19], Xu et al. (2010) [24], Xu and Gao (2012) [74], Slavik et al. (2012) [22], Nan et al. (2016) [20], and 
Wu et al. (2019) [29] are presented in Figures 8-15, respectively. Table 2 lists these comparison results. The second, third, fourth, and fifth columns present the flocculation material, turbulence-generated equipment, flocculation conditions, and shear rate conditions adopted in each experiment, respectively. The values for $L_{0}$ and $L_{s}$ in the sixth and seventh columns were obtained from experimental data sets. The last three columns list the calculated statistical parameter values of $R^{2}, R E$, and $R M S E$ between the proposed entropic model and each group of experimental results, as well as the value for $M$ in the eighth column.

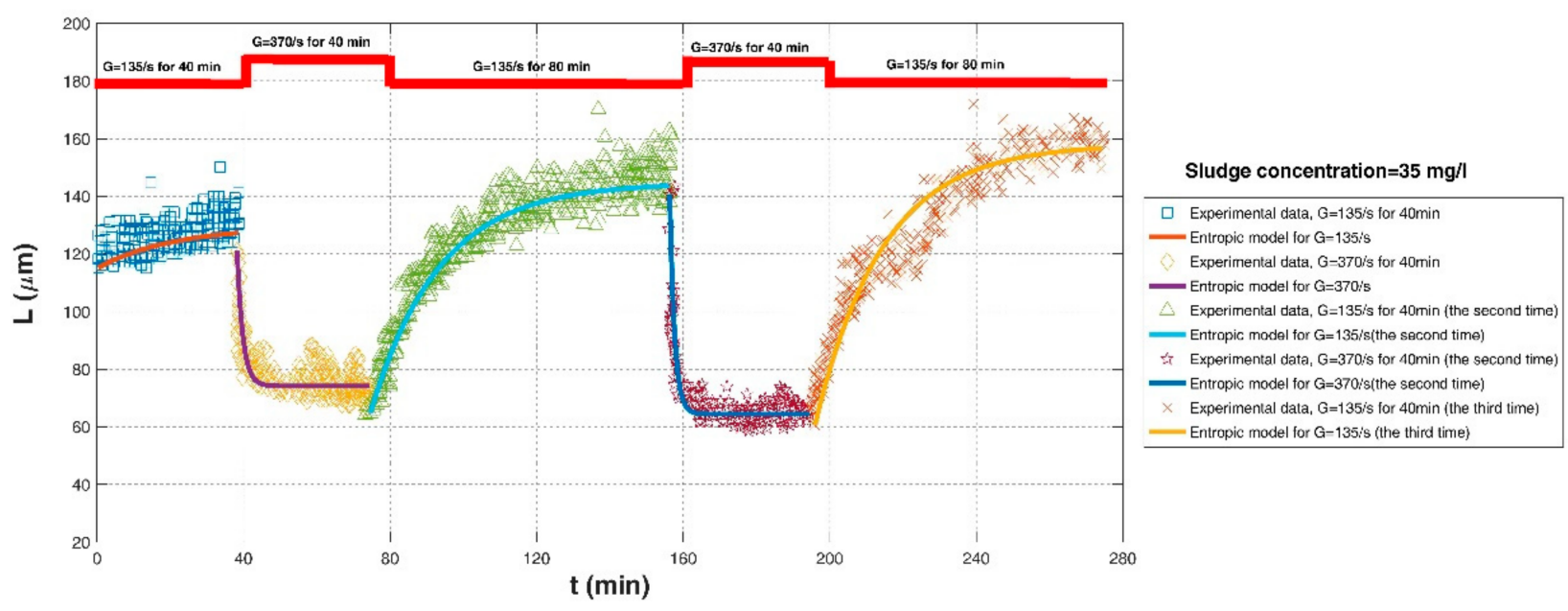

(a)

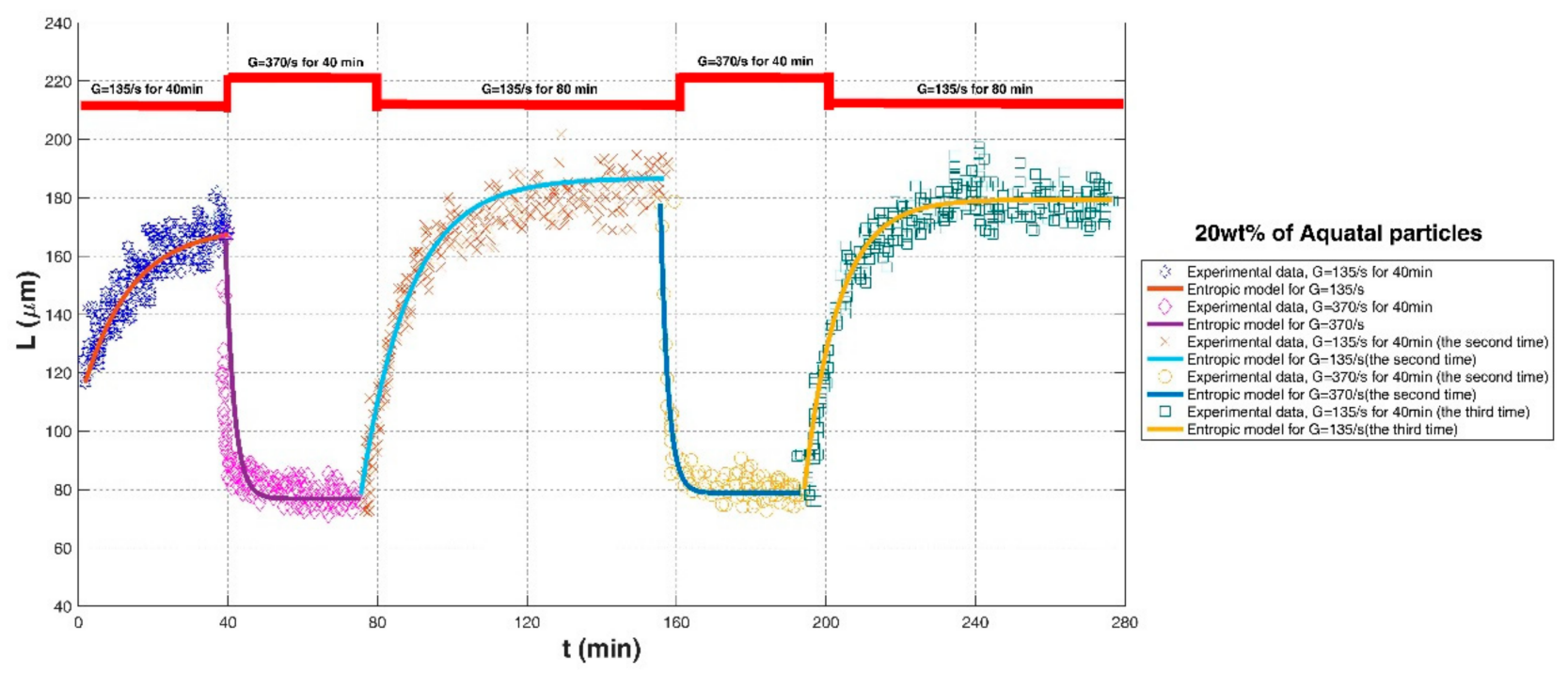

(b)

Figure 8. Comparison of the entropic model with experimental data points of Chaignon et al. (2002) [27]: (a) sludge concentration $=35 \mathrm{mg} / \mathrm{L} ;(\mathbf{b})$ activated sludge spiked with $20 \mathrm{wt} \%$ of aquatic particles. 


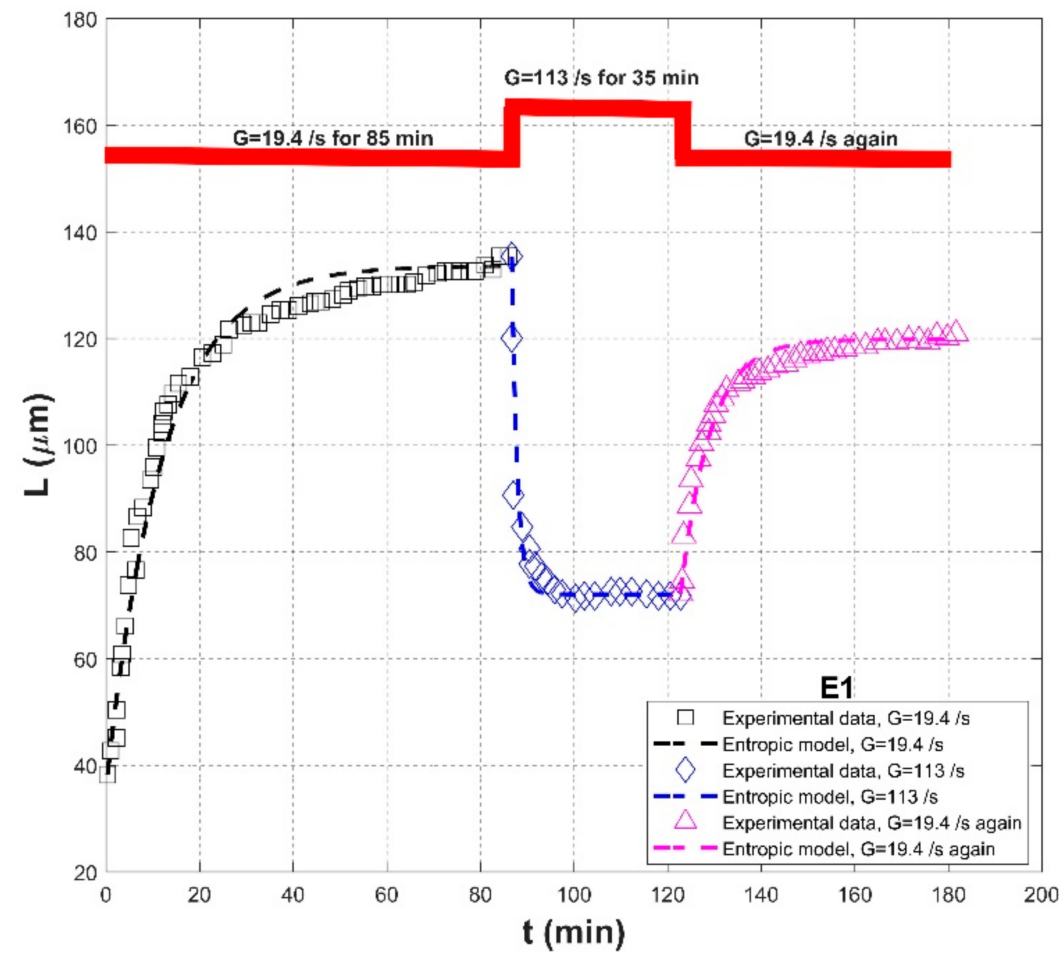

(a)

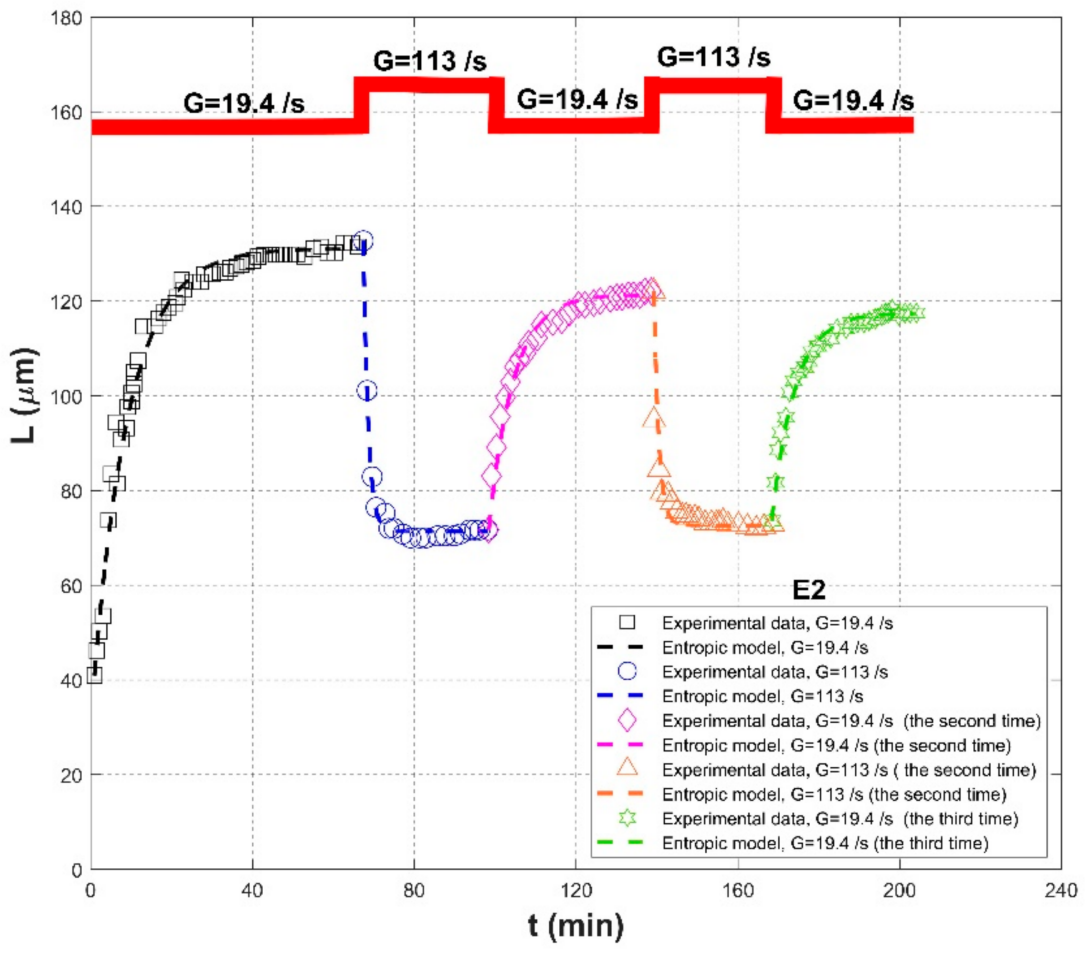

(b)

Figure 9. Comparison of the entropic model with experimental results of Biggs et al. (2003) [18]: (a) E1; (b) E2. 


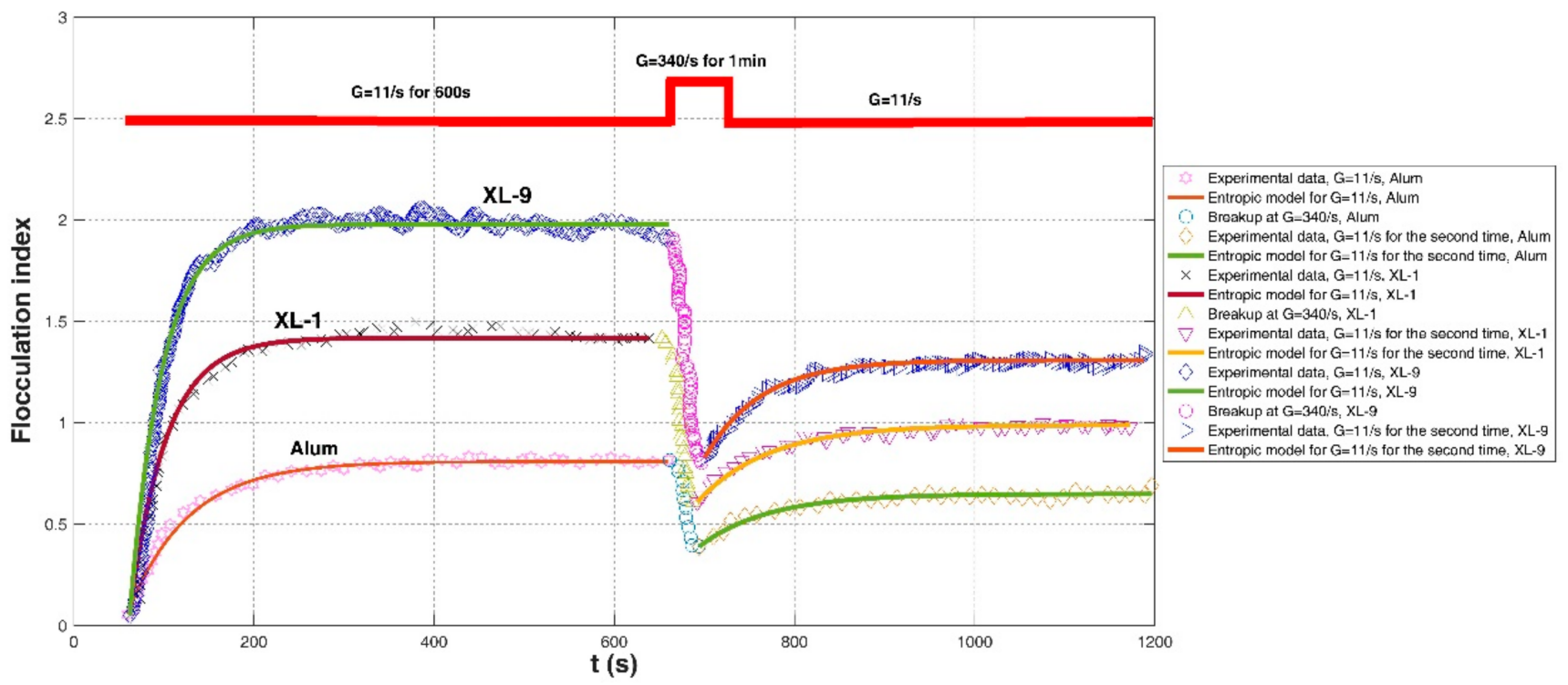

(a)

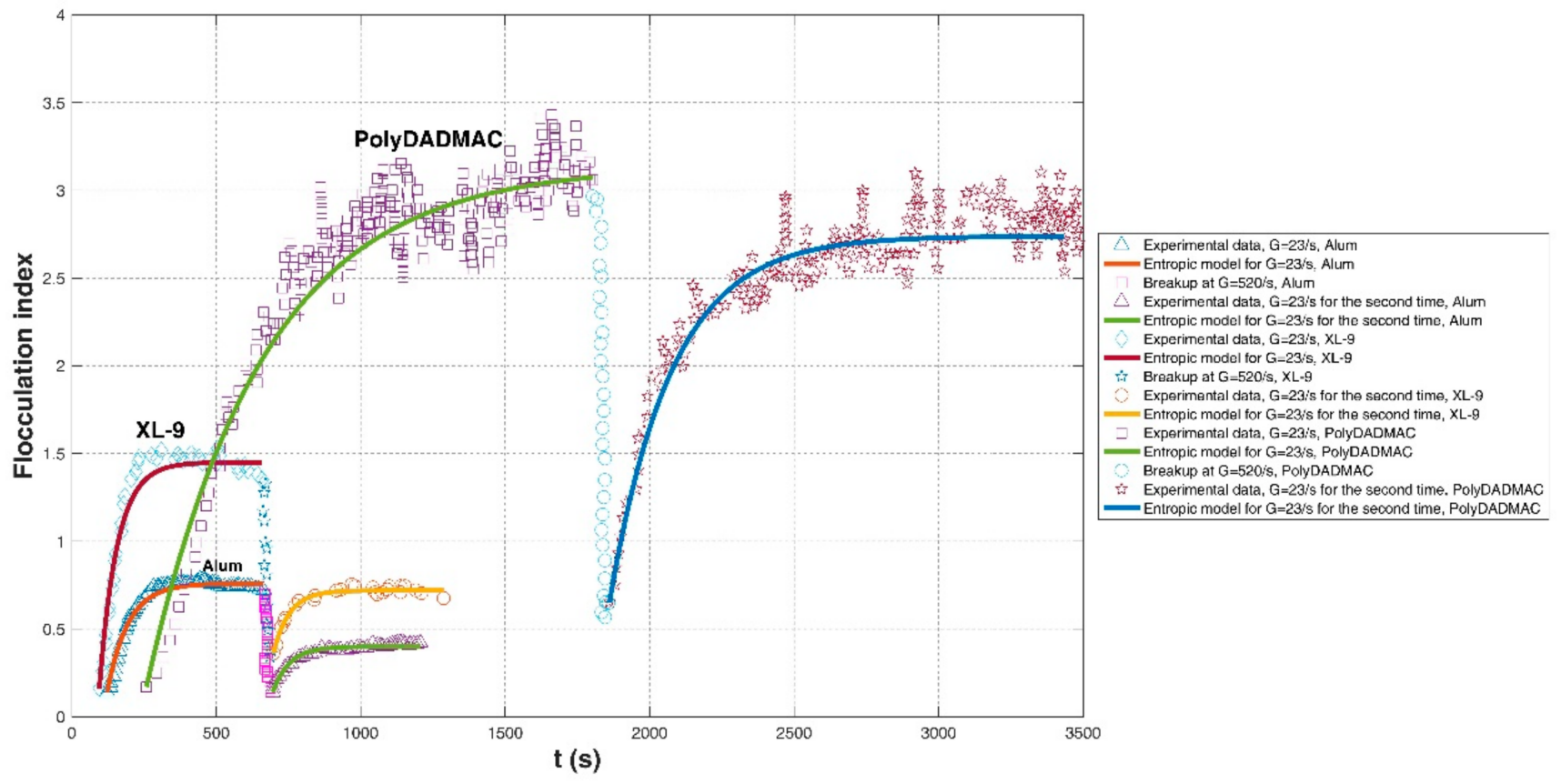

(b)

Figure 10. Comparison of the entropic model with experimental data points of Gregory (2004) [19]: (a) dosing with alum and two PACl samples; (b) dosing kaolin suspensions with alum, $\mathrm{PACl}$, and polyDADMAC. 


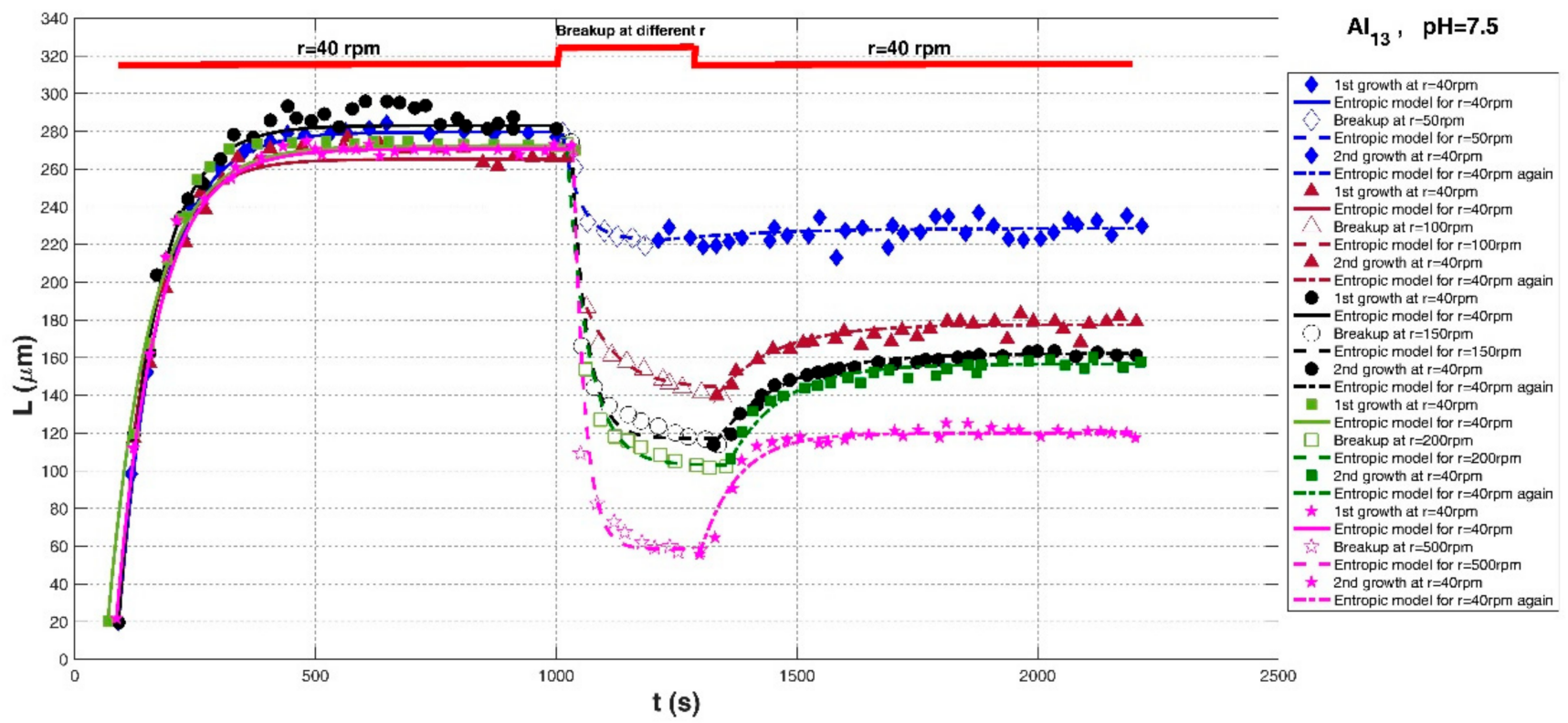

(a)

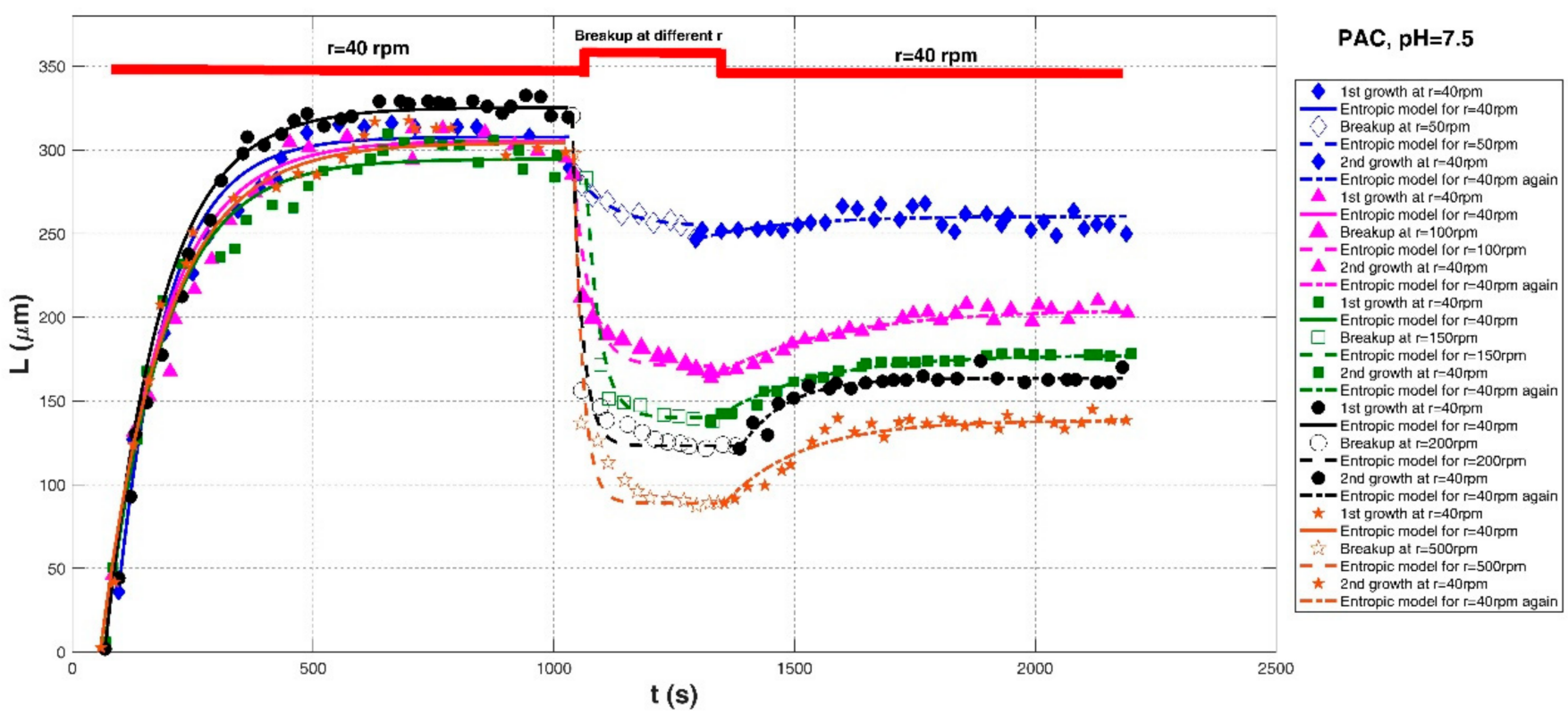

(b)

Figure 11. Cont. 


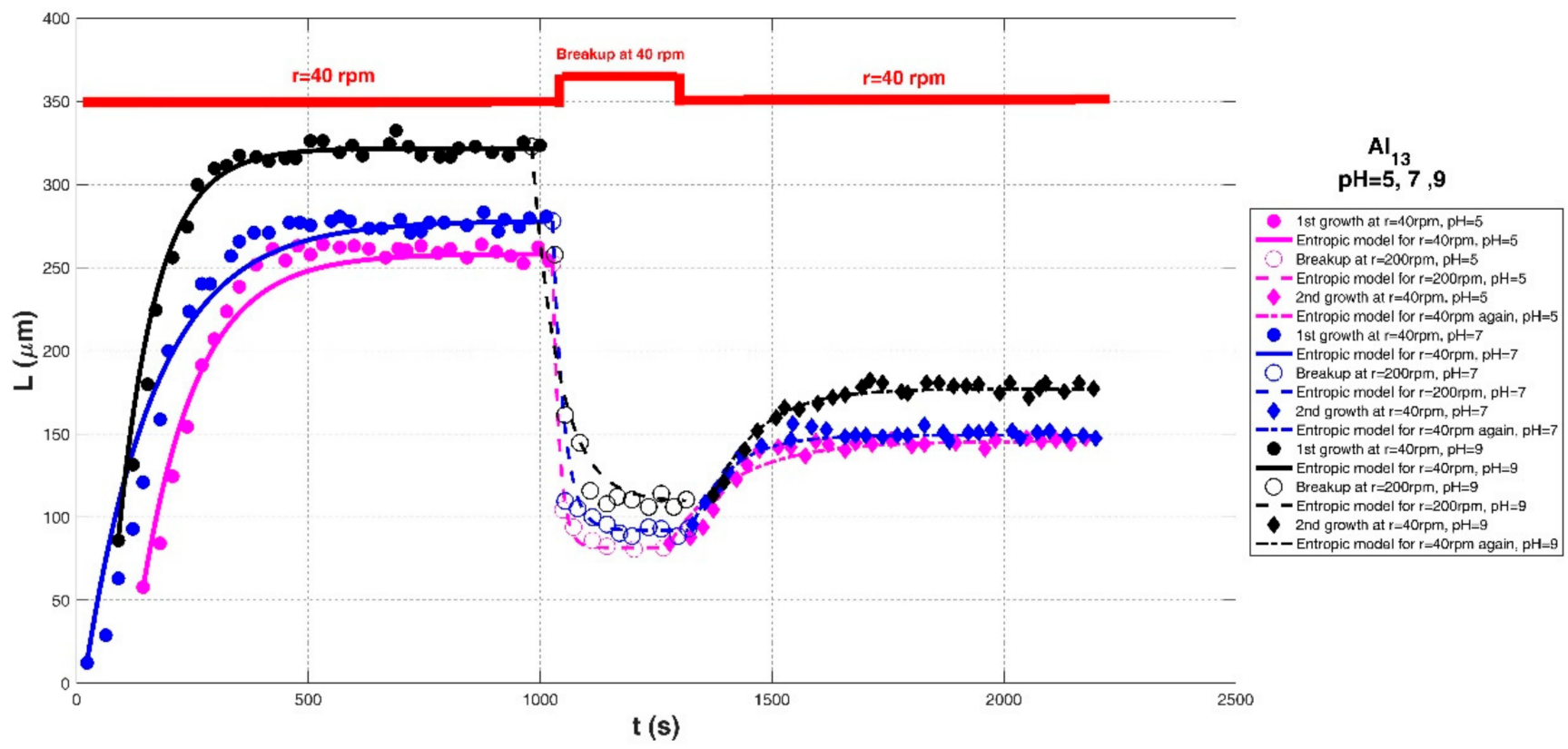

(c)

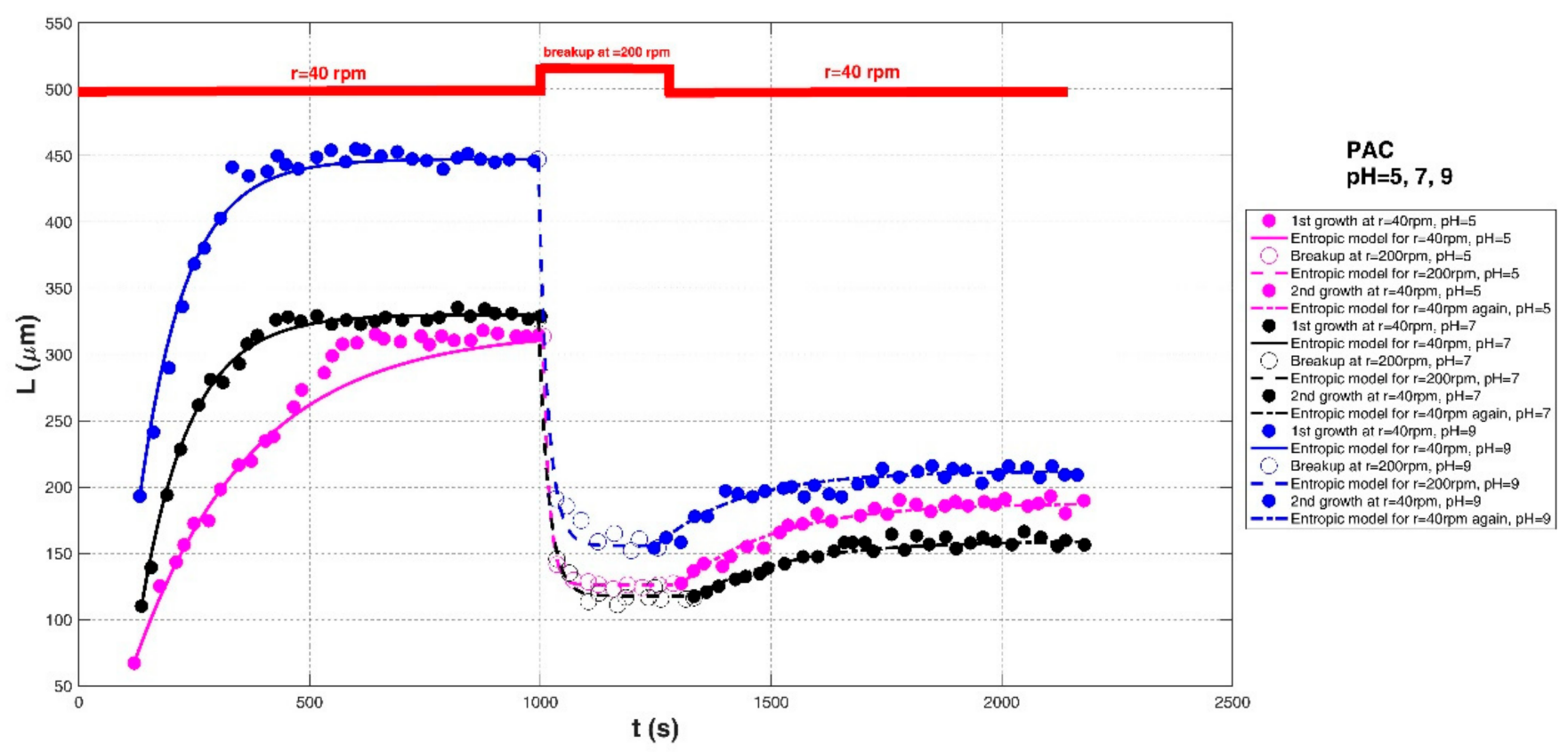

(d)

Figure 11. Comparison of the entropic model with experimental data points of $\mathrm{Xu}$ et al. (2010) [24]: (a) $\mathrm{Al}_{13}, \mathrm{pH}=7.5$; (b) $\mathrm{PAC}, \mathrm{pH}=7.5 ;$ (c) $\mathrm{Al}_{13}, \mathrm{pH}=5,7,9$; (d) $\mathrm{PAC}, \mathrm{pH}=5,7,9$. 


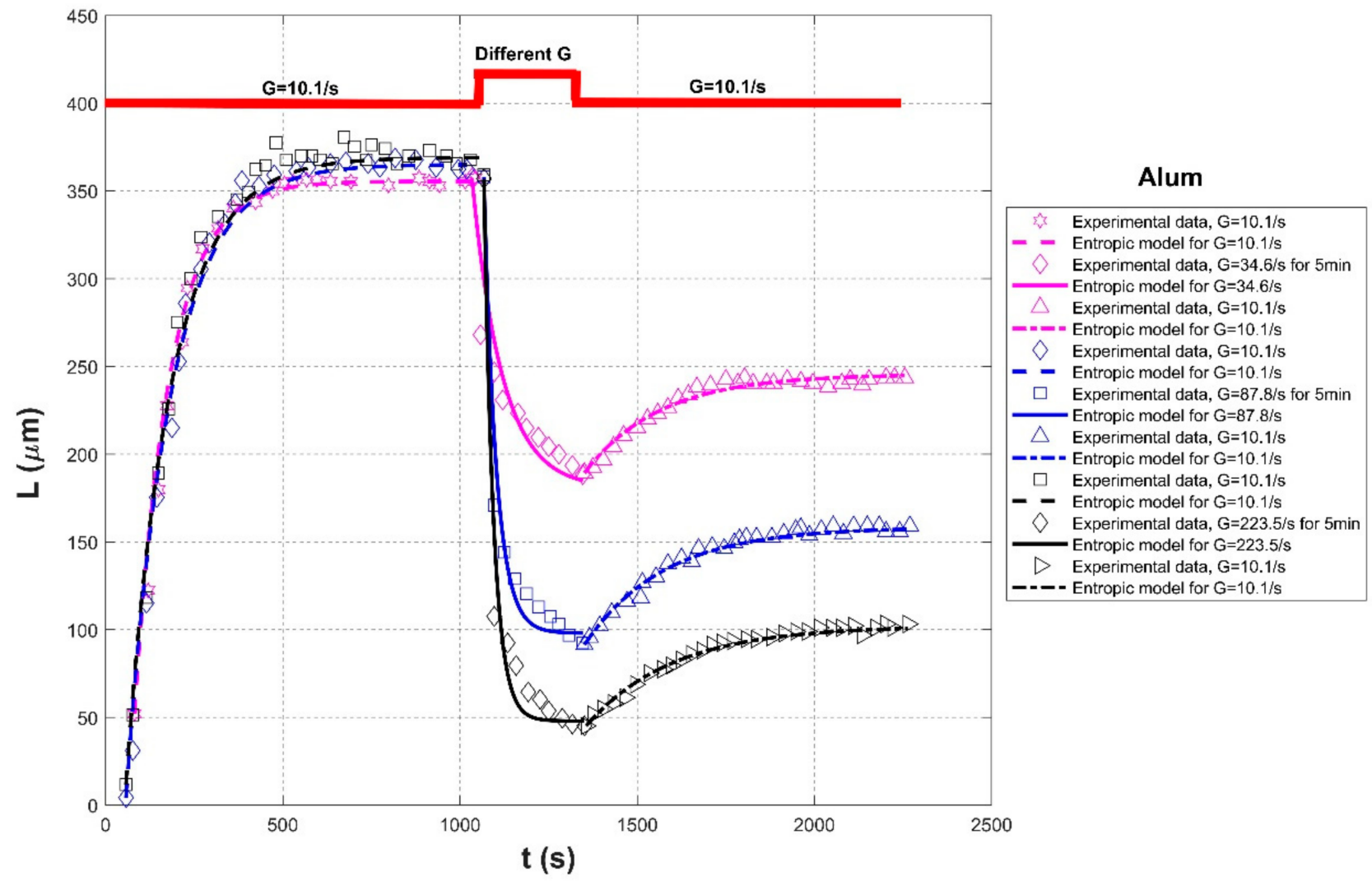

(a)

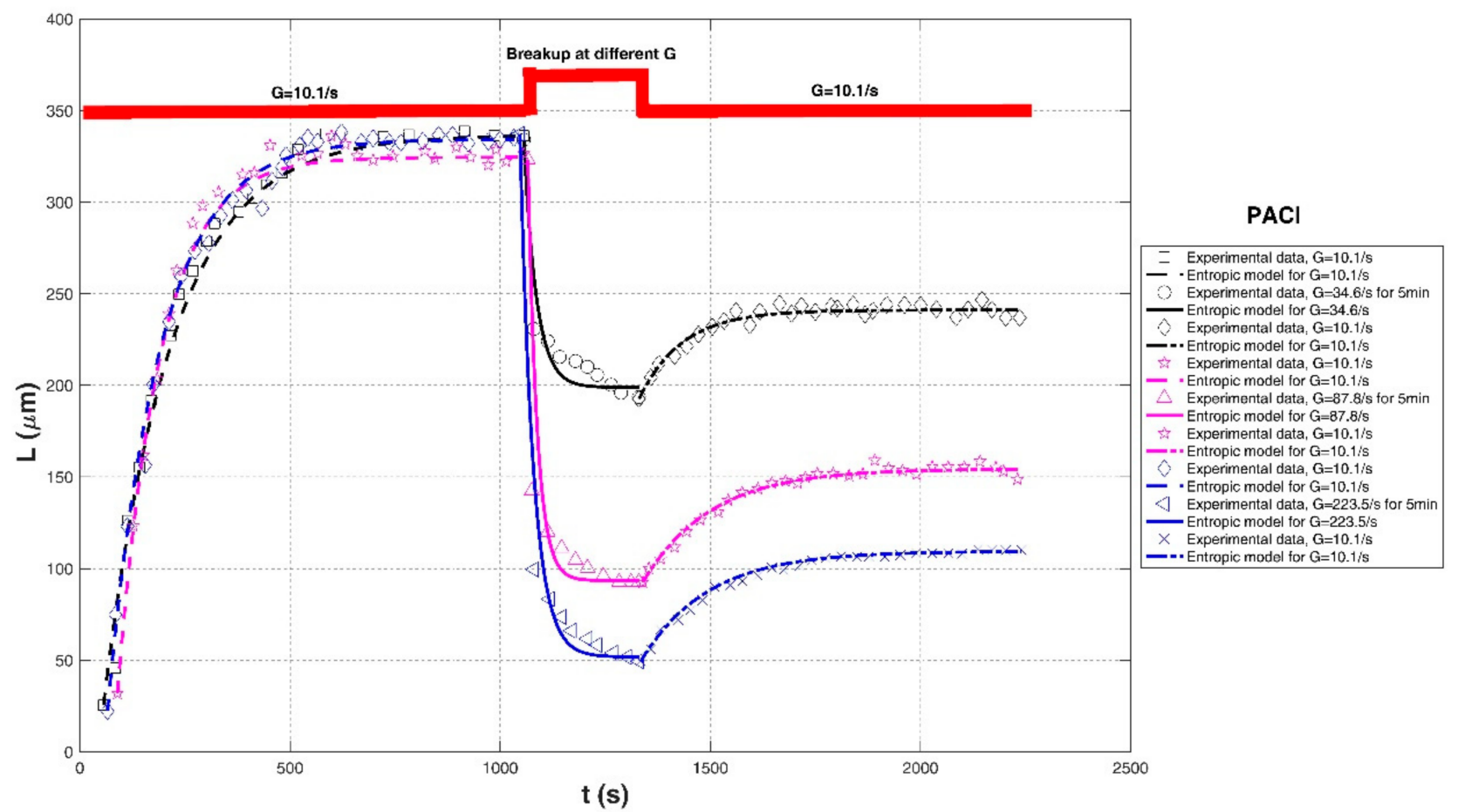

(b)

Figure 12. Cont. 


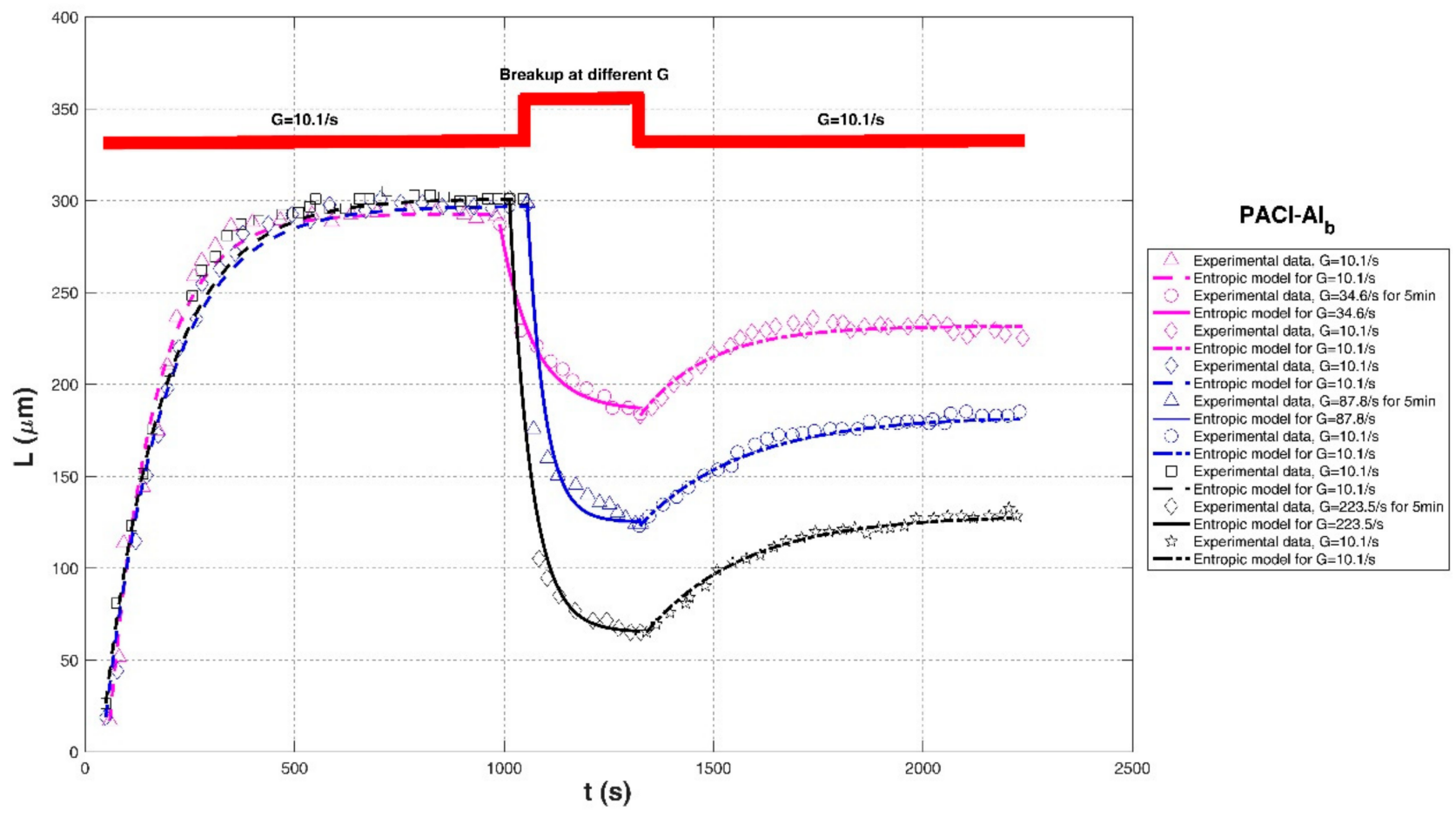

(c)

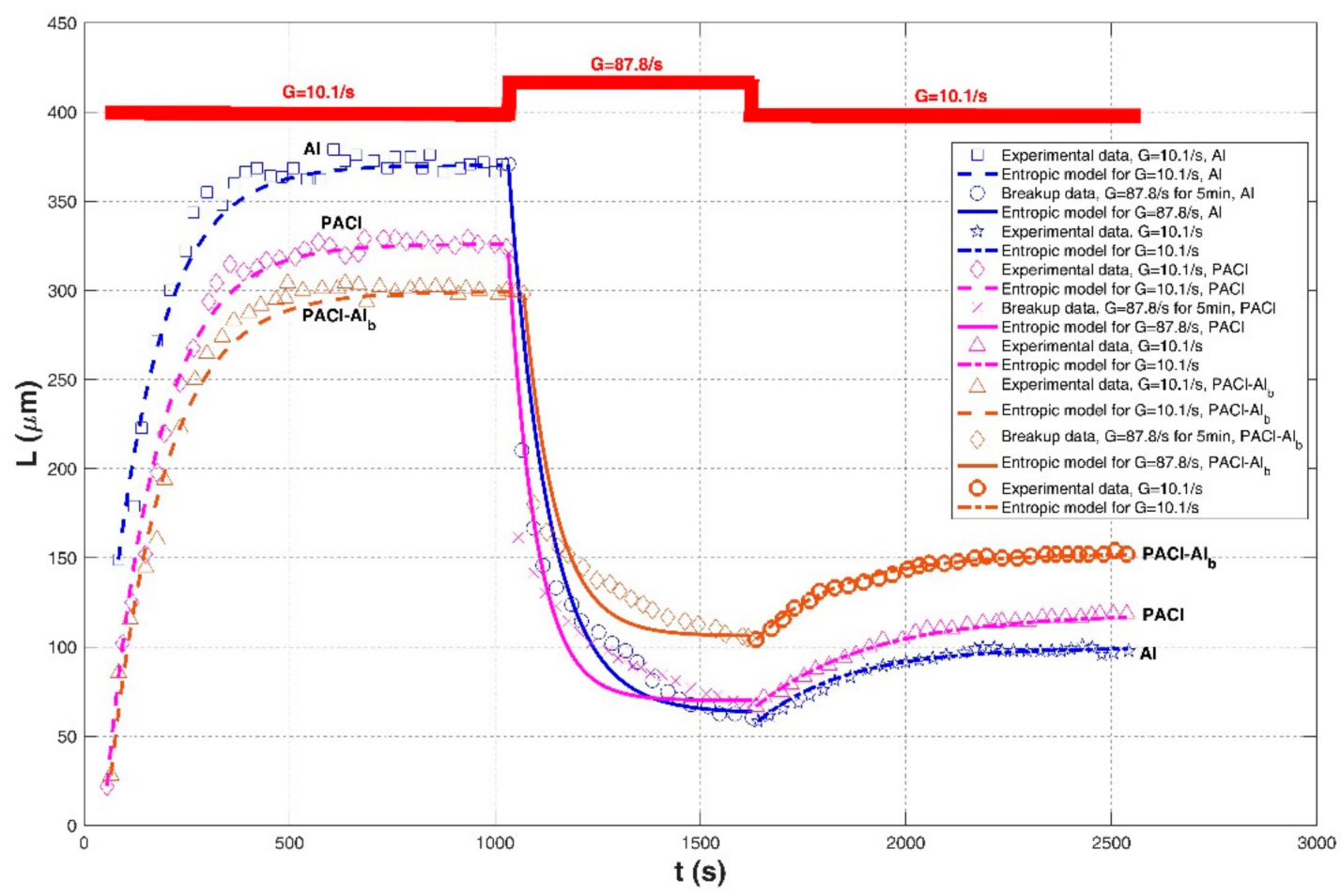

(d)

Figure 12. Comparison of the entropic model with experimental data points of $\mathrm{Xu}$ and Gao (2012) [74]: (a) alum; (b) PACl; (c) $\mathrm{PACl}-\mathrm{Al}_{\mathrm{b}}$ with short breakage period $(5 \mathrm{~min})$; (d) with long breakage period $(10 \mathrm{~min})$ by enhanced shear rates of $87.8 \mathrm{~s}^{-1}$. 


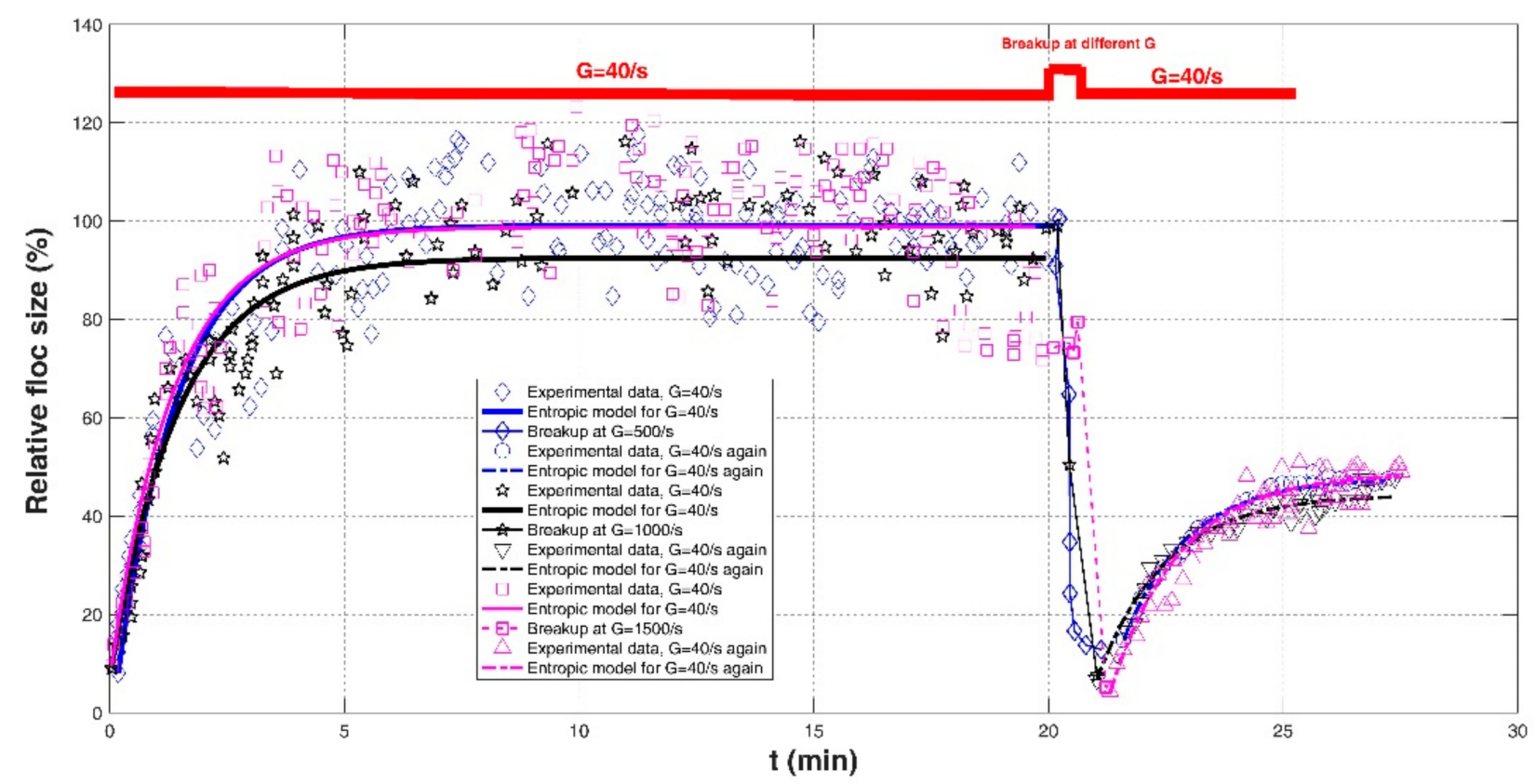

(a)

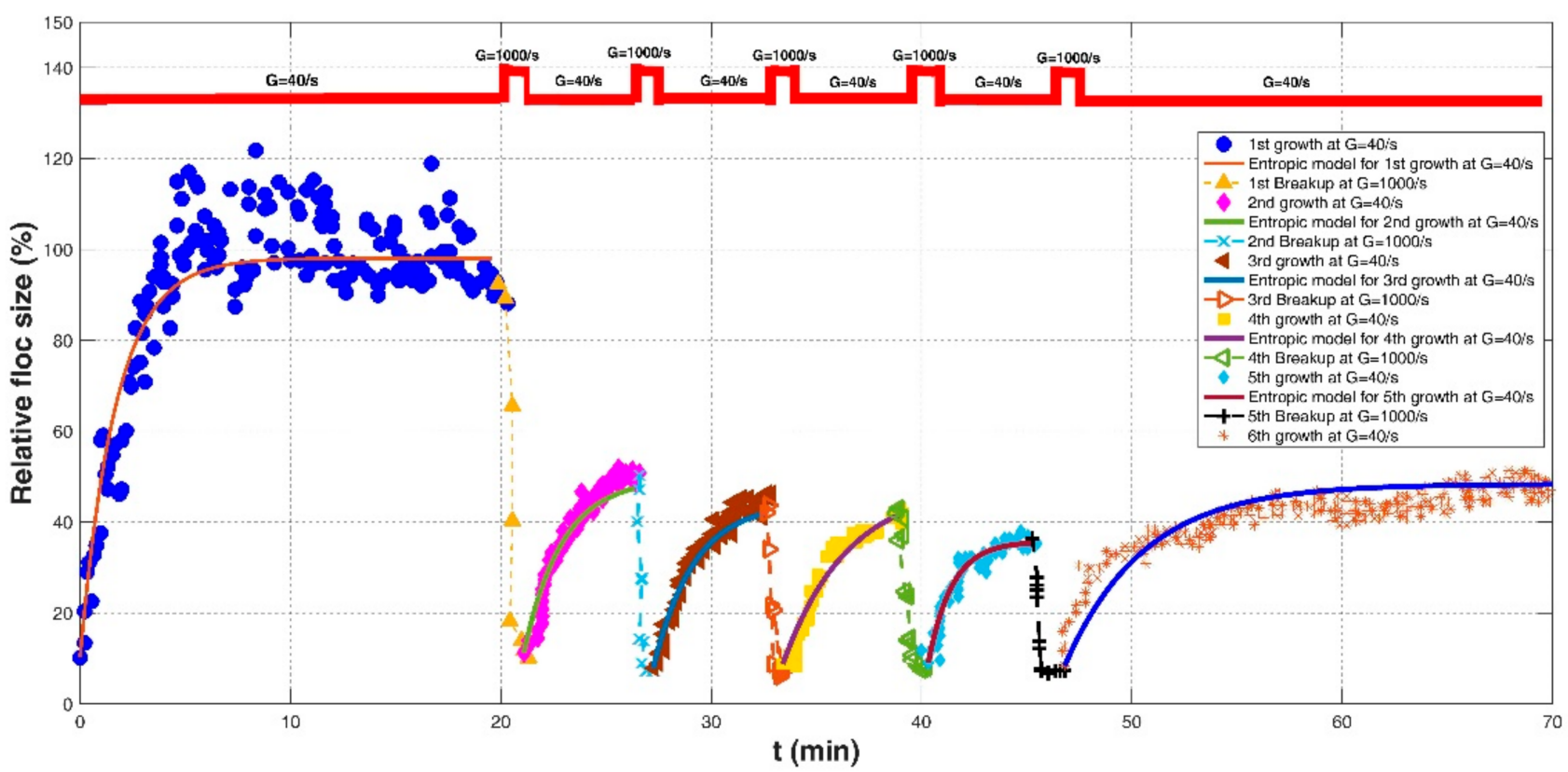

(b)

Figure 13. Cont. 


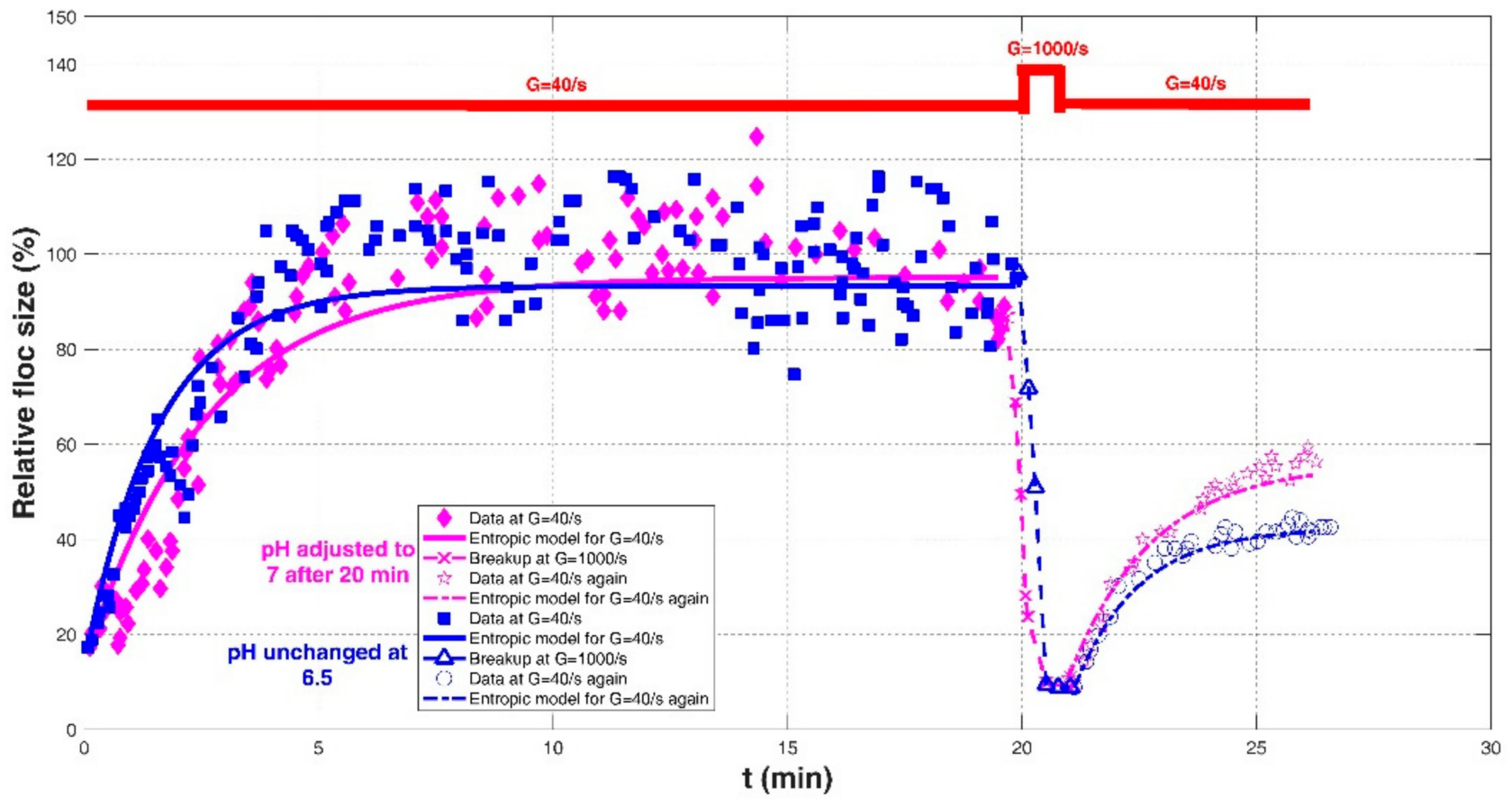

(c)

Figure 13. Comparison of the entropic model with experimental data points of Slavik et al. (2012) [22]: (a) single shear; (b) 5 cycles; (c) $\mathrm{pH}$ increase.

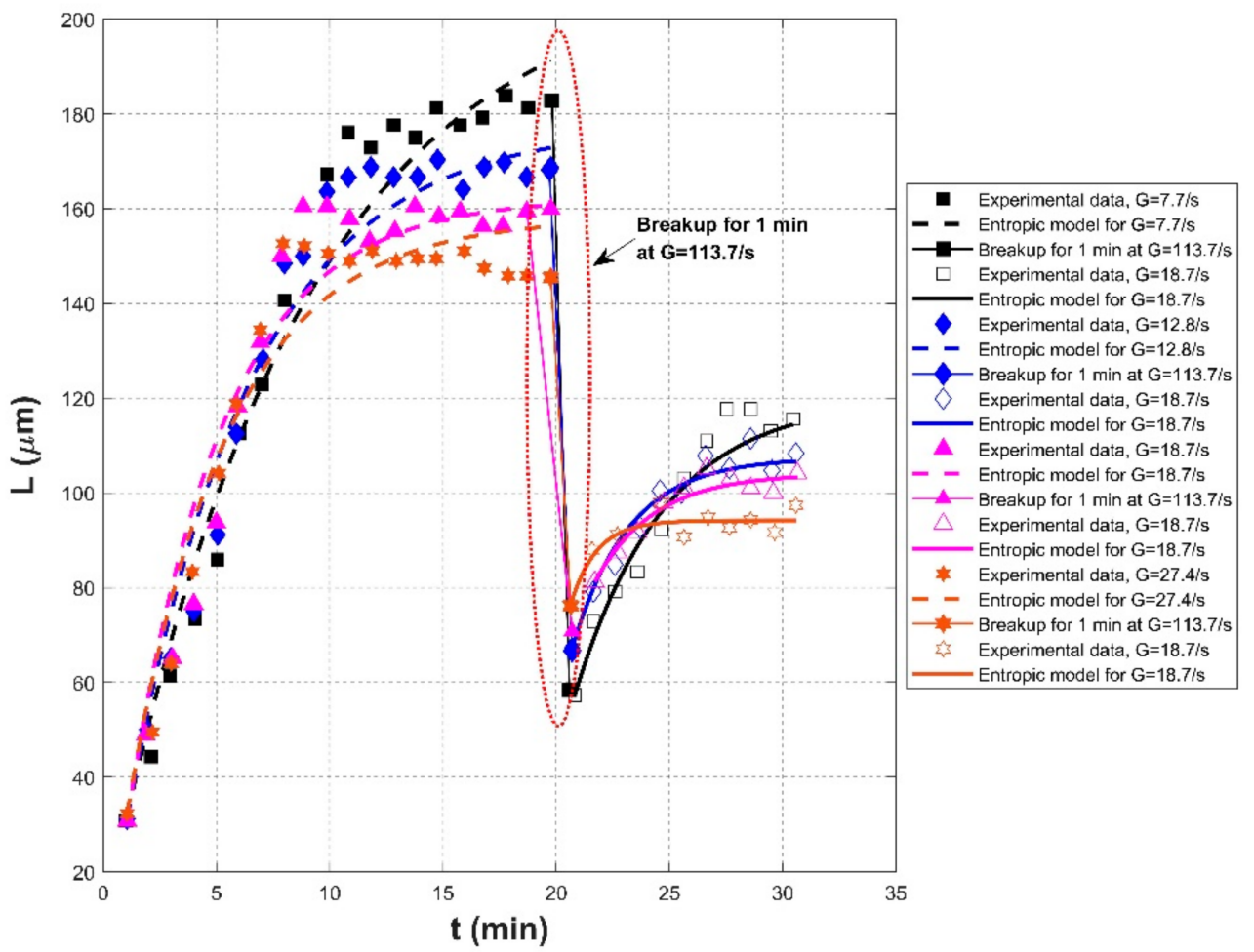

(a)

Figure 14. Cont. 


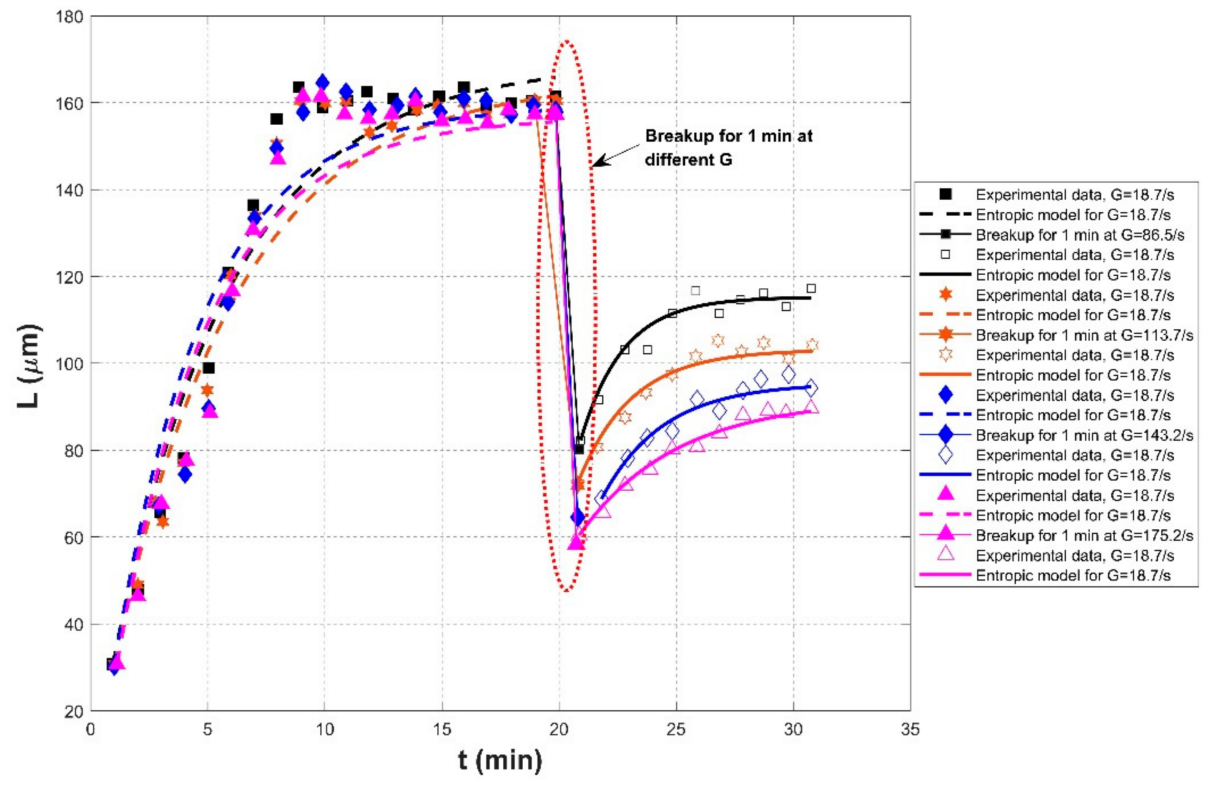

(b)

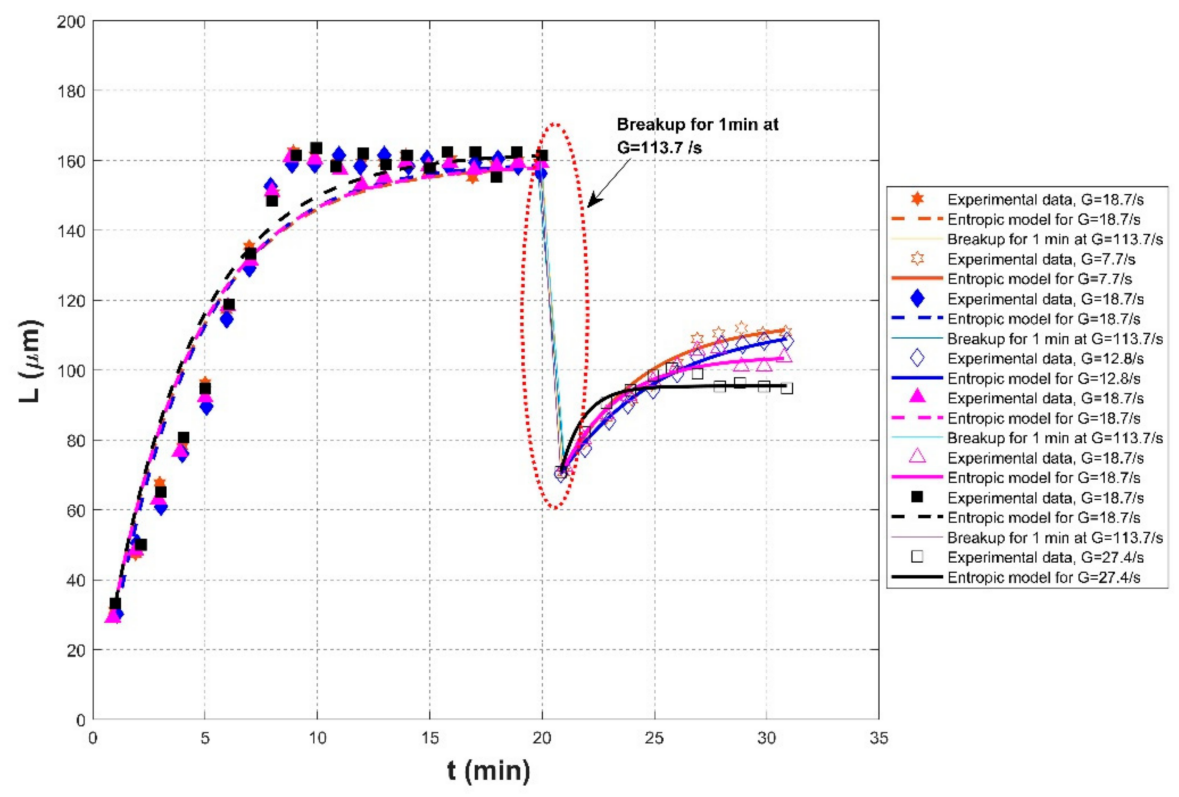

(c)

Figure 14. Comparison of the entropic model with Nan et al. (2016) [20]: (a) before floc breakage; (b) during floc breakage; (c) after floc breakage. 


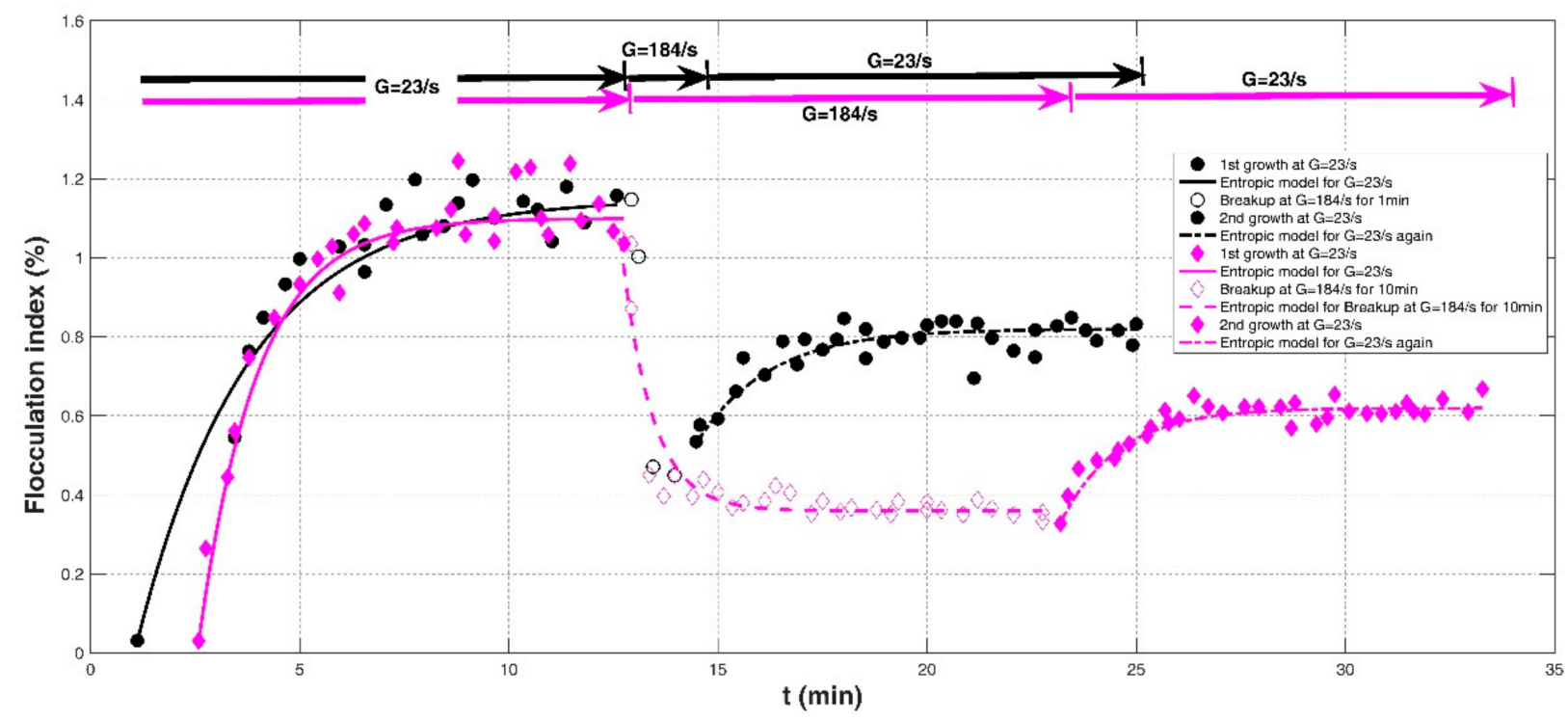

(a)

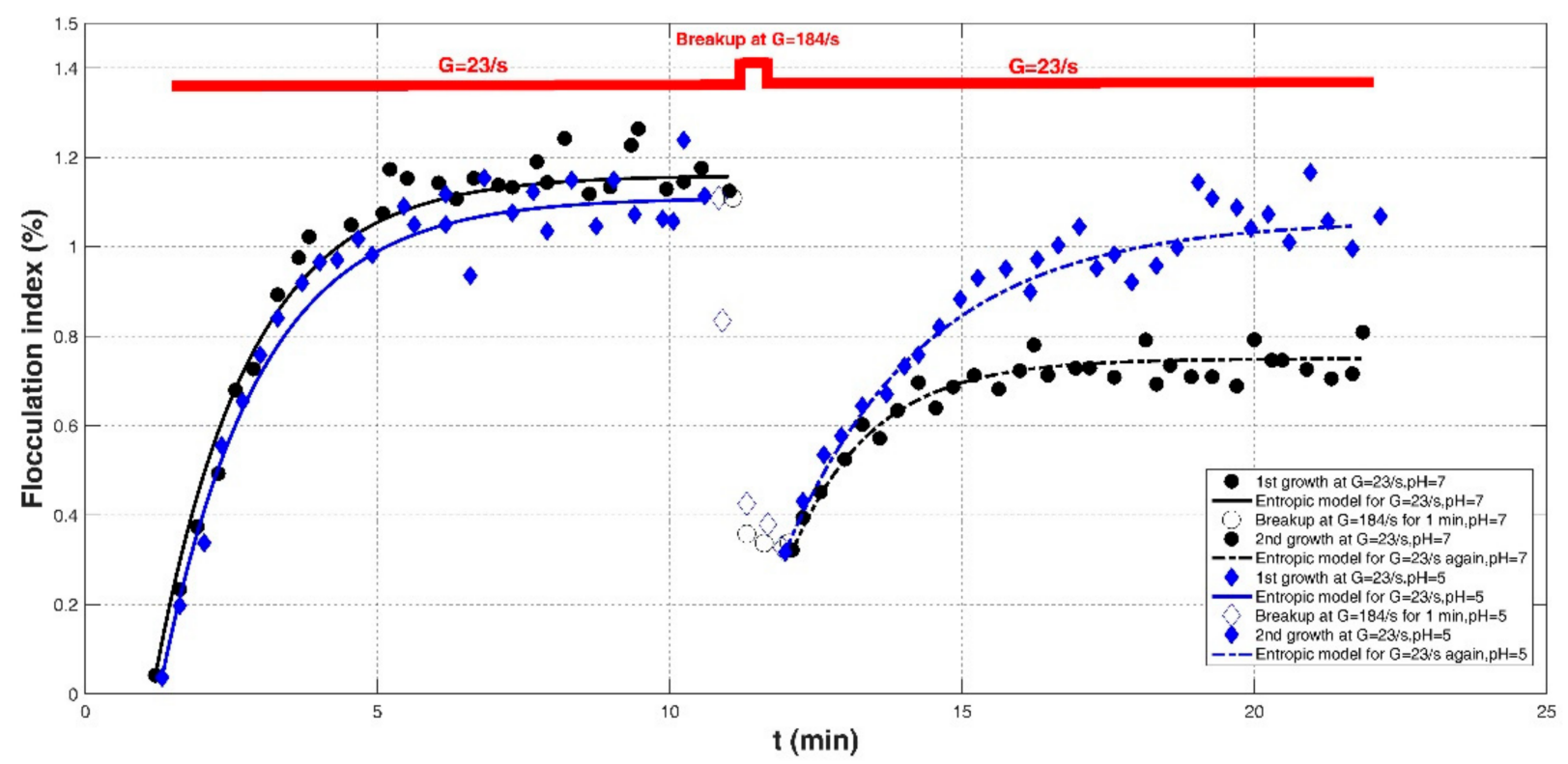

(b)

Figure 15. Comparison of the entropic model with Wu et al. (2019) [29]: (a) effect of 1 min or 10 min floc breakage on flocculation profile of alum flocs; (b) effect of $\mathrm{pH}$ changing on the re-growth of broken alum-kaolin flocs at breakage stage.

Figure 16 shows the Taylor diagram of calculated correlation coefficients and relative errors for these cases. By and large, the entropic model can agree with most experimental data points with a correlation coefficient above 0.88 and a relative error below 0.1 . As listed in the last row of Table 2, the average values of $R^{2}, R E$, and $R M S E$ are 0.9301, 0.0475, and 6.6286. Three obvious large deviations in Figure 16 are from the case of $G=135 \mathrm{~s}^{-1}$ with sludge concentration of $35 \mathrm{mg} / \mathrm{L}$ in Chaignon et al. (2002), the case of $G=370 \mathrm{~s}^{-1}$ with activated sludge spiked with $20 \mathrm{wt} \%$ of aquatic particles in Chaignon et al. (2002), and the case of $\mathrm{r}=40 \mathrm{rpm}$ (50-rpm breakup after 40-rpm growth) in the humic acid flocculation experiment of Xu et al. (2010), as shown in F, respectively. It can be observed from Figure 8a that there was a serious data crowd in the first floc growth phase of $G=135 \mathrm{~s}^{-1}$, for which no flocculation models may hold; there was also no obvious trend of floc size growth from a rapid condition to a steady state. There was also a large data scatter in Figure $8 \mathrm{~b}$ so that the entropic model 
did not yield a fairly satisfactory fitting effect as for other cases. In Figure 11a, the reason why the entropic model had a poor effect for the case of $r=40 \mathrm{rpm}$ (50-rpm breakup after 40-rpm growth) is that there was no distinct floc growth phase directly observed from experimental data points in the authors' paper.

As shown in Figures 9a, 10-12, 13a,c, 14, and 15, the flocs that formed in a low shear condition experienced an obvious breakage effect when they were abruptly subject to a strong shear rate. However, when the shear rate further went back to the original low shear condition, floc size hardly returned to the original one before that strong shear rate, indicating a limited floc recoverability. For this type of floc size variation due to a sequenced flow shear process (low shear $\rightarrow$ high shear $\rightarrow$ the original low shear), the proposed entropic model (Equation (11)) can capture well the evolution trend of floc size and have a good agreement with data points. In Figures 8 and $9 \mathrm{~b}$, there is a cycled flow shear procedure (low shear $\rightarrow$ high shear $\rightarrow$ the original low shear $\rightarrow$ the original high shear $\rightarrow$ the original low shear), and the flocs experienced a growth phase three times and a breakage phase two times. When the shear rate went back to the original low condition after floc breakage, floc size increased to (even passing) the original one before breakage in Figure 8, indicating a strong floc recoverability; in contrast, floc size in Figure $9 \mathrm{~b}$ did not return to the original one before floc breakup even when the shear rate became the original low condition, indicating a limited re-growth of broken flocs. In Figure 13, the flocs experienced five cycles of a low shear $\left(G=40 \mathrm{~s}^{-1}\right)$ and high shear $\left(G=1000 \mathrm{~s}^{-1}\right)$. Steady-state floc size indeed did not recover to the original one at flocculation time of 0 and $20 \mathrm{~min}$ even though the shear rate became the original low shear condition $\left(G=40 \mathrm{~s}^{-1}\right)$ after the first-time floc breakage. However, the final floc size achieved after repeated breakage did not decrease, that is, there were no obvious final floc size variations among the second, third, fourth, fifth, and sixth floc growth phases. It can be seen that from these figures, regardless of irreversible or reversible floc growth, the entropic model can still track well the evolution trend of floc size in a cycled shear condition with high accuracy. Additionally, the entropic model was not plotted here for some floc breakage phases in Figures 10, 13 and 14 due to limited data points.

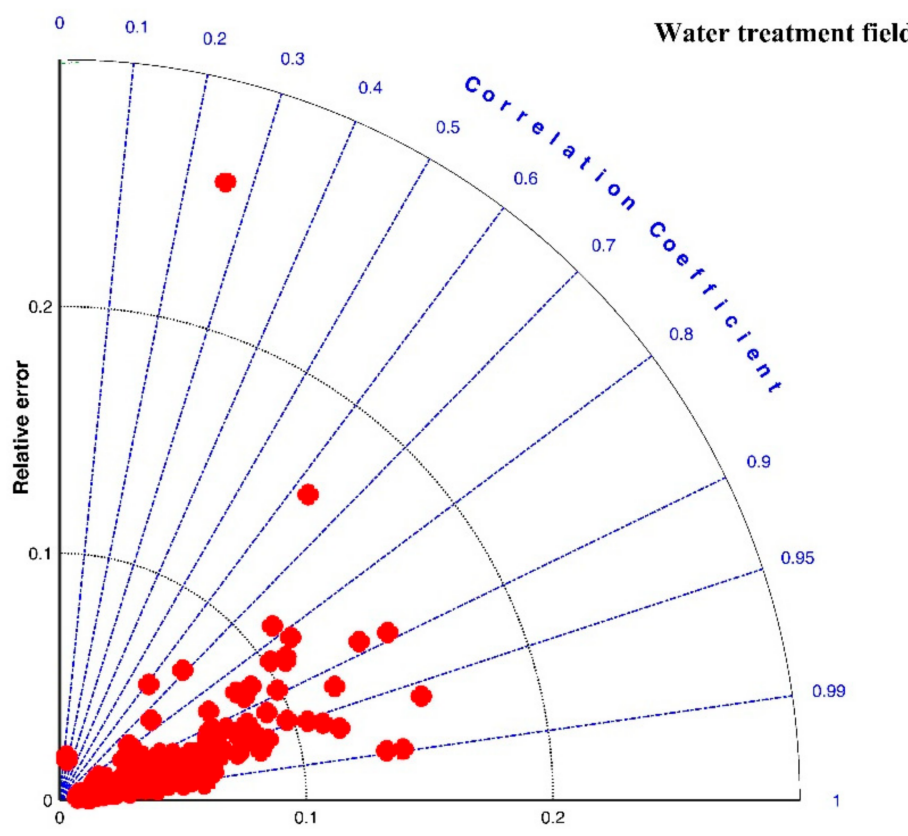

Figure 16. Taylor diagram of calculated correlation coefficients $R^{2}$ and relative errors $R E$ for experimental cases in the wastewater treatment field. 


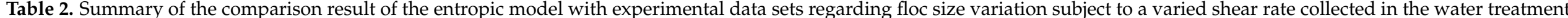
field. The last row shows the average values of statistical errors.

\begin{tabular}{|c|c|c|c|c|c|c|c|c|c|c|}
\hline \multirow{2}{*}{ References } & \multicolumn{6}{|c|}{ Flocculation Experiment Condition } & \multicolumn{4}{|c|}{ Fitting Effect } \\
\hline & Material & $\begin{array}{l}\text { Flocculation } \\
\text { Environment }\end{array}$ & Flocculation Condition & Flocculation Period & $L_{0}(\mu m)$ & $L_{s}(\mu m)$ & $M\left(\mu m^{*} \min \right)$ & $R^{2}$ & $R E$ & RMSE \\
\hline \multirow{4}{*}{$\begin{array}{l}\text { Chaignon et al. } \\
\text { (2002) [27] }\end{array}$} & \multirow{4}{*}{$\begin{array}{l}\text { Activated } \\
\text { sludge }\end{array}$} & \multirow{4}{*}{$\begin{array}{l}\text { Baffled reactor with } \\
\text { a stirring motor }\end{array}$} & \multirow{4}{*}{$\begin{array}{c}\text { Sludge } \\
\text { concentration }=35 \mathrm{mg} / \mathrm{L}\end{array}$} & $\mathrm{G}=135 / \mathrm{s}$, for $40 \mathrm{~min}$ & 115.30 & 129.64 & 300 & 0.2593 & 0.2593 & 6.5020 \\
\hline & & & & $\mathrm{G}=135 / \mathrm{s}$, for $80 \mathrm{~min}$ & 64.67 & 144.69 & 1500 & 0.9286 & 0.0411 & 6.4584 \\
\hline & & & & $\begin{array}{c}\mathrm{G}=370 / \mathrm{s}, \text { for } 40 \mathrm{~min} \\
\text { breakup }\end{array}$ & 140.51 & 64.46 & 100 & 0.6875 & 0.0725 & 10.7549 \\
\hline & & & & $\mathrm{G}=135 / \mathrm{s}$, for $80 \mathrm{~min}$ & 60.58 & 158.16 & 1800 & 0.9215 & 0.0651 & 9.0372 \\
\hline \multirow{5}{*}{$\begin{array}{c}\text { Chaignon et al. } \\
\text { (2002) [27] }\end{array}$} & \multirow{5}{*}{$\begin{array}{l}\text { Activated } \\
\text { sludge }\end{array}$} & \multirow{5}{*}{$\begin{array}{l}\text { Baffled reactor with } \\
\text { a stirring motor }\end{array}$} & \multirow{5}{*}{$\begin{array}{l}\text { Activated sludge spiked with } \\
20 \mathrm{wt} \% \text { of aquatic particles }\end{array}$} & $\mathrm{G}=135 / \mathrm{s}$, for $40 \mathrm{~min}$ & 116.56 & 170.20 & 700 & 0.8092 & 0.0361 & 0.0361 \\
\hline & & & & $\begin{array}{c}\mathrm{G}=370 / \mathrm{s}, \text { for } 40 \mathrm{~min} \\
\text { breakup }\end{array}$ & 165.56 & 76.89 & 200 & 0.6312 & 0.1596 & 28.4818 \\
\hline & & & & $\mathrm{G}=135 / \mathrm{s}$, for $80 \mathrm{~min}$ & 78.15 & 186.81 & 1400 & 0.9514 & 0.0433 & 7.6736 \\
\hline & & & & $\begin{array}{c}\mathrm{G}=370 / \mathrm{s}, \text { for } 40 \mathrm{~min} \\
\text { breakup }\end{array}$ & 178.15 & 78.81 & 200 & 0.7514 & 0.0492 & 10.3384 \\
\hline & & & & $\mathrm{G}=135 / \mathrm{s}$, for $80 \mathrm{~min}$ & 80.13 & 179.47 & 900 & 0.9347 & 0.0407 & 7.5324 \\
\hline \multirow{7}{*}{$\begin{array}{l}\text { Biggs et al. } \\
\text { (2003) [18] }\end{array}$} & \multirow{7}{*}{$\begin{array}{l}\text { Activated } \\
\text { sludge }\end{array}$} & \multirow{7}{*}{$\begin{array}{l}\text { Baffled batch vessel } \\
\text { with an impeller }\end{array}$} & \multirow[t]{2}{*}{ E1 } & $G=113 \mathrm{~s}$ & 135.42 & 72.07 & 75 & 0.8831 & 0.0380 & 7.5874 \\
\hline & & & & $\mathrm{G}=19.4 / \mathrm{s}$ & 72.14 & 119.85 & 300 & 0.9784 & 0.0185 & 2.5094 \\
\hline & & & \multirow{5}{*}{ E2 } & $\mathrm{G}=19.4 / \mathrm{s}$ & 40.92 & 131.08 & 800 & 0.9852 & 0.0205 & 2.9983 \\
\hline & & & & $\mathrm{G}=113 \mathrm{~s}$ & 132.73 & 71.33 & 75 & 0.9946 & 0.0117 & 1.1121 \\
\hline & & & & $\mathrm{G}=19.4 / \mathrm{s}$ & 71.69 & 121.37 & 300 & 0.9852 & 0.0155 & 2.2554 \\
\hline & & & & $\mathrm{G}=113 \mathrm{~s}$ & 122.08 & 72.64 & 60 & 0.8453 & 0.0303 & 6.0052 \\
\hline & & & & $\mathrm{G}=19.4 / \mathrm{s}$ & 73.59 & 117.47 & 250 & 0.9874 & 0.0119 & 1.6873 \\
\hline
\end{tabular}


Table 2. Cont.

\begin{tabular}{|c|c|c|c|c|c|c|c|c|c|c|}
\hline \multirow[b]{2}{*}{ References } & \multicolumn{6}{|c|}{ Flocculation Experiment Condition } & \multicolumn{4}{|c|}{ Fitting Effect } \\
\hline & Material & $\begin{array}{l}\text { Flocculation } \\
\text { Environment }\end{array}$ & Flocculation Condition & Flocculation Period & $L_{0}(\mu m)$ & $L_{s}(\mu m)$ & $M\left(\mu m^{*} \min \right)$ & $R^{2}$ & $R E$ & RMSE \\
\hline \multirow{9}{*}{$\begin{array}{l}\text { Gregory } \\
\text { (2004) [19] }\end{array}$} & \multirow{9}{*}{ Kaolin } & \multirow{9}{*}{$\begin{array}{l}\text { Modified jar test } \\
\text { with different } \\
\text { stirring rates }\end{array}$} & \multirow{3}{*}{ Alum coagulant } & $\mathrm{G}=11 / \mathrm{s}$ & $\begin{array}{l}0.06 \text { (dimen- } \\
\text { sional, } \\
\text { hereinafter) }\end{array}$ & $\begin{array}{l}0.81 \text { (dimen- } \\
\text { sional, } \\
\text { hereinafter) }\end{array}$ & $\begin{array}{c}50(s, \\
\text { hereinafter })\end{array}$ & 0.9921 & 0.0381 & 0.0209 \\
\hline & & & & $\begin{array}{c}\mathrm{G}=340 / \mathrm{s}, \text { for } 10 \mathrm{~s} \\
\text { breakup }\end{array}$ & - & - & - & - & - & - \\
\hline & & & & $\mathrm{G}=11 / \mathrm{s}$ & 0.39 & 0.65 & 20 & 0.9608 & 0.0153 & 0.0134 \\
\hline & & & \multirow{3}{*}{$\begin{array}{c}\text { XL-1: degrees of } \\
\text { neutralization }(\mathrm{OH} / \mathrm{Al})=1.9 \\
5.1 \mathrm{wt.} \% \mathrm{Al}\end{array}$} & $\mathrm{G}=11 / \mathrm{s}$ & 0.05 & 1.42 & 55 & 0.9888 & 0.1341 & 0.0693 \\
\hline & & & & $\begin{array}{c}\mathrm{G}=340 / \mathrm{s}, \text { for } 10 \mathrm{~s} \\
\text { breakup }\end{array}$ & - & - & - & - & - & - \\
\hline & & & & $\mathrm{G}=11 / \mathrm{s}$ & 0.61 & 0.99 & 30 & 0.9835 & 0.0133 & 0.0148 \\
\hline & & & \multirow{3}{*}{$\begin{array}{c}\text { XL-9: degrees of } \\
\text { neutralization }(\mathrm{OH} / \mathrm{Al})=2.1 \\
4.6 \mathrm{wt} . \% \mathrm{Al}\end{array}$} & $\mathrm{G}=11 / \mathrm{s}$ & 0.05 & 1.98 & 70 & 0.9891 & 0.1407 & 0.1113 \\
\hline & & & & $\begin{array}{c}\mathrm{G}=340 / \mathrm{s}, \text { for } 10 \mathrm{~s} \\
\text { breakup }\end{array}$ & - & - & - & - & - & - \\
\hline & & & & $\mathrm{G}=11 / \mathrm{s}$ & 0.83 & 1.31 & 30 & 0.9880 & 0.0113 & 0.0170 \\
\hline \multirow{8}{*}{$\begin{array}{l}\text { Gregory } \\
(2004)[19]\end{array}$} & \multirow{8}{*}{ Kaolin } & \multirow{8}{*}{$\begin{array}{l}\text { Modified jar test } \\
\text { with different } \\
\text { stirring rates }\end{array}$} & \multirow[t]{2}{*}{ Alum coagulant } & $G=520 / s$, for breakup & - & - & - & - & - & - \\
\hline & & & & $\mathrm{G}=23 / \mathrm{s}$ & 0.14 & 0.40 & 15 & 0.9636 & 0.0359 & 0.0151 \\
\hline & & & \multirow{3}{*}{$\begin{array}{c}\text { XL-9: degrees of } \\
\text { neutralization }(\mathrm{OH} / \mathrm{Al})=2.1 \\
4.6 \mathrm{wt} . \% \mathrm{Al}\end{array}$} & $\mathrm{G}=23 / \mathrm{s}$ & 0.16 & 1.45 & 80 & 0.9713 & 0.0840 & 0.0833 \\
\hline & & & & $\mathrm{G}=520 / \mathrm{s}$, for breakup & - & - & - & - & - & - \\
\hline & & & & $\mathrm{G}=23 / \mathrm{s}$ & 0.36 & 0.72 & 20 & 0.9720 & 0.0224 & 0.0175 \\
\hline & & & \multirow{3}{*}{$\begin{array}{c}\text { polyDADMAC coagulant (a } \\
\text { high-charge, } \\
\text { low-molecular-weight } \\
\text { cationic polyelectrolyte) }\end{array}$} & $\mathrm{G}=23 / \mathrm{s}$ & 0.17 & 3.14 & 1200 & 0.9082 & 0.0669 & 0.1840 \\
\hline & & & & $\mathrm{G}=520 / \mathrm{s}$, for breakup & - & - & - & - & - & - \\
\hline & & & & $G=23 / s$ & 0.65 & 2.74 & 450 & 0.9060 & 0.0448 & 0.1442 \\
\hline
\end{tabular}


Table 2. Cont.

\begin{tabular}{|c|c|c|c|c|c|c|c|c|c|c|}
\hline \multirow[b]{2}{*}{ References } & \multicolumn{6}{|c|}{ Flocculation Experiment Condition } & \multicolumn{4}{|c|}{ Fitting Effect } \\
\hline & Material & $\begin{array}{l}\text { Flocculation } \\
\text { Environment }\end{array}$ & Flocculation Condition & Flocculation Period & $L_{0}(\mu m)$ & $L_{s}(\mu m)$ & $M\left(\mu m^{*} \min \right)$ & $R^{2}$ & $R E$ & RMSE \\
\hline \multirow{13}{*}{$\begin{array}{l}\text { Xu et al. } \\
\text { (2010) [24] }\end{array}$} & \multirow{13}{*}{$\begin{array}{l}\text { Humic acid } \\
\text { (HA). }\end{array}$} & \multirow{13}{*}{$\begin{array}{l}\text { Jar-test apparatus } \\
\text { with a stirrer, } \mathrm{Al}_{13} \\
\text { polymer at different } \\
\text { shear rate, } \mathrm{pH}=7.5\end{array}$} & \multirow{3}{*}{$\begin{array}{l}\text { 50-rpm breakup after } \\
\text { 40-rpm growth }\end{array}$} & $\mathrm{r}=40 \mathrm{rpm}$ & 19.63 & 279.74 & $\begin{array}{l}22,000(\mu m * s, \\
\text { hereinafter })\end{array}$ & 0.9984 & 0.0116 & 3.1415 \\
\hline & & & & $\mathrm{r}=50 \mathrm{rpm}$ & 279.27 & 222.55 & 2000 & 0.9576 & 0.0111 & 4.6007 \\
\hline & & & & $\mathrm{r}=40 \mathrm{rpm}$ & 222.28 & 228.76 & 1500 & 0.1546 & 0.0181 & 5.0816 \\
\hline & & & \multirow{2}{*}{$\begin{array}{l}\text { 100-rpm breakup after } \\
\text { 40-rpm growth }\end{array}$} & $\mathrm{r}=40 \mathrm{rpm}$ & 117.55 & 265.28 & 11,000 & 0.9810 & 0.0230 & 6.6168 \\
\hline & & & & $\mathrm{r}=40 \mathrm{rpm}$ & 140.01 & 177.50 & 4500 & 0.8730 & 0.0167 & 3.7291 \\
\hline & & & \multirow{3}{*}{$\begin{array}{l}\text { 150-rpm breakup after } \\
\text { 40-rpm growth }\end{array}$} & $\mathrm{r}=40 \mathrm{rpm}$ & 19.63 & 283.18 & 20,000 & 0.9901 & 0.0222 & 7.0939 \\
\hline & & & & $\mathrm{r}=150 \mathrm{rpm}$ & 274.46 & 117.26 & 5000 & 0.9556 & 0.0458 & 10.2740 \\
\hline & & & & $\mathrm{r}=40 \mathrm{rpm}$ & 113.99 & 162.29 & 6500 & 0.9852 & 0.0089 & 1.7233 \\
\hline & & & \multirow{3}{*}{$\begin{array}{l}\text { 200-rpm breakup after } \\
\text { 40-rpm growth }\end{array}$} & $\mathrm{r}=40 \mathrm{rpm}$ & 20.33 & 272.50 & 22,500 & 0.9909 & 0.0227 & 6.8536 \\
\hline & & & & $\mathrm{r}=200 \mathrm{rpm}$ & 273.10 & 103.04 & 7500 & 0.9822 & 0.0335 & 6.9715 \\
\hline & & & & $\mathrm{r}=40 \mathrm{rpm}$ & 106.43 & 156.72 & 5500 & 0.9487 & 0.0171 & 3.2077 \\
\hline & & & \multirow{2}{*}{$\begin{array}{l}\text { 500-rpm breakup after } \\
\text { 40-rpm growth }\end{array}$} & $\mathrm{r}=500 \mathrm{rpm}$ & 270.35 & 58.56 & 5000 & 0.9210 & 0.0911 & 19.5654 \\
\hline & & & & $\mathrm{r}=40 \mathrm{rpm}$ & 55.79 & 119.96 & 5000 & 0.9489 & 0.0255 & 3.6906 \\
\hline \multirow{9}{*}{$\begin{array}{l}\text { Xu et al. } \\
(2010)[24]\end{array}$} & \multirow{9}{*}{$\begin{array}{l}\text { Humic acid } \\
\text { (HA). }\end{array}$} & \multirow{9}{*}{$\begin{array}{l}\text { Jar-test apparatus } \\
\text { with a stirrer, } \\
\text { polyaluminum } \\
\text { chloride } \\
\text { polymer at different } \\
\text { shear rate, pH = 7.5 }\end{array}$} & \multirow{3}{*}{$\begin{array}{l}\text { 50-rpm breakup } \\
\text { after 40-rpm growth }\end{array}$} & $\mathrm{r}=40 \mathrm{rpm}$ & 36.05 & 307.90 & 28,000 & 0.9735 & 0.0439 & 12.3611 \\
\hline & & & & $\mathrm{r}=50 \mathrm{rpm}$ & 287.22 & 254.27 & 2500 & 0.9447 & 0.0081 & 2.8922 \\
\hline & & & & $\mathrm{r}=40 \mathrm{rpm}$ & 246.78 & 260.54 & 2500 & 0.1824 & 0.0164 & 5.4085 \\
\hline & & & \multirow{3}{*}{$\begin{array}{l}\text { 100-rpm breakup after } \\
\text { 40-rpm growth }\end{array}$} & $\mathrm{r}=40 \mathrm{rpm}$ & 45.80 & 305.79 & 32,000 & 0.9695 & 0.0502 & 14.1697 \\
\hline & & & & $\mathrm{r}=100 \mathrm{rpm}$ & 285.60 & 170.96 & 4000 & 0.9355 & 0.0338 & 9.2723 \\
\hline & & & & $\mathrm{r}=40 \mathrm{rpm}$ & 163.88 & 204.92 & 10,000 & 0.9456 & 0.0139 & 3.4411 \\
\hline & & & \multirow{3}{*}{$\begin{array}{l}\text { 150-rpm breakup after } \\
\text { 40-rpm growth }\end{array}$} & $\mathrm{r}=40 \mathrm{rpm}$ & 5.95 & 294.72 & 35,000 & 0.9781 & 0.0443 & 11.6565 \\
\hline & & & & $\mathrm{r}=150 \mathrm{rpm}$ & 283.18 & 140.06 & 4000 & 0.9728 & 0.0295 & 7.4282 \\
\hline & & & & $\mathrm{r}=40 \mathrm{rpm}$ & 137.86 & 177.69 & 8000 & 0.9851 & 0.0079 & 1.7108 \\
\hline
\end{tabular}


Table 2. Cont.

\begin{tabular}{|c|c|c|c|c|c|c|c|c|c|c|}
\hline \multirow[b]{2}{*}{ References } & \multicolumn{6}{|c|}{ Flocculation Experiment Condition } & \multicolumn{4}{|c|}{ Fitting Effect } \\
\hline & Material & $\begin{array}{l}\text { Flocculation } \\
\text { Environment }\end{array}$ & Flocculation Condition & Flocculation Period & $L_{0}(\mu m)$ & $L_{s}(\mu m)$ & $M\left(\mu m^{*} \min \right)$ & $R^{2}$ & $R E$ & RMSE \\
\hline & & & \multirow{3}{*}{$\begin{array}{l}\text { 200-rpm breakup after } \\
\text { 40-rpm growth }\end{array}$} & $\mathrm{r}=40 \mathrm{rpm}$ & 1.88 & 325.50 & 38,000 & 0.9901 & 0.0541 & 11.6801 \\
\hline & & & & $\mathrm{r}=200 \mathrm{rpm}$ & 320.56 & 123.38 & 4000 & 0.9390 & 0.0505 & 13.4764 \\
\hline & & & & $\mathrm{r}=40 \mathrm{rpm}$ & 121.65 & 163.71 & 4000 & 0.8932 & 0.0156 & 3.8415 \\
\hline & & & \multirow{3}{*}{$\begin{array}{l}\text { 500-rpm breakup after } \\
\text { 40-rpm growth }\end{array}$} & $\mathrm{r}=40 \mathrm{rpm}$ & 2.69 & 304.50 & 40,000 & 0.9877 & 0.0479 & 10.4163 \\
\hline & & & & $\mathrm{r}=500 \mathrm{rpm}$ & 297.79 & 89.07 & 4000 & 0.9253 & 0.0821 & 16.7552 \\
\hline & & & & $\mathrm{r}=40 \mathrm{rpm}$ & 89.10 & 138.51 & 8000 & 0.9207 & 0.0294 & 4.7246 \\
\hline \multirow{8}{*}{$\begin{array}{l}\text { Xu et al. } \\
\text { (2010) [24] }\end{array}$} & \multirow{8}{*}{$\begin{array}{l}\text { Humic acid } \\
\text { (HA). }\end{array}$} & \multirow{8}{*}{$\begin{array}{c}\text { Jar-test apparatus } \\
\text { with a stirrer, } \mathrm{Al}_{13} \\
\text { polymer at different } \\
\text { shear rate }\end{array}$} & \multirow{3}{*}{$\mathrm{pH}=5$} & $\mathrm{r}=40 \mathrm{rpm}$ & 57.89 & 258.33 & 24,000 & 0.9744 & 0.0431 & 10.7588 \\
\hline & & & & $\mathrm{r}=200 \mathrm{rpm}$ & 252.63 & 81.58 & 2500 & 0.9907 & 0.0351 & 5.7008 \\
\hline & & & & $\mathrm{r}=40 \mathrm{rpm}$ & 84.21 & 145.61 & 8500 & 0.9329 & 0.0317 & 5.5597 \\
\hline & & & \multirow{3}{*}{$\mathrm{pH}=7$} & $\mathrm{r}=40 \mathrm{rpm}$ & 12.28 & 278.22 & 40,500 & 0.9685 & 0.1172 & 17.4689 \\
\hline & & & & $\mathrm{r}=200 \mathrm{rpm}$ & 278.07 & 92.11 & 4500 & 0.9459 & 0.0589 & 13.3823 \\
\hline & & & & $\mathrm{r}=40 \mathrm{rpm}$ & 95.61 & 149.27 & 4500 & 0.9525 & 0.0161 & 3.4224 \\
\hline & & & \multirow[t]{2}{*}{$\mathrm{pH}=9$} & $\mathrm{r}=200 \mathrm{rpm}$ & 322.81 & 109.21 & 12,500 & 0.9326 & 0.0667 & 18.3096 \\
\hline & & & & $\mathrm{r}=40 \mathrm{rpm}$ & 113.16 & 177.19 & 6500 & 0.9730 & 0.0149 & 3.1652 \\
\hline \multirow{9}{*}{$\begin{array}{l}\text { Xu et al. } \\
\text { (2010) [24] }\end{array}$} & \multirow{9}{*}{$\begin{array}{l}\text { Humic acid } \\
\text { (HA). }\end{array}$} & \multirow{9}{*}{$\begin{array}{c}\text { Jar-test apparatus } \\
\text { with a stirrer, } \\
\text { polyaluminum } \\
\text { chloride } \\
\text { polymer at different } \\
\text { shear rate }\end{array}$} & \multirow{3}{*}{$\mathrm{pH}=5$} & $\mathrm{r}=40 \mathrm{rpm}$ & 67.34 & 318.50 & 64,000 & 0.9817 & 0.0393 & 14.2694 \\
\hline & & & & $\mathrm{r}=200 \mathrm{rpm}$ & 313.70 & 126.08 & 2500 & 0.9987 & 0.0122 & 2.0395 \\
\hline & & & & $\mathrm{r}=40 \mathrm{rpm}$ & 127.36 & 187.98 & 12,500 & 0.9567 & 0.0191 & 4.1434 \\
\hline & & & \multirow{3}{*}{$\mathrm{pH}=7$} & $\mathrm{r}=40 \mathrm{rpm}$ & 110.33 & 330.10 & 23,500 & 0.9932 & 0.0143 & 4.9210 \\
\hline & & & & $\mathrm{r}=200 \mathrm{rpm}$ & 326.61 & 117.96 & 4500 & 0.9946 & 0.0287 & 4.3394 \\
\hline & & & & $\mathrm{r}=40 \mathrm{rpm}$ & 117.65 & 159.39 & 8500 & 0.9259 & 0.0208 & 4.1117 \\
\hline & & & \multirow{3}{*}{$\mathrm{pH}=9$} & $\mathrm{r}=40 \mathrm{rpm}$ & 193.13 & 447.35 & 25,500 & 0.9846 & 0.0168 & 9.4848 \\
\hline & & & & $\mathrm{r}=200 \mathrm{rpm}$ & 447.04 & 155.76 & 6000 & 0.9921 & 0.0399 & 8.8524 \\
\hline & & & & $\mathrm{r}=40 \mathrm{rpm}$ & 154.30 & 211.99 & 10,500 & 0.8975 & 0.0209 & 5.3591 \\
\hline
\end{tabular}


Table 2. Cont.

\begin{tabular}{|c|c|c|c|c|c|c|c|c|c|c|}
\hline \multirow{2}{*}{ References } & \multicolumn{6}{|c|}{ Flocculation Experiment Condition } & \multicolumn{4}{|c|}{ Fitting Effect } \\
\hline & Material & $\begin{array}{l}\text { Flocculation } \\
\text { Environment }\end{array}$ & Flocculation Condition & Flocculation Period & $L_{0}(\mu m)$ & $L_{s}(\mu m)$ & $M\left(\mu m^{*} \min \right)$ & $R^{2}$ & $R E$ & RMSE \\
\hline \multirow{9}{*}{$\begin{array}{l}\mathrm{Xu} \text { and Gao } \\
(2012)[74]\end{array}$} & \multirow{9}{*}{ Humic acid } & \multirow{9}{*}{$\begin{array}{l}\text { Jar-test apparatus } \\
\text { with different } \\
\text { mixing rates }\end{array}$} & \multirow{9}{*}{ Alum coagulant } & $\mathrm{G}=10.1 / \mathrm{s}$, for $15 \mathrm{~min}$ & 52.13 & 355.51 & $\begin{array}{l}\text { 30,000 }(\mu m * s, \\
\text { hereinafter })\end{array}$ & 0.9437 & 0.0977 & 24.1654 \\
\hline & & & & $\begin{array}{c}\mathrm{G}=34.6 / \mathrm{s}, \text { for } 5 \mathrm{~min} \\
\text { breakup }\end{array}$ & 357.45 & 180.54 & 15,000 & 0.9248 & 0.0496 & 16.5140 \\
\hline & & & & $\mathrm{G}=10.1 / \mathrm{s}$, for $15 \mathrm{~min}$ & 189.36 & 245.60 & 12,000 & 0.9703 & 0.0101 & 2.8881 \\
\hline & & & & $\mathrm{G}=10.1 / \mathrm{s}$, for $15 \mathrm{~min}$ & 4.30 & 365.05 & 45,000 & 0.9937 & 0.0590 & 10.3406 \\
\hline & & & & $\begin{array}{c}\mathrm{G}=87.8 / \mathrm{s}, \text { for } 5 \mathrm{~min} \\
\text { breakup }\end{array}$ & 358.06 & 98.00 & 9000 & 0.9663 & 0.0753 & 14.7623 \\
\hline & & & & $\mathrm{G}=10.1 / \mathrm{s}$, for $15 \mathrm{~min}$ & 91.40 & 158.38 & 15,000 & 0.9882 & 0.0145 & 2.5093 \\
\hline & & & & $\mathrm{G}=10.1 / \mathrm{s}$, for $15 \mathrm{~min}$ & 11.83 & 369.06 & 45,000 & 0.9913 & 0.0351 & 10.6234 \\
\hline & & & & $\begin{array}{c}\mathrm{G}=223.5 / \mathrm{s}, \text { for } 5 \mathrm{~min} \\
\text { breakup }\end{array}$ & 356.99 & 47.95 & 8500 & 0.9611 & 0.1525 & 18.5870 \\
\hline & & & & $\mathrm{G}=10.1 / \mathrm{s}$, for $15 \mathrm{~min}$ & 45.16 & 102.15 & 14,000 & 0.9911 & 0.0196 & 1.9381 \\
\hline \multirow{8}{*}{$\begin{array}{l}\mathrm{Xu} \text { and Gao } \\
(2012)[74]\end{array}$} & \multirow{8}{*}{ Humic acid } & \multirow{8}{*}{$\begin{array}{l}\text { Jar-test apparatus } \\
\text { with different } \\
\text { mixing rates }\end{array}$} & \multirow{8}{*}{ PACl coagulant } & $\mathrm{G}=10.1 / \mathrm{s}$, for $15 \mathrm{~min}$ & 25.46 & 336.66 & 50,000 & 0.9924 & 0.0506 & 9.5759 \\
\hline & & & & $\mathrm{G}=10.1 / \mathrm{s}$, for $15 \mathrm{~min}$ & 192.62 & 241.12 & 5000 & 0.9513 & 0.0097 & 2.8908 \\
\hline & & & & $\mathrm{G}=10.1 / \mathrm{s}$, for $15 \mathrm{~min}$ & 31.84 & 324.52 & 30,000 & 0.9944 & 0.0179 & 7.0992 \\
\hline & & & & $\begin{array}{c}\mathrm{G}=87.8 / \mathrm{s}, \text { for } 5 \mathrm{~min} \\
\text { breakup }\end{array}$ & 323.29 & 93.50 & 5000 & 0.8354 & 0.1023 & 32.0393 \\
\hline & & & & $\mathrm{G}=10.1 / \mathrm{s}$, for $15 \mathrm{~min}$ & 92.59 & 154.47 & 10,000 & 0.9837 & 0.0133 & 2.4118 \\
\hline & & & & $\mathrm{G}=10.1 / \mathrm{s}$, for $15 \mathrm{~min}$ & 22.22 & 334.26 & 39,000 & 0.9921 & 0.0211 & 7.2941 \\
\hline & & & & $\begin{array}{c}\mathrm{G}=223.5 / \mathrm{s}, \text { for } 5 \mathrm{~min} \\
\text { breakup }\end{array}$ & 337.31 & 51.82 & 9000 & 0.9598 & 0.1112 & 17.3637 \\
\hline & & & & $\mathrm{G}=10.1 / \mathrm{s}$, for $15 \mathrm{~min}$ & 49.59 & 109.48 & 9500 & 0.9921 & 0.0159 & 1.8107 \\
\hline
\end{tabular}


Table 2. Cont.

\begin{tabular}{|c|c|c|c|c|c|c|c|c|c|c|}
\hline \multirow[b]{2}{*}{ References } & \multicolumn{6}{|c|}{ Flocculation Experiment Condition } & \multicolumn{4}{|c|}{ Fitting Effect } \\
\hline & Material & $\begin{array}{l}\text { Flocculation } \\
\text { Environment }\end{array}$ & Flocculation Condition & Flocculation Period & $L_{0}(\mu m)$ & $L_{s}(\mu m)$ & $M\left(\mu m^{*} \min \right)$ & $R^{2}$ & $R E$ & RMSE \\
\hline \multirow{7}{*}{$\begin{array}{l}\text { Xu and Gao } \\
\text { (2012) [74] }\end{array}$} & \multirow{7}{*}{ Humic acid } & \multirow{7}{*}{$\begin{array}{l}\text { Jar-test apparatus } \\
\text { with different } \\
\text { mixing rates }\end{array}$} & \multirow{7}{*}{ PACl- $\mathrm{Al}_{\mathrm{b}}$ coagulant } & $\mathrm{G}=10.1 / \mathrm{s}$, for $15 \mathrm{~min}$ & 16.84 & 292.84 & 30,000 & 0.9859 & 0.0480 & 10.0659 \\
\hline & & & & $\mathrm{G}=10.1 / \mathrm{s}$, for $15 \mathrm{~min}$ & 183.16 & 231.89 & 8000 & 0.9357 & 0.0144 & 3.8579 \\
\hline & & & & $\mathrm{G}=10.1 / \mathrm{s}$, for $15 \mathrm{~min}$ & 18.95 & 297.14 & 40,000 & 0.9941 & 0.0401 & 7.7517 \\
\hline & & & & $\mathrm{G}=10.1 / \mathrm{s}$, for $15 \mathrm{~min}$ & 123.16 & 183.03 & 15,000 & 0.9883 & 0.0129 & 2.7313 \\
\hline & & & & $\mathrm{G}=10.1 / \mathrm{s}$, for $15 \mathrm{~min}$ & 26.32 & 301.18 & 40,000 & 0.9941 & 0.0226 & 7.6730 \\
\hline & & & & $\begin{array}{c}\mathrm{G}=223.5 / \mathrm{s}, \text { for } 5 \mathrm{~min} \\
\text { breakup }\end{array}$ & 301.05 & 65.26 & 12,000 & 0.9908 & 0.0445 & 7.0965 \\
\hline & & & & $\mathrm{G}=10.1 / \mathrm{s}$, for $15 \mathrm{~min}$ & 65.26 & 128.87 & 15,000 & 0.9911 & 0.0172 & 2.2243 \\
\hline \multirow{9}{*}{$\begin{array}{l}\text { Xu and Gao } \\
\text { (2012) [74] }\end{array}$} & \multirow{9}{*}{ Humic acid } & \multirow{9}{*}{$\begin{array}{c}\text { Jar-test apparatus } \\
\text { with different } \\
\text { mixing rates }\end{array}$} & \multirow{3}{*}{ Alum coagulant } & $\mathrm{G}=10.1 / \mathrm{s}$, for $15 \mathrm{~min}$ & 148.96 & 370.24 & 27000 & 0.9770 & 0.0228 & 9.8363 \\
\hline & & & & $\begin{array}{c}\mathrm{G}=87.8 / \mathrm{s}, \text { for } 10 \mathrm{~min} \\
\text { breakup }\end{array}$ & 370.83 & 63.02 & 30,000 & 0.9241 & 0.1206 & 26.1279 \\
\hline & & & & $\mathrm{G}=10.1 / \mathrm{s}$, for $15 \mathrm{~min}$ & 58.33 & 99.66 & 9000 & 0.9813 & 0.0171 & 1.9847 \\
\hline & & & \multirow{3}{*}{$\mathrm{PACl}$ coagulant } & $\mathrm{G}=10.1 / \mathrm{s}$, for $15 \mathrm{~min}$ & 21.88 & 326.04 & 38,000 & 0.9909 & 0.0239 & 8.1788 \\
\hline & & & & $\begin{array}{c}\mathrm{G}=87.8 / \mathrm{s}, \text { for } 10 \mathrm{~min} \\
\text { breakup }\end{array}$ & 320.83 & 70.05 & 17,000 & 0.8838 & 0.1374 & 23.0509 \\
\hline & & & & $\mathrm{G}=10.1 / \mathrm{s}$, for $15 \mathrm{~min}$ & 66.67 & 118.71 & 14,500 & 0.9949 & 0.0149 & 1.7564 \\
\hline & & & \multirow{3}{*}{$\mathrm{PACl}-\mathrm{Al}_{\mathrm{b}}$ coagulant } & $\mathrm{G}=10.1 / \mathrm{s}$, for $15 \mathrm{~min}$ & 28.13 & 299.31 & 36,000 & 0.9885 & 0.0324 & 8.6583 \\
\hline & & & & $\begin{array}{c}\mathrm{G}=87.8 / \mathrm{s}, \text { for } 10 \mathrm{~min} \\
\text { breakup }\end{array}$ & 297.92 & 106.25 & 15,000 & 0.8735 & 0.0856 & 19.8588 \\
\hline & & & & $\mathrm{G}=10.1 / \mathrm{s}$, for $15 \mathrm{~min}$ & 104.17 & 152.34 & 10,000 & 0.9931 & 0.0073 & 1.2614 \\
\hline
\end{tabular}


Table 2. Cont.

\begin{tabular}{|c|c|c|c|c|c|c|c|c|c|c|}
\hline \multirow{2}{*}{ References } & \multicolumn{6}{|c|}{ Flocculation Experiment Condition } & \multicolumn{4}{|c|}{ Fitting Effect } \\
\hline & Material & $\begin{array}{l}\text { Flocculation } \\
\text { Environment }\end{array}$ & Flocculation Condition & Flocculation Period & $L_{0}(\mu m)$ & $L_{s}(\mu m)$ & $M\left(\mu m^{*} \min \right)$ & $R^{2}$ & $R E$ & RMSE \\
\hline \multirow{9}{*}{$\begin{array}{l}\text { Slavik et al. } \\
\text { (2012) [22] }\end{array}$} & \multirow{9}{*}{$\begin{array}{c}\text { Raw water in } \\
\text { Saxony } \\
\text { (Germany) }\end{array}$} & \multirow{9}{*}{$\begin{array}{c}\text { Jar test with single } \\
\text { mixers }\end{array}$} & \multirow{9}{*}{$\begin{array}{c}\mathrm{pH} 6.5 \text { with coagulant } \\
\text { dosages of } \\
0.2 \mathrm{mmol} / \mathrm{L} \text { and } \mathrm{G}=40 / \mathrm{s} \text { for } \\
20 \mathrm{~min} .\end{array}$} & $\mathrm{G}=40 / \mathrm{s}$ for $20 \mathrm{~min}$ & $\begin{array}{c}8.10(\%, \\
\text { hereinafter })\end{array}$ & $\begin{array}{c}99.13(\%, \\
\text { hereinafter })\end{array}$ & $\begin{array}{l}120\left(\%{ }^{*} \text { min, }\right. \\
\text { hereinafter })\end{array}$ & 0.8447 & 0.1085 & 9.7307 \\
\hline & & & & $\begin{array}{c}\mathrm{G}=500 / \mathrm{s} \text { for } 1 \mathrm{~min} \\
\text { breakup }\end{array}$ & - & - & - & - & - & - \\
\hline & & & & $\mathrm{G}=40 / \mathrm{s}$ & 14.76 & 47.79 & 45 & 0.9863 & 0.0212 & 1.1262 \\
\hline & & & & $\mathrm{G}=40 / \mathrm{s}$ for $20 \mathrm{~min}$ & 9.05 & 92.55 & 120 & 0.8519 & 0.1075 & 10.1488 \\
\hline & & & & $\begin{array}{c}\mathrm{G}=1000 / \mathrm{s} \text { for } 1 \mathrm{~min} \\
\text { breakup }\end{array}$ & - & - & - & - & - & - \\
\hline & & & & $\mathrm{G}=40 / \mathrm{s}$ & 6.67 & 44.39 & 55 & 0.9622 & 0.0562 & 2.0993 \\
\hline & & & & $\mathrm{G}=40 / \mathrm{s}$ for $20 \mathrm{~min}$ & 9.52 & 98.83 & 120 & 0.7737 & 0.1114 & 11.5515 \\
\hline & & & & $\begin{array}{c}\mathrm{G}=1500 / \mathrm{s} \text { for } 1 \mathrm{~min} \\
\text { breakup }\end{array}$ & - & - & - & - & - & - \\
\hline & & & & $\mathrm{G}=40 / \mathrm{s}$ & 4.29 & 48.71 & 65 & 0.9182 & 0.0734 & 3.2751 \\
\hline \multirow{10}{*}{$\begin{array}{l}\text { Slavik et al. } \\
\text { (2012) [22] }\end{array}$} & \multirow{10}{*}{$\begin{array}{c}\text { Raw water in } \\
\text { Saxony } \\
\text { (Germany) }\end{array}$} & \multirow{10}{*}{$\begin{array}{l}\text { Jar test with single } \\
\text { mixers }\end{array}$} & \multirow{10}{*}{$\begin{array}{c}\mathrm{pH} 6.5 \text { with coagulant } \\
\text { dosages of } \\
0.2 \mathrm{mmol} / \mathrm{L} \text { and } \\
\text { repeatedshearing }\end{array}$} & $\mathrm{G}=40 / \mathrm{s}$ for $20 \mathrm{~min}$ & 10.22 & 98.12 & 150 & 0.8529 & 0.0837 & 8.7473 \\
\hline & & & & $\mathrm{G}=40 / \mathrm{s}$ & 11.26 & 49.62 & 70 & 0.9603 & 0.0880 & 3.1496 \\
\hline & & & & $\begin{array}{c}\mathrm{G}=1000 / \mathrm{s} \text { for } 1 \mathrm{~min} \\
\text { breakup }\end{array}$ & - & - & - & - & - & \\
\hline & & & & $\mathrm{G}=40 / \mathrm{s}$ & 7.87 & 44.26 & 70 & 0.9676 & 0.0745 & 2.6660 \\
\hline & & & & $\begin{array}{c}\mathrm{G}=1000 / \mathrm{s} \text { for } 1 \mathrm{~min} \\
\text { breakup }\end{array}$ & - & - & - & - & - & - \\
\hline & & & & $\mathrm{G}=40 / \mathrm{s}$ & 8.78 & 48.10 & 120 & 0.9529 & 0.1054 & 2.5735 \\
\hline & & & & $\begin{array}{c}\mathrm{G}=1000 / \mathrm{s} \text { for } 1 \mathrm{~min} \\
\text { breakup }\end{array}$ & - & - & - & - & - & - \\
\hline & & & & $\mathrm{G}=40 / \mathrm{s}$ & 9.13 & 35.78 & 30 & 0.8923 & 0.0989 & 2.8444 \\
\hline & & & & $\begin{array}{c}\mathrm{G}=1000 / \mathrm{s} \text { for } 1 \mathrm{~min} \\
\text { breakup }\end{array}$ & - & - & - & - & - & - \\
\hline & & & & $\mathrm{G}=40 / \mathrm{s}$ & 8.42 & 48.40 & 150 & 0.8595 & 0.0902 & 4.0423 \\
\hline
\end{tabular}


Table 2. Cont

\begin{tabular}{|c|c|c|c|c|c|c|c|c|c|c|}
\hline \multirow{2}{*}{ References } & \multicolumn{6}{|c|}{ Flocculation Experiment Condition } & \multicolumn{4}{|c|}{ Fitting Effect } \\
\hline & Material & $\begin{array}{l}\text { Flocculation } \\
\text { Environment }\end{array}$ & Flocculation Condition & Flocculation Period & $L_{0}(\mu m)$ & $L_{s}(\mu m)$ & $M\left(\mu m^{*} \min \right)$ & $R^{2}$ & $R E$ & RMSE \\
\hline \multirow{5}{*}{$\begin{array}{l}\text { Slavik et al. } \\
\text { (2012) [22] }\end{array}$} & \multirow{5}{*}{$\begin{array}{l}\text { Raw water in } \\
\text { Saxony } \\
\text { (Germany) }\end{array}$} & \multirow{5}{*}{$\begin{array}{l}\text { Jar test with } \\
\text { single mixers }\end{array}$} & \multirow{3}{*}{$\mathrm{pH}$ adjusted to 7 after $20 \mathrm{~min}$} & $\mathrm{G}=40 / \mathrm{s}$ for $20 \mathrm{~min}$ & 17.33 & 95.17 & 200 & 0.8906 & 0.1493 & 11.4095 \\
\hline & & & & $\begin{array}{c}\mathrm{G}=1000 / \mathrm{s} \text { for } 1 \mathrm{~min} \\
\text { breakup }\end{array}$ & - & - & - & - & - & - \\
\hline & & & & $\mathrm{G}=40 / \mathrm{s}$ & 10.89 & 55.94 & 80 & 0.9845 & 0.0633 & 2.8540 \\
\hline & & & \multirow{2}{*}{ pH unchanged at 6.5} & $\mathrm{G}=40 / \mathrm{s}$ for $20 \mathrm{~min}$ & 17.33 & 93.36 & 120 & 0.8176 & 0.1145 & 0.1145 \\
\hline & & & & $\mathrm{G}=40 / \mathrm{s}$ & 8.91 & 42.35 & 45 & 0.9742 & 0.0368 & 1.7954 \\
\hline \multirow{11}{*}{$\begin{array}{l}\text { Nan et al. } \\
\text { (2016) [20] }\end{array}$} & \multirow{11}{*}{ Kaolin clay } & \multirow{11}{*}{$\begin{array}{l}\text { Jar test reactor with } \\
\text { aR1342-type } \\
\text { impeller }\end{array}$} & \multirow{11}{*}{$\begin{array}{l}\text { Effect of slow } \\
\text { mixing before breakage }\end{array}$} & $\mathrm{G}=7.7 / \mathrm{s}$, for $20 \mathrm{~min}$ & 30.73 & 210.13 & 1500 & 0.9682 & 0.0661 & 9.7669 \\
\hline & & & & $\begin{array}{c}\mathrm{G}=113.7 / \mathrm{s}, \text { for } 1 \mathrm{~min} \\
\text { breakup }\end{array}$ & - & - & - & - & - & - \\
\hline & & & & $\mathrm{G}=18.7 / \mathrm{s}$, for $10 \mathrm{~min}$ & 57.29 & 120.02 & 250 & 0.9604 & 0.0346 & 4.5132 \\
\hline & & & & $\mathrm{G}=12.8 / \mathrm{s}$, for $20 \mathrm{~min}$ & 31.25 & 177.60 & 800 & 0.9675 & 0.0603 & 8.8210 \\
\hline & & & & $\mathrm{G}=18.7 / \mathrm{s}$, for $10 \mathrm{~min}$ & 67.19 & 107.42 & 100 & 0.9641 & 0.0214 & 2.7208 \\
\hline & & & & $\mathrm{G}=18.7 / \mathrm{s}$, for $20 \mathrm{~min}$ & 30.73 & 162.25 & 550 & 0.9556 & 0.0644 & 9.6154 \\
\hline & & & & $\begin{array}{c}\mathrm{G}=113.7 / \mathrm{s}, \text { for } 1 \mathrm{~min} \\
\text { breakup }\end{array}$ & - & - & - & - & - & - \\
\hline & & & & $\mathrm{G}=18.7 / \mathrm{s}$, for $10 \mathrm{~min}$ & 81.25 & 104.08 & 60 & 0.9289 & 0.0164 & 2.0539 \\
\hline & & & & $\mathrm{G}=27.4 / \mathrm{s}$, for $20 \mathrm{~min}$ & 32.29 & 157.98 & 550 & 0.9435 & 0.0666 & 9.0538 \\
\hline & & & & $\begin{array}{c}\mathrm{G}=113.7 / \mathrm{s}, \text { for } 1 \mathrm{~min} \\
\text { breakup }\end{array}$ & - & - & - & - & - & - \\
\hline & & & & $\mathrm{G}=18.7 / \mathrm{s}$, for $10 \mathrm{~min}$ & 76.56 & 94.17 & 20 & 0.8483 & 0.0184 & 2.2616 \\
\hline
\end{tabular}


Table 2. Cont.

\begin{tabular}{|c|c|c|c|c|c|c|c|c|c|c|}
\hline \multirow{2}{*}{ References } & \multicolumn{6}{|c|}{ Flocculation Experiment Condition } & \multicolumn{4}{|c|}{ Fitting Effect } \\
\hline & Material & $\begin{array}{l}\text { Flocculation } \\
\text { Environment }\end{array}$ & Flocculation Condition & Flocculation Period & $L_{0}(\mu m)$ & $L_{s}(\mu m)$ & $M\left(\mu m^{*} \min \right)$ & $R^{2}$ & $R E$ & RMSE \\
\hline \multirow{10}{*}{$\begin{array}{l}\text { Nan et al. } \\
\text { (2016) [20] }\end{array}$} & \multirow{10}{*}{ Kaolin clay } & \multirow{10}{*}{$\begin{array}{c}\text { Jar-test reactor } \\
\text { with a } \\
\text { R1342-type impeller }\end{array}$} & \multirow{10}{*}{$\begin{array}{l}\text { Effect of rapid mixing } \\
\text { during breakage }\end{array}$} & $\mathrm{G}=18.7 / \mathrm{s}$, for $20 \mathrm{~min}$ & 30.73 & 169.02 & 700 & 0.9501 & 0.0687 & 10.2591 \\
\hline & & & & $\begin{array}{c}\mathrm{G}=86.5 / \mathrm{s}, \text { for } 1 \mathrm{~min} \\
\text { breakup }\end{array}$ & - & - & - & - & - & - \\
\hline & & & & $\mathrm{G}=18.7 / \mathrm{s}$, for $10 \mathrm{~min}$ & 82.29 & 115.23 & 60 & 0.9558 & 0.0162 & 2.3454 \\
\hline & & & & $\mathrm{G}=18.7 / \mathrm{s}$, for $20 \mathrm{~min}$ & 30.73 & 165.11 & 700 & 0.9506 & 0.0664 & 10.6025 \\
\hline & & & & $\mathrm{G}=18.7 / \mathrm{s}$, for $10 \mathrm{~min}$ & 72.40 & 103.13 & 70 & 0.9697 & 0.0168 & 2.0119 \\
\hline & & & & $\mathrm{G}=18.7 / \mathrm{s}$, for $20 \mathrm{~min}$ & 30.21 & 159.27 & 500 & 0.9345 & 0.0762 & 11.4771 \\
\hline & & & & $\begin{array}{c}\mathrm{G}=143.2 \mathrm{~s}, \text { for } 1 \mathrm{~min} \\
\text { breakup }\end{array}$ & - & - & - & - & - & - \\
\hline & & & & $\mathrm{G}=18.7 / \mathrm{s}$, for $10 \mathrm{~min}$ & 68.75 & 95.44 & 70 & 0.9566 & 0.0158 & 1.9016 \\
\hline & & & & $\mathrm{G}=18.7 / \mathrm{s}$, for $20 \mathrm{~min}$ & 30.73 & 156.68 & 500 & 0.9509 & 0.0780 & 11.0099 \\
\hline & & & & $\mathrm{G}=18.7 / \mathrm{s}$, for $10 \mathrm{~min}$ & 60.42 & 91.81 & 130 & 0.9880 & 0.0121 & 1.1794 \\
\hline \multirow{10}{*}{$\begin{array}{l}\text { Nan et al. } \\
\text { (2016) [20] }\end{array}$} & \multirow{10}{*}{ Kaolin clay } & \multirow{10}{*}{$\begin{array}{c}\text { Jar-test reactor } \\
\text { with a } \\
\text { R1342-type impeller }\end{array}$} & \multirow{10}{*}{$\begin{array}{l}\text { Effect of slow mixing } \\
\text { after breakage }\end{array}$} & $\mathrm{G}=18.7 / \mathrm{s}$, for $20 \mathrm{~min}$ & 31.25 & 158.75 & 500 & 0.9540 & 0.0798 & 10.7711 \\
\hline & & & & $\begin{array}{c}\mathrm{G}=113.7 / \mathrm{s}, \text { for } 1 \mathrm{~min} \\
\text { breakup }\end{array}$ & - & - & - & - & - & - \\
\hline & & & & $\mathrm{G}=7.7 / \mathrm{s}$, for $10 \mathrm{~min}$ & 70.83 & 113.94 & 150 & 0.9733 & 0.0210 & 2.4718 \\
\hline & & & & $\mathrm{G}=18.7 / \mathrm{s}$, for $20 \mathrm{~min}$ & 30.21 & 159.59 & 500 & 0.9461 & 0.0835 & 11.3822 \\
\hline & & & & $\begin{array}{c}\mathrm{G}=113.7 / \mathrm{s}, \text { for } 1 \mathrm{~min} \\
\text { breakup }\end{array}$ & - & - & - & - & - & - \\
\hline & & & & $\mathrm{G}=12.8 / \mathrm{s}$, for $10 \mathrm{~min}$ & 70.31 & 113.81 & 200 & 0.9914 & 0.0119 & 1.3387 \\
\hline & & & & $\mathrm{G}=18.7 / \mathrm{s}$, for $20 \mathrm{~min}$ & 29.17 & 158.75 & 500 & 0.9519 & 0.0791 & 10.8267 \\
\hline & & & & $\begin{array}{c}\mathrm{G}=113.7 / \mathrm{s}, \text { for } 1 \mathrm{~min} \\
\text { breakup }\end{array}$ & - & - & - & - & - & - \\
\hline & & & & $\mathrm{G}=18.7 / \mathrm{s}$, for $10 \mathrm{~min}$ & 72.40 & 103.99 & 80 & 0.9590 & 0.0167 & 2.2380 \\
\hline & & & & $\mathrm{G}=18.7 / \mathrm{s}$, for $20 \mathrm{~min}$ & 33.33 & 162.42 & 500 & 0.9531 & 0.0834 & 10.9332 \\
\hline
\end{tabular}


Table 2. Cont

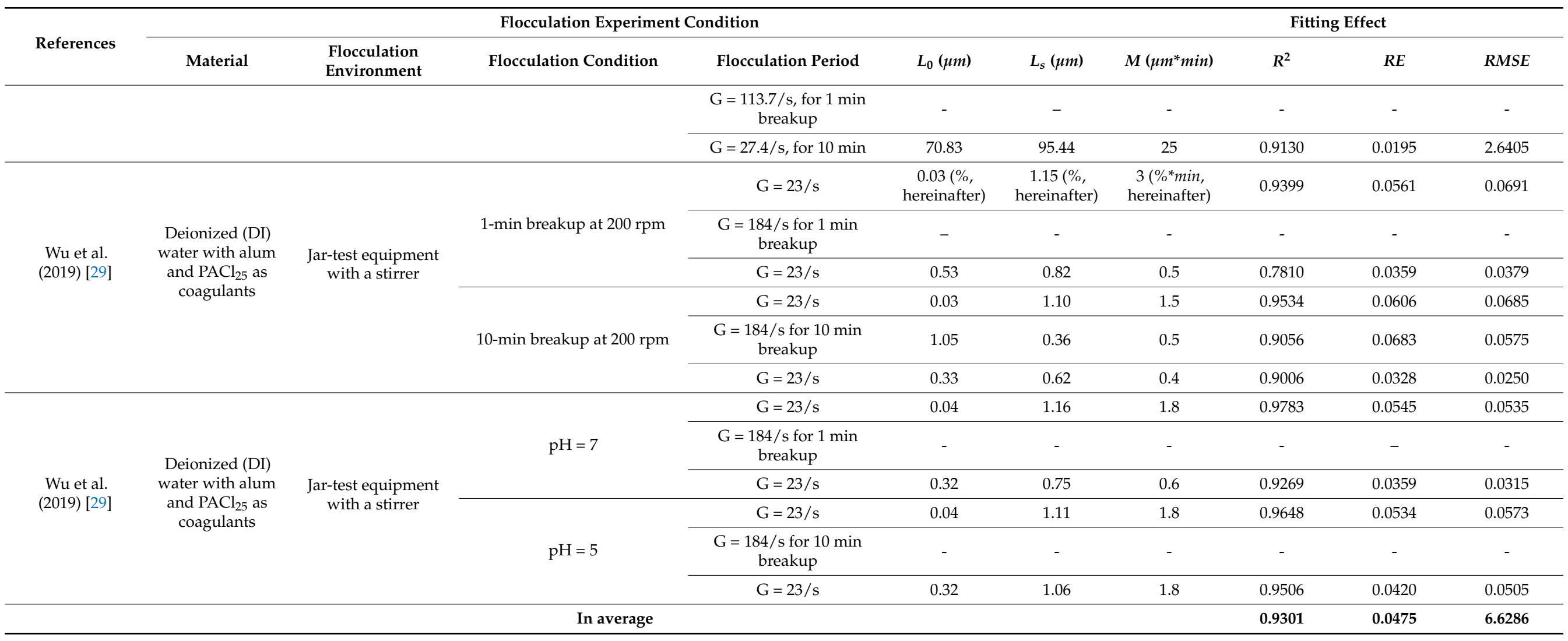




\subsubsection{Colloidal Science Field}

Two experimental data sets were collected from the literature in the colloidal science field to investigate the effect of varied shear rates on the floc size in this study, including Spicer et al. (1998) [23] and Wu and Ven (2009).

In the laboratory experiment of Spicer et al. (1998) [23], the impact of a varied shear history on the evolution of the polystyrene-alum floc size, density, and structure was investigated. Flocculation material was suspensions of monodisperse polystyrene particles, and the flocculation apparatus was 2.8-L baffled tank with a radial flow Lightnin R100 impeller. The particle volume fraction was $1.4 \times 10^{-5}$. Floc size distribution and floc structure were estimated by small-angle light scattering measurements via a Malvern Mastersizer E. In this experiment, two kinds of shear procedures were involved, including (1) cycled-shear flocculation: $G=50 \mathrm{~s}^{-1}$ for floc formation $\rightarrow G=100,300$ and $500 \mathrm{~s}^{-1}$ of 1 min for floc breakage $\rightarrow G=50 \mathrm{~s}^{-1}$ for floc re-growth; and (2) tapered-shear flocculation: $G=300 \mathrm{~s}^{-1}$ of $15 \mathrm{~min}$ for floc formation $\rightarrow G=200 \mathrm{~s}^{-1}$ of $15 \mathrm{~min}$ for floc formation $\rightarrow$ $G=100 \mathrm{~s}^{-1}$ of $15 \mathrm{~min}$ for floc formation $\rightarrow G=50 \mathrm{~s}^{-1}$ of $15 \mathrm{~min}$ for floc formation. In the experimental study of $\mathrm{Wu}$ and Ven (2009), coagulation materials were separated from thermomechanical pulp particles (TMP) with a size range of 1-20 $\mu \mathrm{m}$, and they were allowed to flocculate in a beaker. The flocculation degree was measured by a photometric dispersion analysis (PDA) for small fines and by focused beam reflectance measurements (FBRM) for a mixture of fines and fibers in distilled water or salt water. In this experiment, the effects of salt and poly (ethylene oxide) (PEO) entanglement on the flocculation of small particles were investigated. Five $\mathrm{NaCl}$ concentrations, 0 (no salt), 10, 20, 50, and $100 \mathrm{Nm}$, and three classes of stirring speeds, $100 \mathrm{rpm}$ for floc formation, $450 \mathrm{rpm}$ for floc breakage, and $100 \mathrm{rpm}$ for floc re-growth, were adopted in the experiment, respectively. Since the ratio of light transmittance value to mean transmittance value was only recorded, the flocculation index was adopted to represent the relative floc size during coagulation in their study.

Figures 17 and 18 compare the entropic model (Equation (11)) with experimental data points of Spicer et al. (1998) [23] and Wu and Ven (2009), respectively. Table 3 presents these comparison results. Similar to Tables 1 and 2, the second through seventh columns of this table list the information regarding flocculation material, flocculation apparatus, flocculation condition, the adopted shear rates, and the values for $L_{0}$ and $L_{s}$, respectively. The performance of the entropic model for each experimental data set in terms of three statistical parameters, $R^{2}, R E$, and $R M S E$, is provided in the last three columns, as well as the fitting values $M$ in the eighth column.

Figure 19 presents the Taylor diagram of the calculated correlation coefficients and relative errors for these experimental cases. Compared with Figures 7 and 16, it is clear that the proposed entropic model can have a stronger correlation with experimental data sets but with a larger relative error. In general, as shown in the last row of Table 3, the average values of $R^{2}, R E$, and $R M S E$ are $0.9419,0.0805$, and 2.7264. Four large relative errors came from the third floc growth case of $G=500 \mathrm{~s}^{-1}$ in the Cycled-shear flocculation experiment of Spicer et al. (1998), three floc growth phases of $\mathrm{r}=100 \mathrm{rpm}(\mathrm{NaCl}$ concentrations were 10,50 , and $100 \mathrm{mM}$ in the flocculation experiment of $\mathrm{Wu}$ and Ven (2009), as illustrated by Figures $17 \mathrm{a}$ and 18, respectively. In Figure 17a, as denoted by the orange color, floc size slowly increases at the first $G=500 \mathrm{~s}^{-1}$, whereas the entropic model overestimated these data points since it predicted a rapid floc growth phase at the initial flocculation stage. It can be observed from Figure 18 that there were some deviations between the modeled and the measured data, especially at the first floc growth period of $r=100 \mathrm{rpm}$ when $\mathrm{NaCl}$ concentrations were 10,50, and $100 \mathrm{mM}$. The measured floc size seemed to approach its steady state earlier than that predicted by the model, which led to an error between the predicted values and the measured ones. 


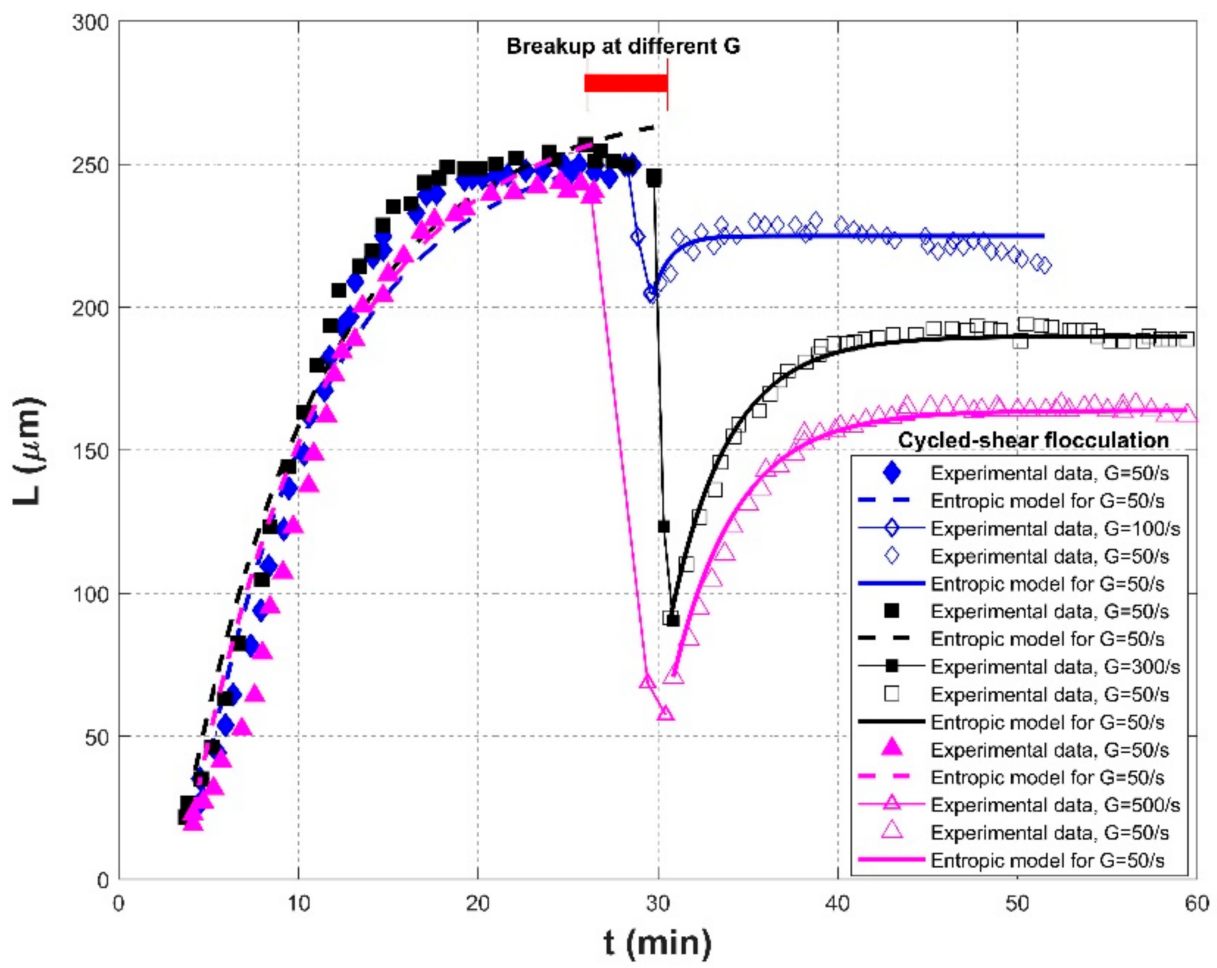

(a)

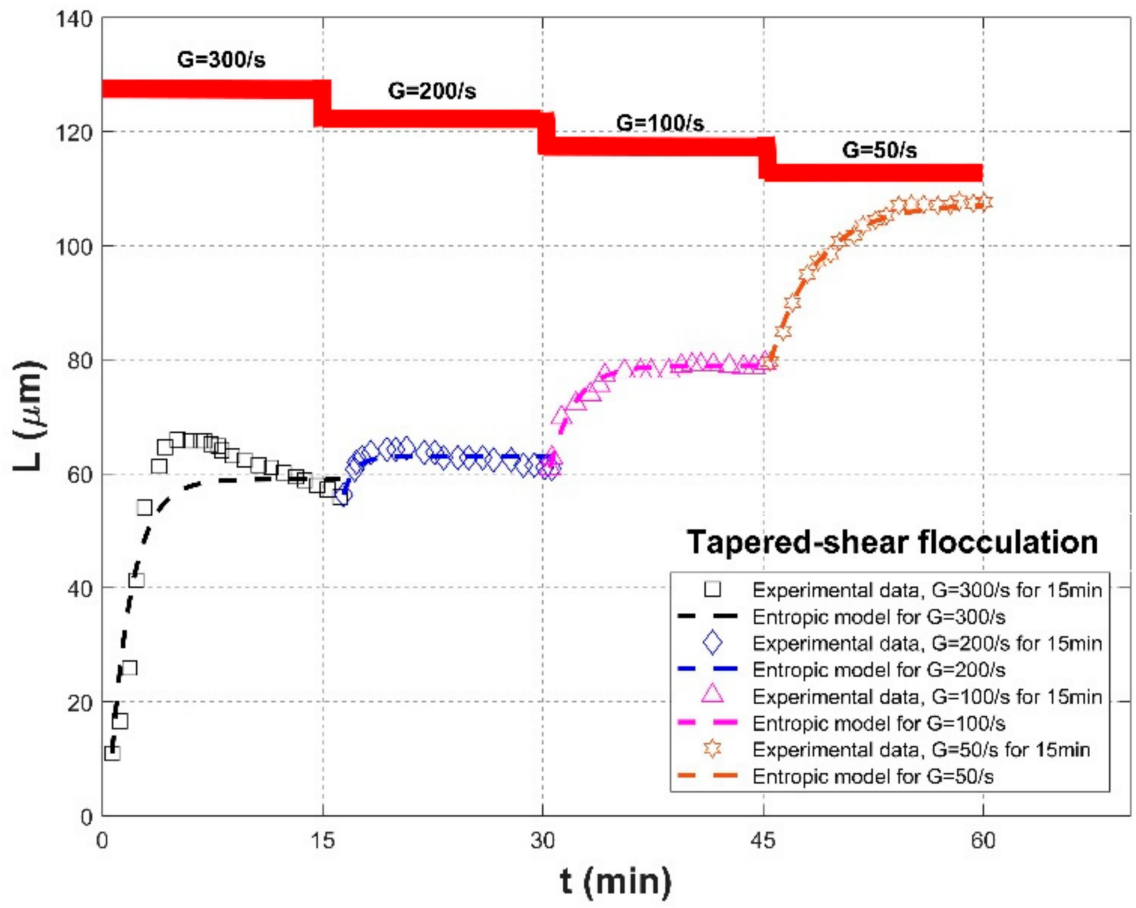

(b)

Figure 17. Comparison of the entropic model with experimental results of Spicer et al. (1998) [23]: (a) effect of cycled-shear; (b) effect of tapered-shear.

In Figure 17a, polystyrene-alum floc size increased until a steady state was reached at $G=50 \mathrm{~s}^{-1}$; however, when a stronger shear was applied into the flocculation system, a strong floc breakage was obvious. As the shear rate went back to $G=50 \mathrm{~s}^{-1}$, floc size did not recover to the original level. The entropic model can depict well this 
pattern of irreversible floc growth. In Figure $17 \mathrm{~b}$, a piecewise decrease in the shear rate $\left(G=300 \rightarrow 200 \rightarrow 100 \rightarrow 50 \mathrm{~s}^{-1}\right.$ ) for $15 \mathrm{~min}$ allowed the flocs to have enough time to grow toward different equilibrium conditions. For this type of floc size variation in a piecewise decreasing shear condition, the entropic model can exhibit good performance. However, it is also notable that there was a deviation between the model and the data points at $G=300 \mathrm{~s}^{-1}$. This is because there was a floc restructuring during flocculation, as pointed out by Spicer et al. (1998) [23], for which the proposed entropy-based model did not hold. In Figure 18, the entropic model could trace well the entire process of floc growth at a low shear rate, floc breakage at a strong shear condition, and floc re-growth at a returning low shear environment for all cases.

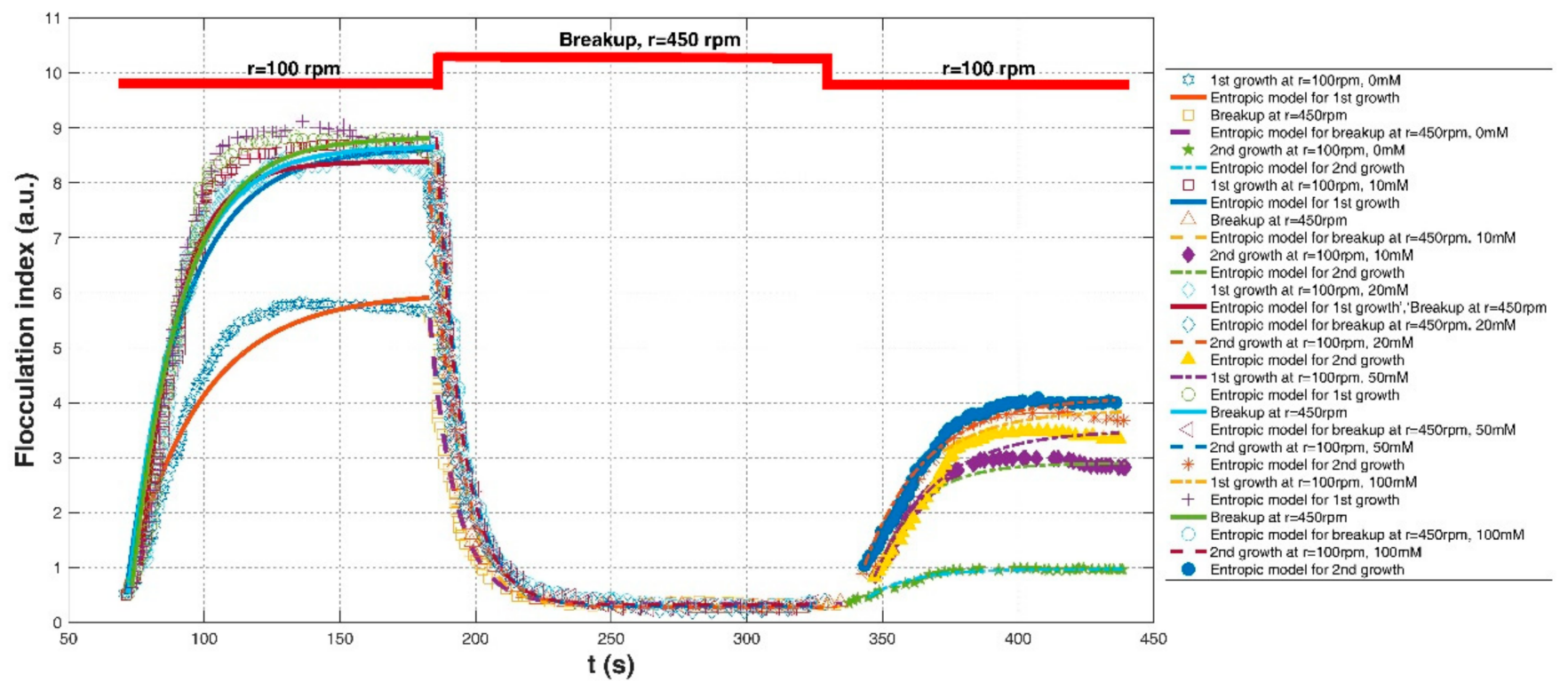

Figure 18. Comparison of the entropic model with experimental data of $\mathrm{Wu}$ and Ven (2009).

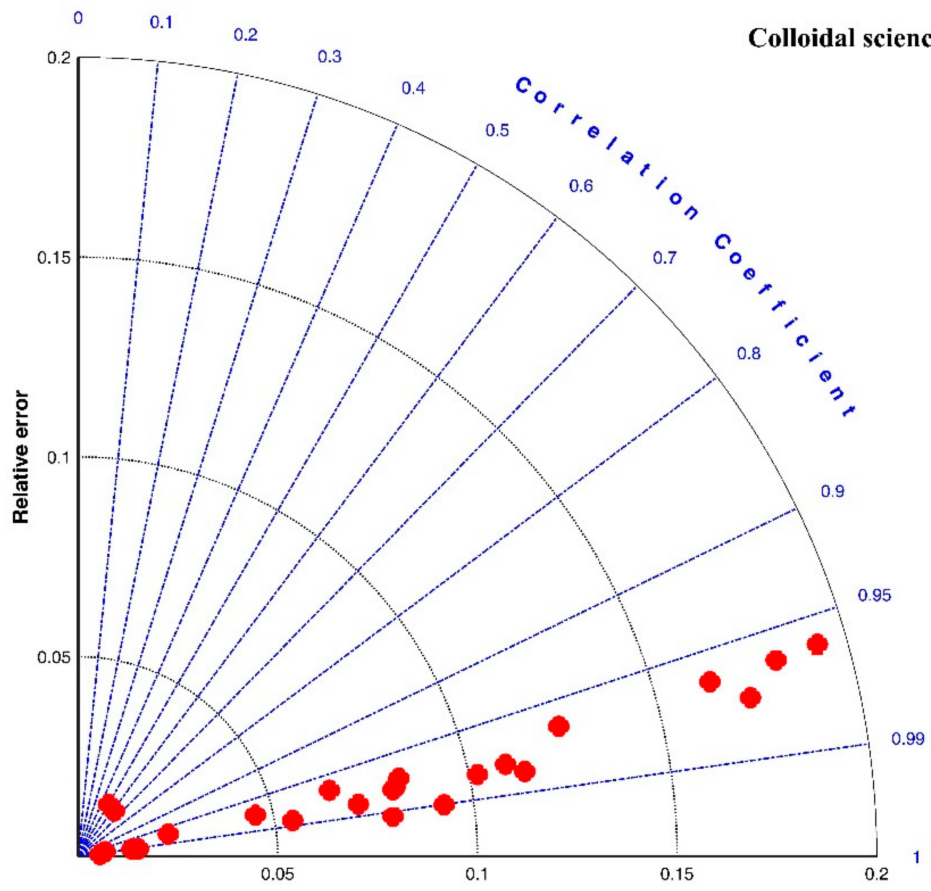

Figure 19. Taylor diagram of calculated correlation coefficients $R^{2}$ and relative errors $R E$ for experimental cases in the colloidal science field. 


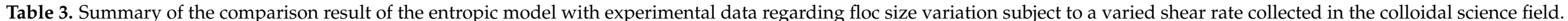
The last row shows the average values of statistical errors.

\begin{tabular}{|c|c|c|c|c|c|c|c|c|c|c|}
\hline \multirow[b]{2}{*}{ References } & \multicolumn{6}{|c|}{ Flocculation Experiment Condition } & \multicolumn{4}{|c|}{ Fitting Effect } \\
\hline & Material & $\begin{array}{l}\text { Flocculation } \\
\text { Environment }\end{array}$ & $\begin{array}{l}\text { Flocculation } \\
\text { Condition }\end{array}$ & Flocculation Period & $L_{0}($ um) & $L_{s}(\mathrm{um})$ & $M\left(\right.$ um $\left.^{*} \mathrm{~min}\right)$ & $R^{2}$ & $R E$ & RMSE \\
\hline \multirow{11}{*}{$\begin{array}{l}\text { Spicer et al. } \\
(1998) \text { [23] }\end{array}$} & \multirow{11}{*}{ Polystyrene-alum floc } & \multirow{11}{*}{$\begin{array}{l}\text { Stirred tank with a } \\
\text { Rushton impeller }\end{array}$} & \multirow{3}{*}{$\begin{array}{l}\text { Tapered-shear } \\
\text { flocculation }\end{array}$} & $\mathrm{G}=300 / \mathrm{s}$, for $15 \mathrm{~min}$ & 10.93 & 59.03 & 70 & 0.9064 & 0.1043 & 5.8630 \\
\hline & & & & $\mathrm{G}=100 / \mathrm{s}$, for $15 \mathrm{~min}$ & 60.93 & 78.98 & 30 & 0.9834 & 0.0069 & 0.7520 \\
\hline & & & & $\mathrm{G}=50 / \mathrm{s}$, for $15 \mathrm{~min}$ & 79.63 & 107.35 & 90 & 0.9947 & 0.0055 & 0.7335 \\
\hline & & & \multirow{8}{*}{$\begin{array}{l}\text { Cycled-shear } \\
\text { flocculation }\end{array}$} & $\mathrm{G}=50 / \mathrm{s}$, for $30 \mathrm{~min}$ & 26.66 & 260.42 & 1700 & 0.9782 & 0.0806 & 12.4689 \\
\hline & & & & $\mathrm{G}=50 / \mathrm{s}$, for $30 \mathrm{~min}$ & 204.28 & 224.91 & 20 & 0.5020 & 0.0151 & 4.2064 \\
\hline & & & & $\mathrm{G}=50 / \mathrm{s}$, for $30 \mathrm{~min}$ & 21.81 & 272.52 & 2000 & 0.9768 & 0.0812 & 12.9654 \\
\hline & & & & $\mathrm{G}=300 / \mathrm{s}$, for $1 \mathrm{~min}$ & - & - & - & - & - & - \\
\hline & & & & $\mathrm{G}=50 / \mathrm{s}$, for $30 \mathrm{~min}$ & 91.49 & 189.90 & 320 & 0.9907 & 0.0136 & 2.7977 \\
\hline & & & & $\mathrm{G}=50 / \mathrm{s}$, for $30 \mathrm{~min}$ & 22.80 & 272.52 & 2000 & 0.9732 & 0.1730 & 19.0067 \\
\hline & & & & $\mathrm{G}=500 / \mathrm{s}$, for $1 \mathrm{~min}$ & - & - & - & - & - & - \\
\hline & & & & $\mathrm{G}=50 / \mathrm{s}$, for $30 \mathrm{~min}$ & 70.73 & 163.88 & 330 & 0.9920 & 0.0152 & 2.8624 \\
\hline \multirow{8}{*}{$\begin{array}{l}\text { Wu and Ven } \\
\text { (2009) [25] }\end{array}$} & \multirow{8}{*}{$\begin{array}{l}\text { Thermomechanical } \\
\text { pulp (TMP) particles } \\
\text { at various CPR } \\
\text { (carboxylated phenolic } \\
\text { resin) - PEO } \\
\text { (poly(ethylene oxide)) } \\
\text { ratios }\end{array}$} & \multirow{8}{*}{$\begin{array}{l}\text { A beaker with a stirrer } \\
\text { (the stirring speed } \\
\text { from } 100 \text { to } 450 \mathrm{rpm} \text { ) }\end{array}$} & \multirow[t]{2}{*}{$\begin{array}{c}\mathrm{NaCl} \text { concentration: } \\
0 \mathrm{mM}\end{array}$} & $\begin{array}{c}\mathrm{r}=450 \mathrm{rpm} \text { for } \\
\text { breakup }\end{array}$ & 5.54 & 0.34 & 50 & 0.9715 & 0.0827 & 0.2920 \\
\hline & & & & $\mathrm{r}=100 \mathrm{rpm}$ & 0.46 & 0.97 & 8 & 0.9702 & 0.0233 & 0.0267 \\
\hline & & & \multirow{3}{*}{$\begin{array}{c}\mathrm{NaCl} \text { concentration: } \\
10 \mathrm{mM}\end{array}$} & $\mathrm{r}=100 \mathrm{rpm}$ & 0.51 & 8.64 & 170 & 0.9626 & 0.1816 & 0.7183 \\
\hline & & & & $\begin{array}{c}\mathrm{r}= \\
\text { breakup }\end{array}$ & 8.37 & 0.29 & 70 & 0.9775 & 0.1095 & 0.4264 \\
\hline & & & & $\mathrm{r}=100 \mathrm{rpm}$ & 0.85 & 2.9 & 32 & 0.9737 & 0.0456 & 0.1249 \\
\hline & & & \multirow{3}{*}{$\begin{array}{c}\mathrm{NaCl} \text { concentration: } \\
20 \mathrm{mM}\end{array}$} & $\mathrm{r}=100 \mathrm{rpm}$ & 1.04 & 8.39 & 100 & 0.9823 & 0.1139 & 0.5077 \\
\hline & & & & $\begin{array}{c}\mathrm{r}=450 \mathrm{rpm} \text { for } \\
\text { breakup }\end{array}$ & 8.04 & 0.27 & 85 & 0.9902 & 0.0926 & 0.2762 \\
\hline & & & & $\mathrm{r}=100 \mathrm{rpm}$ & 0.83 & 3.5 & 60 & 0.9670 & 0.0651 & 0.2028 \\
\hline
\end{tabular}


Table 3. Cont

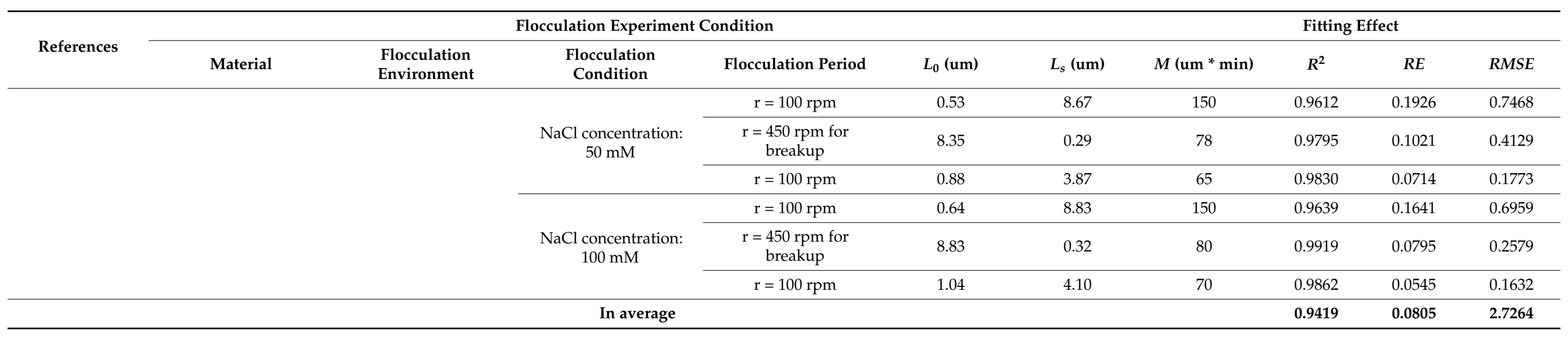




\section{Discussion}

\subsection{Parameterization of $L_{s}$ and $M$}

Two important parameters remain to be determined in Equations (10)-(12): $L_{s}$ and $M$. It can be seen from Tables 1-3 that they were varied in orders of magnitude, which implies that these parameters might be dependent on different flocculation environments (i.e., flocculation material, flocculant, particle concentration) and flow turbulent conditions, as well as flocculation recoverability (partially or completely). This study focused on the effect of varied flow shear rate on the flocculation process. Furthermore, since there are few laboratory flocculation studies concerning a continuously varied flow shear environment (except for Spicer et al. (1998) [23]), as presented in Section 3, and the units for $M$ are sometimes different in Tables 1-3, it seemed difficult to compare the estimated values of $L_{s}$ and $M$ for specific water/sediment, wastewater, and colloidal systems. However, for a specific particle flocculation system, if a continuously varied flow shear environment is only applied while keeping other conditions fixed, it is feasible to find the single dependencies of $L_{s}$ and $M$ on the flow shear rate. For example, Spicer et al. (1998) [23] measured polystyrene alum floc size variations when the flow shear rate $G$ piecewise decreased from 300, 200, and 100 to $50 \mathrm{~s}^{-1}$, as presented by Figure $17 \mathrm{~b}$. This case could facilitate us to parameterize $L_{s}$ and $M$, as shown as follows.

Some flocculation experiments have shown that the characteristic size of the floc population at the steady state, often denoted by median size $L_{S}$ or maximum floc size $L_{f \text {,max }}$, decays monotonically with an increasing shear rate $G$. A power function has always been adopted to describe this relationship $[21,23,26,49,78-80]$ :

$$
L_{s} \text { or } L_{f, \max }=c *(G)^{-1 * \gamma}
$$

where $c$ and $\gamma$ are two empirical dimensional coefficients $(c>0$, and $\gamma>0)$. The parameter $c$ represents the floc strength subject to a flow shear, which is dependent on the method adopted to measure the floc size [3,42]. The $\gamma$ is the floc size exponent, which depends on the hydrodynamic mechanism of floc breakup. When floc size is smaller than the smallest eddy scale of the turbulent flow (i.e., the Kolmogorov microscale length equal to $\left.\left(v^{3} / \varepsilon\right)^{1 / 4}\right)$, some particles or fragile flocs on the surface of the "mother" floc are eroded, and the floc undergoes the breakage effect in terms of surface erosion. For those flocs larger than the Kolmogorov microscale, they experience a large-scale fragmentation due to a large fluctuation of the turbulent flow [3,42]. As summarized by Zhu et al. (2010) [81] and Rau et al. (2018) [82] for some experimental data sets of the steady-state floc size-flow shear rate relationship collected from the literature, $\gamma$ has a range of $0.11-0.75$, whereas $c$ has different values for different types of flocs and flocculants.

Regarding the proposed parameter, i.e., the maximum capacity for floc size increase (or decay) $M$, Zhu (2018) estimated its values with various flow shear rates $G$ by fitting Equation (1) to experimental data sets from Oles (1992), Serra et al. (1997), Serra and Casamitjana (1998), Biggs and Lant (2000), and Colomer et al. (2005). There exists an empirical power function similar to Equation (13) to describe the dependence of $M$ on $G$ : $M=10^{6} G^{-0.844}$ with a high correlation coefficient above 0.93 , indicating an important role of floc breakage due to an increasing flow shear rate in the flocculation process. Thus, the following expression can be adopted to describe $M$ as a function of $G$ in this study:

$$
M=a *(G)^{-1 * b}
$$

where $a$ and $b$ are two empirical coefficients $(a>0$, and $b>0)$.

For the floc size evolution in a piecewise decaying (or enhancing) shear condition, floc size could monotonically increase (or decrease) toward an equilibrium, provided flocculation time is enough at each constant shear rate period. In this case, Equation (13) could be used to estimate the steady-state floc size, i.e., $L_{s}$ in Equations (10)-(12), as also presented by Keyvani and Strom (2014) [28] and Slavik et al. (2012) [22], who reported that 
the final floc size was only dependent on the turbulent shear rate. Equation (14) can also be adopted to characterize the parameter $M$ as a function of the shear rate $G$ in Equations (10)-(12). Take the abovementioned experimental data sets in Spicer et al. (1998) [23] as an example, as shown by Figure 17b, except the case of $G=300 \mathrm{~s}^{-1}$ (where floc restructuring plays a role and the model does not hold as already mentioned). In Figure $17 \mathrm{~b}$, the steadystate floc size $L_{s}$ can be found to increase with a decaying shear rate $G$. An increasing trend of the fitted parameter $M$ with the shear rate $G$ can be also found in Table 3. Figure 20a shows the dependences of $L_{s}$ and $M$ on $G$ using Equations (13) and (14), respectively. In this figure, two exponential relations, $L_{s}=476.65 * G^{-0.384}$ and $M=352130 * G^{-2.085}$, can have a good fitting effect with calculated data points (correlation coefficients $R^{2}$ reach 0.9924 and 0.9812, respectively). Substituting them into Equation (11) can calibrate the proposed entropic model, and a comparison of floc size inverted by the calibrated entropic model with measured floc size data at $G=200,100$, and $50 \mathrm{~s}^{-1}$ from Spicer et al. (1998) [23] is presented in Figure 20b. It can be seen from this figure that, in general, a good agreement between the measured values and the estimated values is noticeable with a high $R^{2}$ value of 0.9704 , low $R E$ value of 0.0306 , and a low RMSE value of 3.5567. The discrepancy that the model overestimated the measured data for the cases of $G=50$ and $100 \mathrm{~s}^{-1}$ may have been due to underestimated $M$ values by the model.

It needs to be pointed out that Equations (13) and (14) solely characterize the dependencies of $L_{s}$ and $M$ on $G$. Other factors, such as particle concentration and suspended solid size related to water quality variation, will also affect the steady-state floc size $L_{s}$, as revealed by some laboratory experiments. However, these dependency analyses were not performed in this study due to few relevant complete data sets from laboratory-controlled flocculation experiments and/or in situ observation from literature. Performing complete flocculation experiments subject to multiple factors and/or field floc size observations in a complicated hydrodynamic environment is worthy of further investigation in future studies.

\subsection{Sensitivity of the Model to Four Empirical Parameters}

Furthermore, introducing Equations (13) and (14) into Equation (11) can yield an entropic flocculation model,

$$
L_{i}(t)=c * G_{i}^{-\gamma}-\left(c * G_{i}^{-\gamma}-c * G_{i-1}^{-\gamma}\right) \exp \left[-\frac{\left|c * G_{i}^{-\gamma}-c * G_{i-1}^{-\gamma}\right|}{a * G_{i}^{-b}}\left(t-t_{i-1}\right)\right]
$$

which can be adopted to predict the floc size evolution in a piecewise varied shear provided flocculation time is enough to allow the floc size growth to reach the steady state at each constant shear rate period. It will be then interesting to determine the sensitivity of this model to its parameters. To this end, derivatives of $L_{i}(t)$ with respect to four input parameters $a, b, c$, and $\gamma$ are written:

$$
\begin{gathered}
\frac{\partial L_{i}(t)}{\partial c}=G_{i}^{-\gamma}-\left(G_{i}^{-\gamma}-G_{i-1}^{-\gamma}\right) f(t)-\left(c * G_{i}^{-\gamma}-c * G_{i-1}^{-\gamma}\right) f(t) \\
*\left[-\frac{\left(G_{i}^{-\gamma}-G_{i-1}^{-\gamma}\right)}{a * G_{i}^{-b}}\left(t-t_{i-1}\right)\right] \\
\frac{\partial L_{i}(t)}{\partial \gamma}=c *(-\gamma) * G_{i}^{-\gamma-1}-\left[c *(-\gamma) * G_{i}^{-\gamma-1}-c *(-\gamma) * G_{i-1}^{-\gamma-1}\right] f(t) \\
-\left(c * G_{i}^{-\gamma}-c * G_{i-1}^{-\gamma}\right) f(t)\left\{-\frac{\left[c *(-\gamma) * G_{i}^{-\gamma-1}-c *(-\gamma) * G_{i-1}^{-\gamma-1}\right]}{a * G_{i}^{-b}}\left(t-t_{i-1}\right)\right\} \\
\frac{\partial L_{i}(t)}{\partial a}=c * G_{i}^{-\gamma}-\left(c * G_{i}^{-\gamma}-c * G_{i-1}^{-\gamma}\right) f(t)\left[\frac{\left(c * G_{i}^{-\gamma}-c * G_{i-1}^{-\gamma}\right)}{a^{2} * G_{i}^{-b}}\left(t-t_{i-1}\right)\right]
\end{gathered}
$$




$$
\begin{aligned}
& \frac{\partial L_{i}(t)}{\partial b}=c * G_{i}^{-\gamma}-\left(c * G_{i}^{-\gamma}-c * G_{i-1}^{-\gamma}\right) f(t) \\
& \quad *\left[-\frac{\left(c * G_{i}^{-\gamma}-c * G_{i-1}^{-\gamma}\right)}{a} b\left(t-t_{i-1}\right) G_{i}^{b-1}\right]
\end{aligned}
$$

where $f(t)=\exp \left[-\frac{\left(c * G_{i}^{-\gamma}-c * G_{i-1}^{-\gamma}\right)}{a * G_{i}^{-b}}\left(t-t_{i-1}\right)\right]$ and $c * G_{i}^{-\gamma}>c * G_{i-1}^{-\gamma}$ for convenience. Each derivative of $L_{i}(t)$, with respect to the mentioned parameter while fixing other parameters, can be regarded to be a sensitivity coefficient [70] and it can help evaluate the effect or significance of each parameter on the floc size evolution. As an example, Figure 21a-d shows the calculated values of sensitivity coefficients for the tapered-shear flocculation cases ( $G=200,100$, and $\left.50 \mathrm{~s}^{-1}\right)$ of Spicer et al. (1998) [23] using Equations (16), respectively. It shows that the sensitivity coefficients to $a$ and $b$ exhibit a discontinuous and piecewise increase with flocculation time $t$, and they are much larger than the sensitivity coefficients to $c$ and $\gamma$. The sensitivity to $c$ increases piecewise as flocculation time proceeds, while the sensitivity to $\gamma$ decreases piecewise.

Specifically, a simple flocculation model at a constant shear rate can be obtained by introducing Equations (13) and (14) into Equation (10) and adopting the initial condition: $L=L_{0}$ at $t=t_{0}=0$,

$$
L(t)=c G^{-\gamma}-\left(c G^{-\gamma}-L_{0}\right) \exp \left(-\frac{\left|c G^{-\gamma}-L_{0}\right|}{a G^{-b}} t\right)
$$

Take the flocculation experimental results of activated sludge at four different kinds of constant shear rates: $G=19.4,37,113$, and $346 \mathrm{~s}^{-1}$ by Biggs and Lant (2000) as an example. In their study, flocculation started not from the primary particle but $L_{0}=15 \mu \mathrm{m}$. Steady-state floc size $L_{s}$ as a function of shear rate $G$ is plotted in Figure 22a, where the dependence of the fitting parameter $M$ on the shear rate $G$ calculated by Zhu (2018) is also plotted. From it, there are $a=25045, b=0.944, c=714.1$, and $\gamma=0.561$. Figure 22b shows the influence of the variation of each parameter $( \pm 5 \%, \pm 10 \%)$ on the floc growth curve while fixing other parameters at $G=37 \mathrm{~s}^{-1}$ in Biggs and Lant (2000). It can be seen that increasing $c$ or decreasing $\gamma$ leads to an increase of the steady-state floc size, whereas either increasing $a$ or decreasing $b$ makes the floc growth curve become much gentler toward the steady state. This qualitative result could help fit Equation (17) with experimental data points at a constant shear rate.

\subsection{Effect of Repeated Cycles of a Low and High Shear Rate on the Floc Size Growth}

For the flocculation due to multiple cycles of a high and low turbulent shear $[17,55,58,83,84]$, it will be interesting to see whether repeated cycles of a high and low shear play a role in affecting the floc growth pattern and the steady-state floc size from one cycle to another cycle. There are two groups of experimental results collected from the literature: one from Keyvani and Strom (2014) [28] in the cohesive sediment field and the rest from Slavik et al. (2012) [22] in the water treatment field, as shown by Figures 6 and 13b in Sections 3.2.1 and 3.2.2, respectively. In Keyvani and Strom (2014) [28], mud flocs experienced seven times cycles of a high and low turbulent shear ( $G=35 \mathrm{~s}^{-1}$ for floc growth followed by $G=400 \mathrm{~s}^{-1}$ of $15 \mathrm{~h}$ for floc breakup), whereas Fe-DOM flocs were subject to five times cycles of a highly and lowly turbulent shear $\left(G=40 \mathrm{~s}^{-1}\right.$ for floc growth followed by $G=1000 \mathrm{~s}^{-1}$ of $1 \mathrm{~min}$ for floc breakup) in Slavik et al. (2012) [22]. Despite different experimental conditions, both found that multiple cycles of high and low shear conditions play no obvious role in affecting the equilibrium floc size. In other words, the final steady-state floc size is only dependent on the applied shear rate, as also shown by Figures 6 and 13b. However, for each floc re-growth phase of the cycle, the floc re-growth rate decreased with the number of times that the flocculation system was subject to the high shear condition. We attempted to estimate the time required for the attainment of a steady-state floc size for each floc growth phase of the cycle and to relate it to the times that the suspension was exposed to cycles of a varied shear rate. In the 
entropic model (Equation (1)), the required time $t_{\text {req }}$ for approaching the steady state was almost approximated by $3 M /\left(L_{s}-L_{0}\right)$, as also mentioned in Section 2.1.1. Figure 23a,b shows the relation between the calculated time $t_{\text {req }}$ using the $M$ values in Tables 1 and 2 and cycle times of a highly and lowly turbulent shear. It can be seen from Figure 23a that there is an obvious increasing trend of the required time with cycling shear times. A similar trend is also observed in Figure $2 b$ except for the fourth floc growth phase, which could be regarded as an outlier because of a lower floc size plateau value compared to other floc growth phases that might be due to measurement uncertainty, as shown by the sky-blue color in Figure 13b. This confirms that, as multiple cycles of high and low turbulent shear proceed, the floc re-growth rate decreases and the floc growth needs more time to approach its steady state.

Regarding the proposed entropic model due to a piecewise varied shear rate, i.e., Equation (11) or Equation (12), specifically, if the same time interval $\Delta t$ is adopted, i.e., $t_{i}=i * \Delta t$ and $\left|L_{s, i}-L_{i-1}\right| / M_{i}$ is assumed to keep a constant $\alpha$ for each of $i$-th flocculation stage, floc size becomes after calculating the first-step flocculation stage based on Equation (10):

$$
L_{1}=[1-\exp (-\alpha \Delta t)] L_{s, 1}+\exp (-\alpha \Delta t) * L_{0}
$$

Then, after the second-step flocculation stage, floc size gets:

$$
L_{2}=[1-\exp (-\alpha \Delta t)] L_{s, 2}+\exp (-\alpha \Delta t) * L_{1}
$$

Substituting Equation (18) into Equation (19) can yield:

$$
L_{2}=[1-\exp (-\alpha \Delta t)]\left[L_{s, 2}+\exp (-\alpha \Delta t) * L_{s, 1}\right]+\exp (-2 \alpha \Delta t) * L_{0}
$$

Similarly, for the $n$-th flocculation period, floc size can be estimated by the following expression:

$$
L_{n}=[1-\exp (-\alpha \Delta t)] \sum_{i=1}^{n} \exp [-(n-i) \alpha \Delta t] * L_{s, i}+\exp (-n \alpha \Delta t) * L_{0}
$$

At a large $n$, the second term in the right-hand side of Equation (21) approaches rapidly 0 , which indicates that the initial size distribution of the floc population plays little role in determining the floc size at a later flocculation stage. As $n=1$, Equation (21) can reduce to Equation (10).

\subsection{Application of the Entropic Model in Engineering Practices and Its Limitations}

In the governing equations for the three-dimensional transport of cohesive sediment, one of the most important parameters is the floc settling velocity [12,15,85-90]. It depends on the floc's physical properties (size, shape, effective density, etc.) and the bulk properties (fluid viscosity, particle concentration, fluid turbulent condition) $[4,91,92]$. Flocculation models, either a Lagrangian Winterwerp model (1998) and the modified version [2,9,30-32], which can track the temporal evolution of a simple representative floc size, or a PBM model $[35,37,93,94]$, which solves the aggregation and breakage processes of multi-class floc sizes by different mathematical methods, can be adopted to calculate a dynamic floc settling flux, and they are applicable to be coupled into the present mature hydrodynamic models to model the suspended sediment transport in estuarine and coastal waters [95].

The entropic model proposed in this study, which is analogous to the Winterwerp model, mainly mimics the variation of a representative floc size with flocculation time with less computational cost. Compared with the Winterwerp model and the PBM, it contains few input parameters, has a simple mathematical form, and avoids a complicated mathematical iteration; compared with the work of Zhu (2018), it can be applicable for particle flocculation kinetics' estimation in a varied flow shear environment. This is especially true when the water-sediment system is frequently subject to multiple cycles of high and low shear rates in the river mouth, tidal estuary, and coastal waters $[17,52-56]$, 
for which other models could require more computational works to predict the floc size distribution $[83,96]$. Some empirical parameters in the entropic model can be calibrated based on limited experimental or field observational data to account for the physical, chemical, and biological properties of particles and fluid.

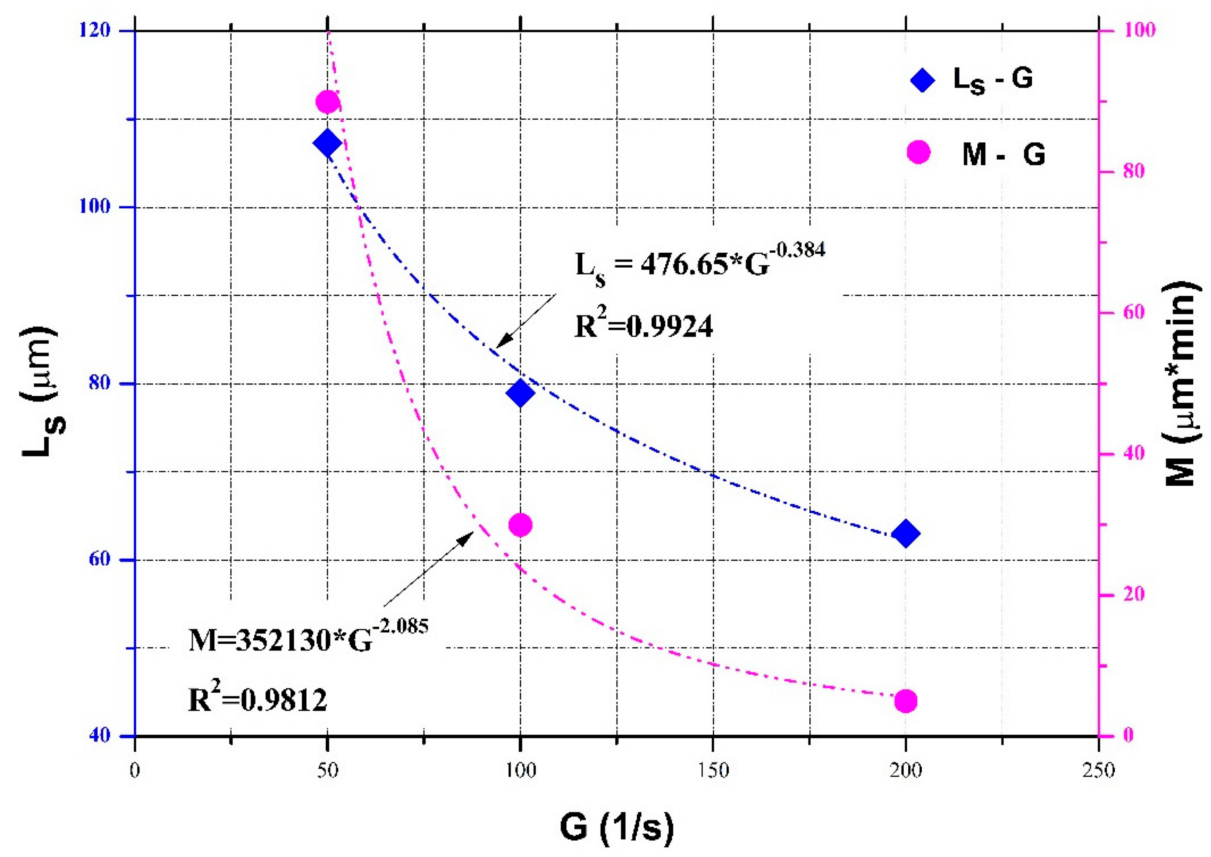

(a)

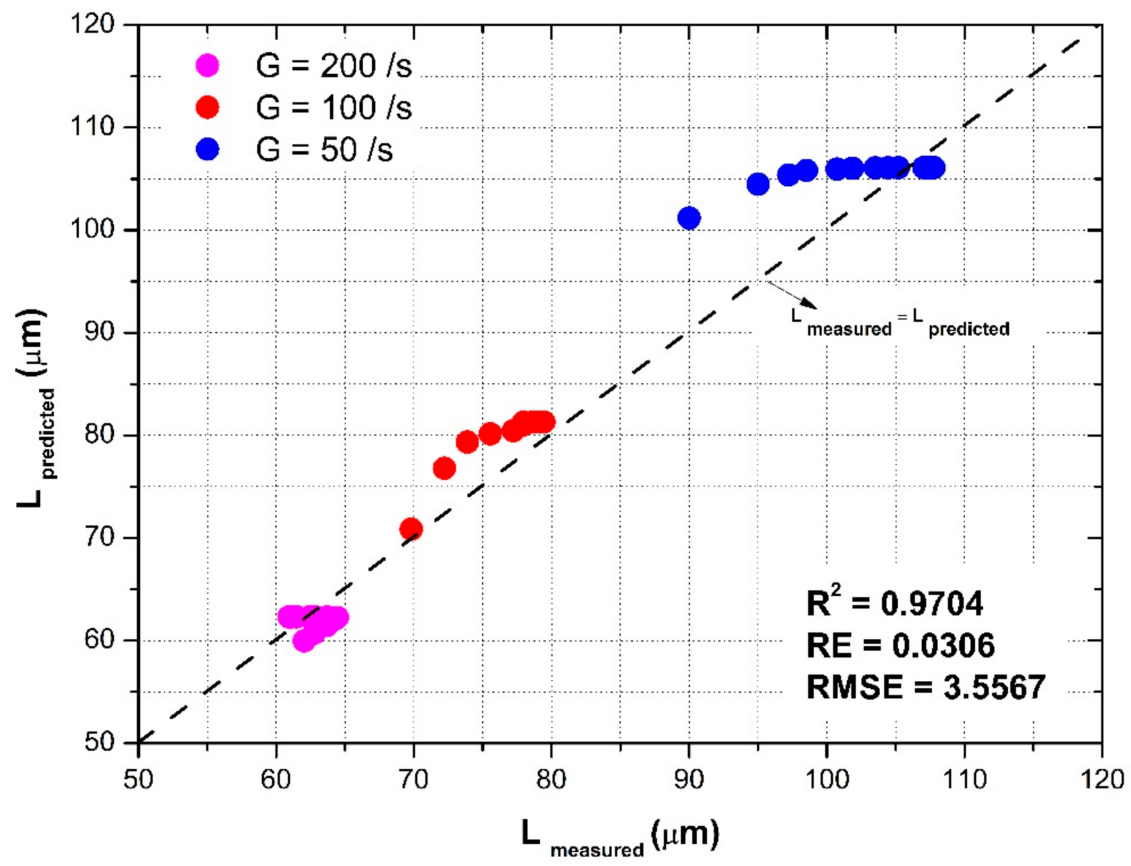

(b)

Figure 20. (a) Dependences of the steady-state floc size and the capacity parameter in the entropic model on the shear rate based on experimental data of Spicer et al. (1998) [23]; (b) comparison of the calibrated entropic model with measured floc size data at $G=200,100$, and $50 \mathrm{~s}^{-1}$ from Spicer et al. (1998) [23]. 


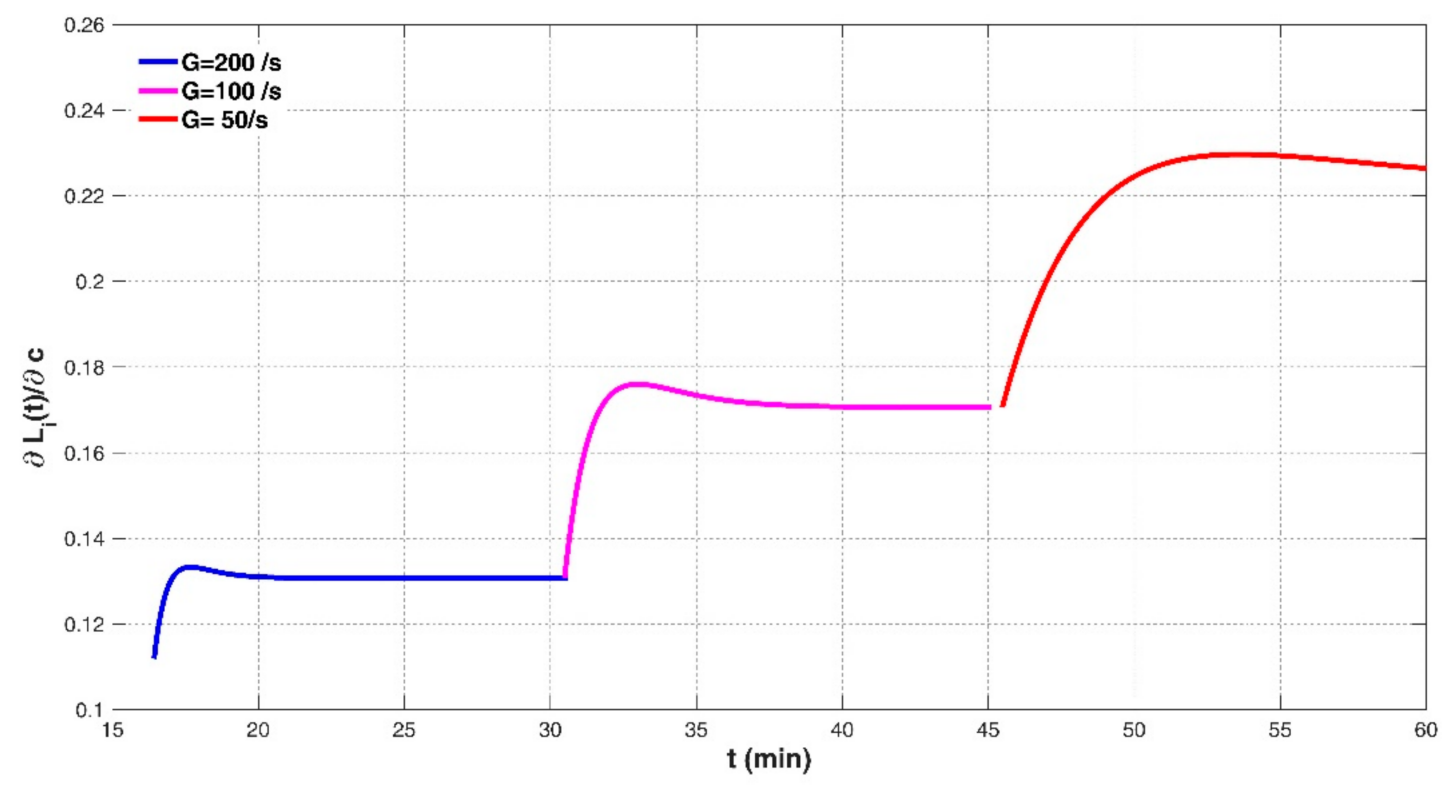

(a)

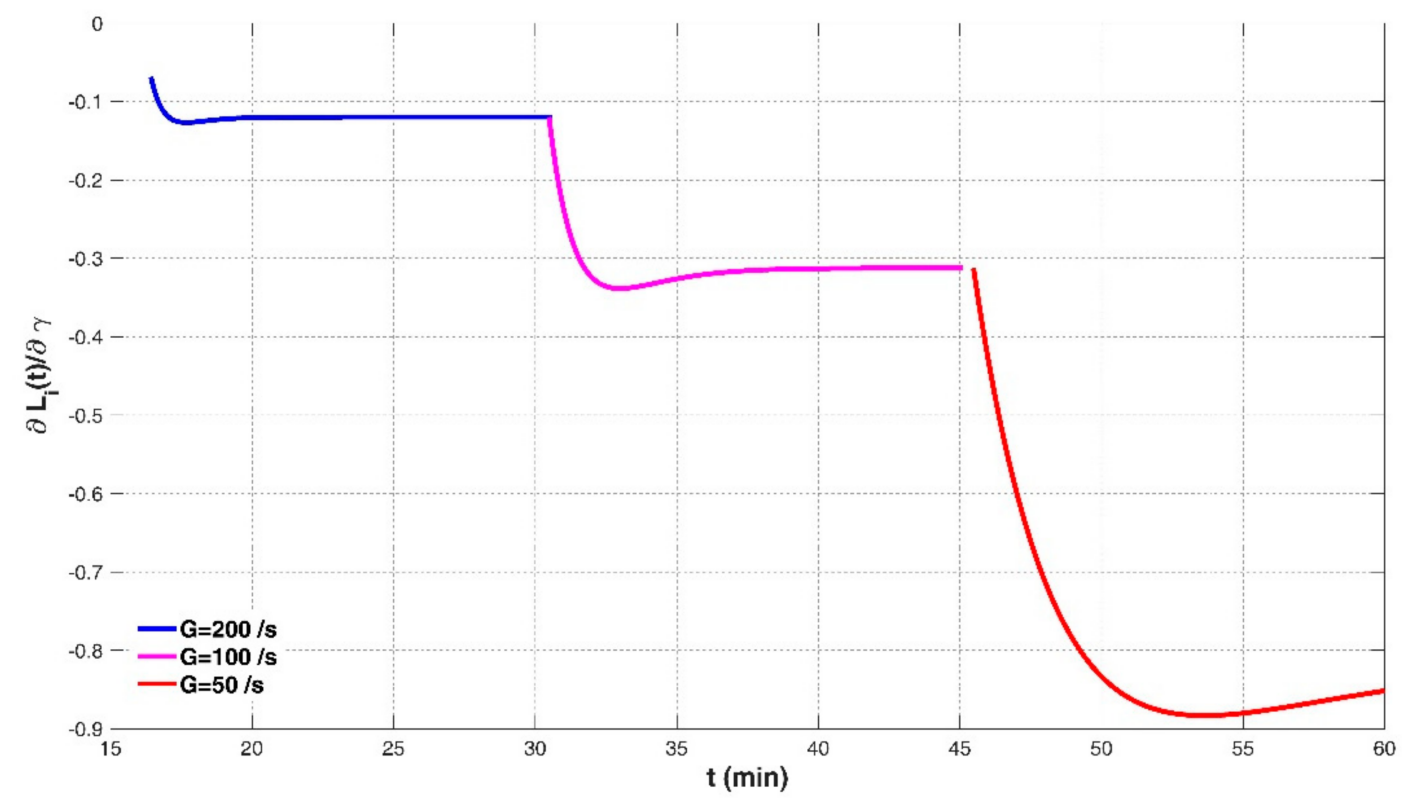

(b)

Figure 21. Cont. 

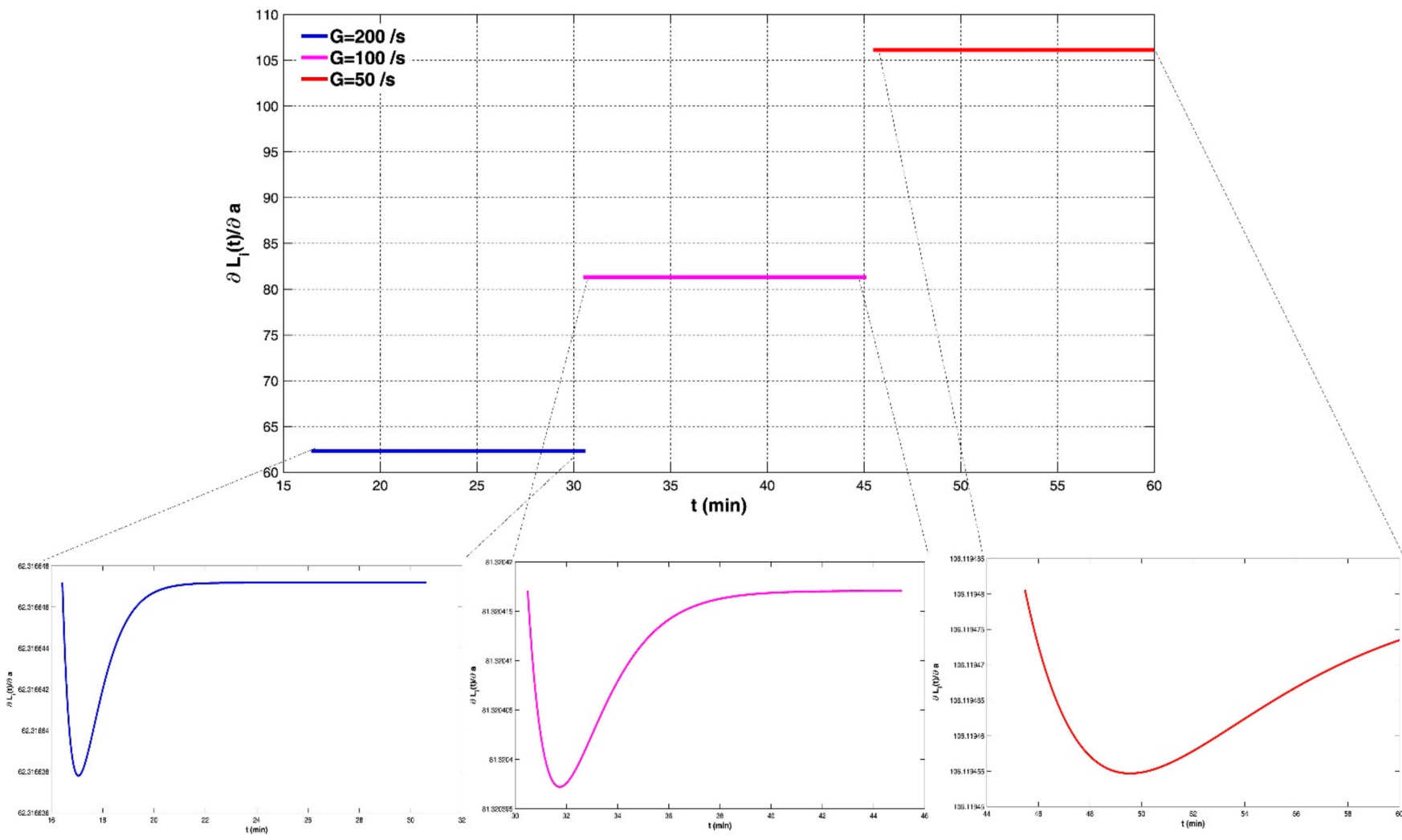

(c)
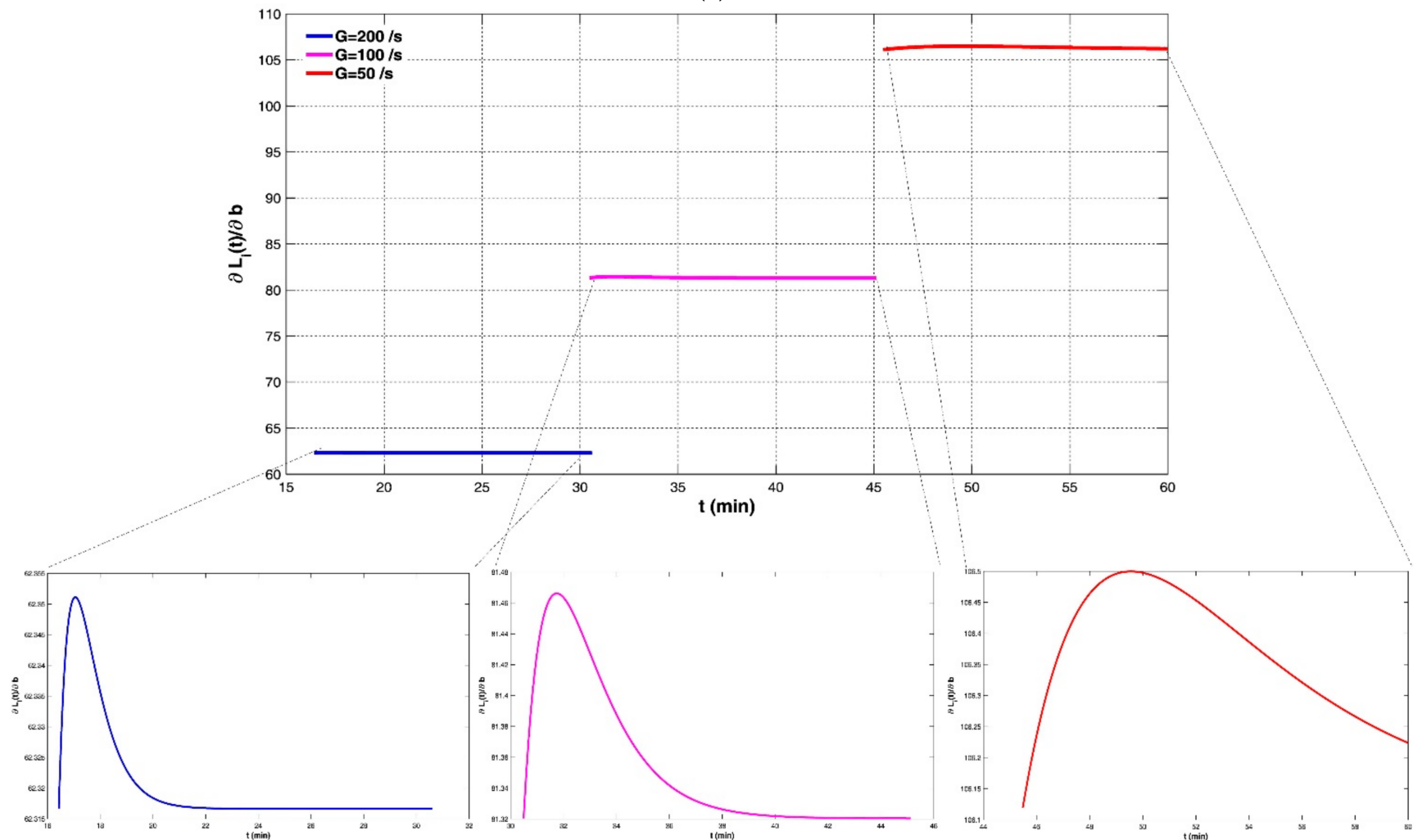

(d)

Figure 21. Sensitivity of the entropic flocculation model to four empirical parameters, including (a) $c$, (b) $\gamma$, (c) $a$, and (d) $b$ for the tapered-shear flocculation cases of $G=200,100$, and $50 \mathrm{~s}^{-1}$ in Spicer et al. (1998) [23]. 


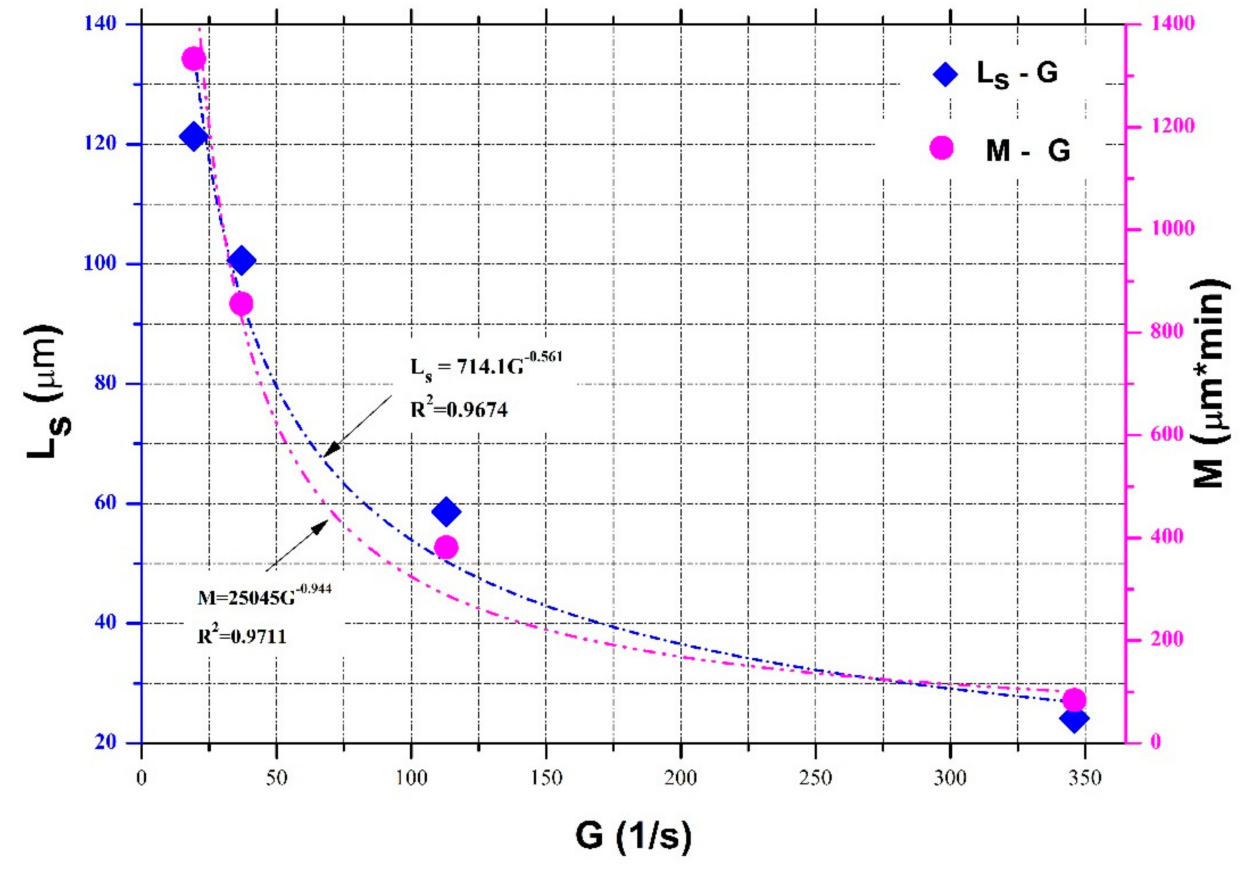

(a)
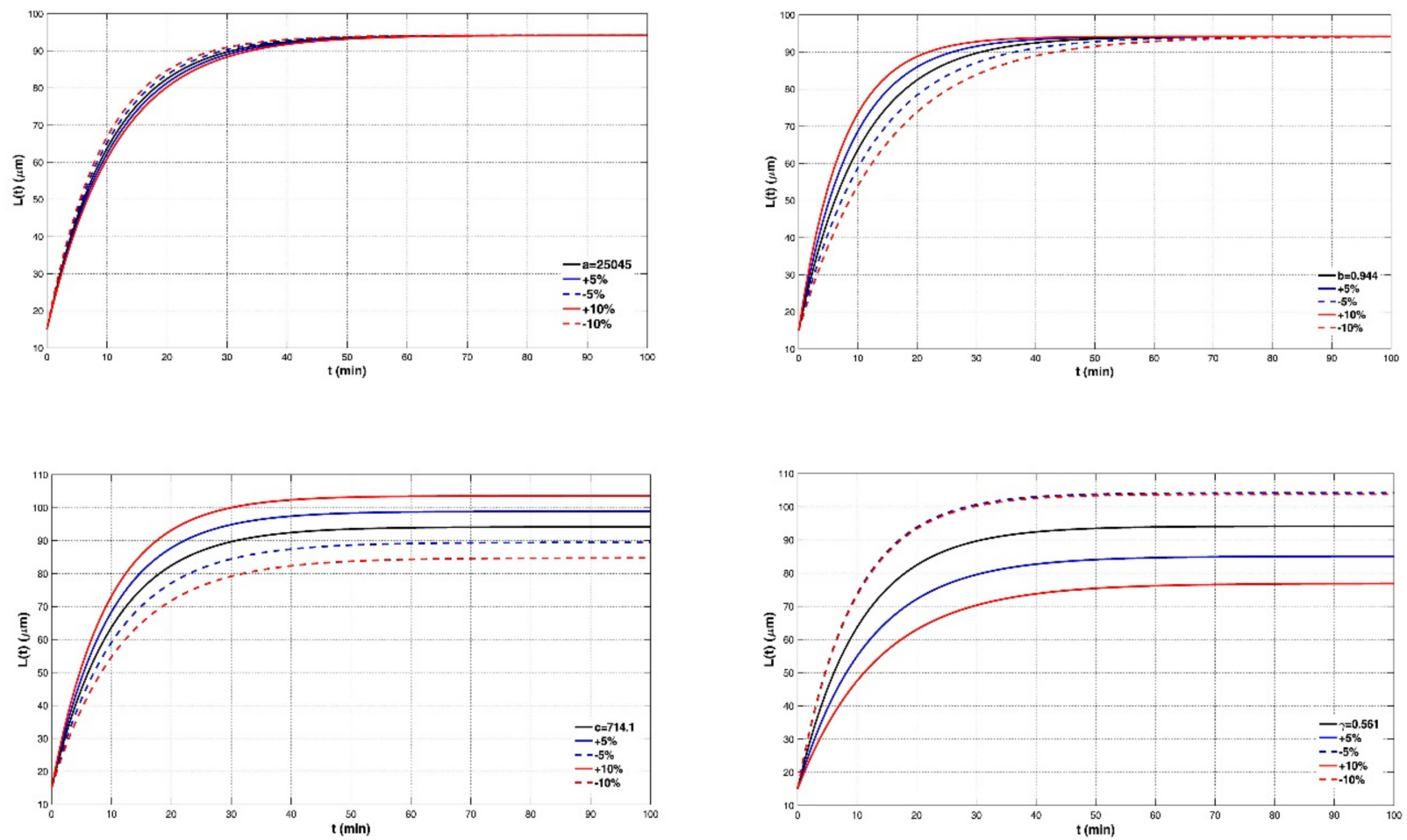

(b)

Figure 22. (a) Dependences of the steady-state floc size $L_{s}$ and the capacity parameter $M$ on the shear rate $G$ from Biggs and Lant (2000); (b) qualitative impacts of all of four parameters on the flow growth curve, including $a$ (left, upper panel), $b$ (right, upper panel), $c$ (left, lower panel), and $\gamma$ (right, lower panel). 


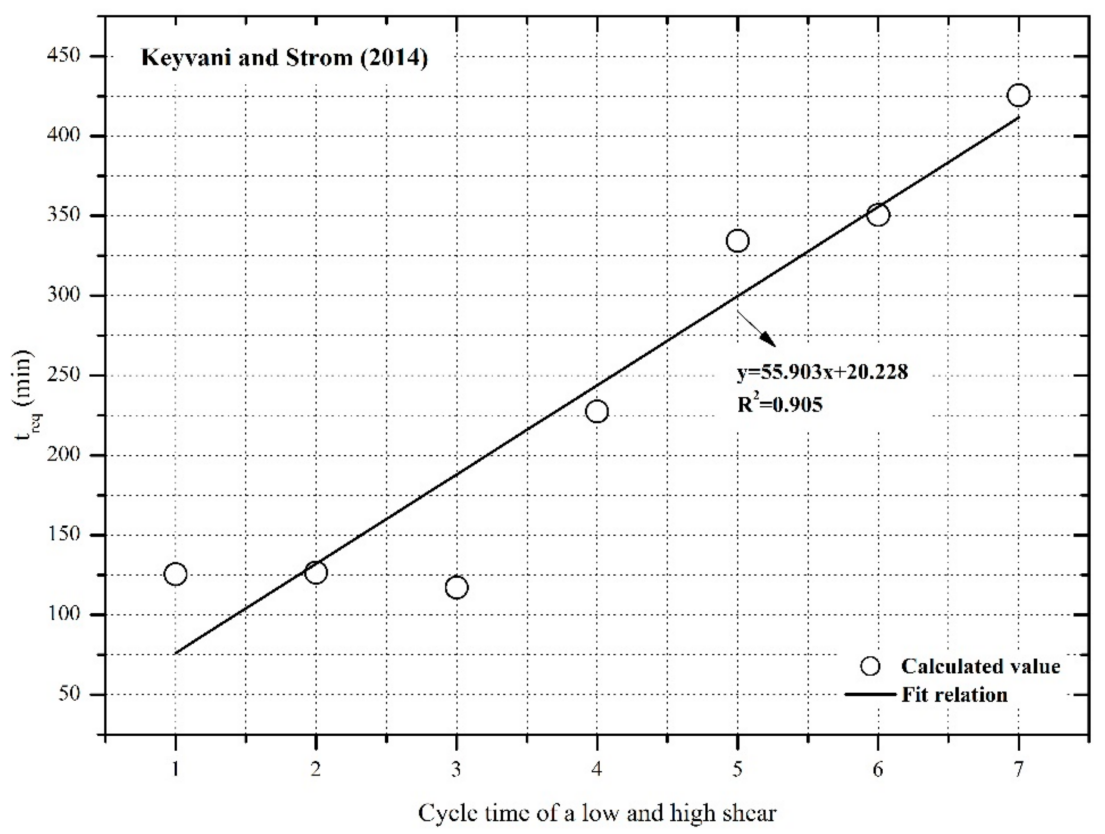

(a)

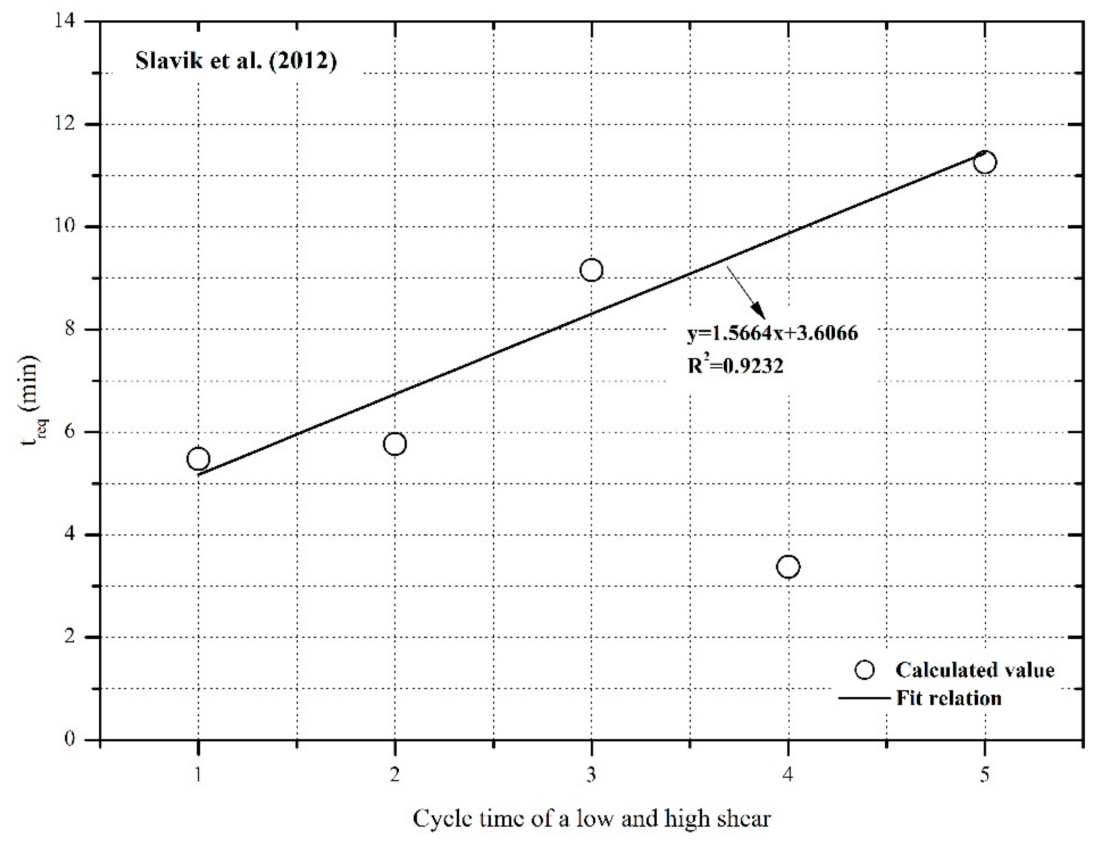

(b)

Figure 23. Relation between the required time $t_{r e q}$ and cycle times of a highly and lowly turbulent shear that the suspension was subject to in the (a) mud flocculation experiment of Keyvani and Strom (2014) [28]; (b) Fe-DOM flocculation experiment of Slavik et al. (2012) [22].

However, it points out that some physical mechanisms regarding the aggregation and the breakage of cohesive particles, which are present in the Winterwerp model and the PBM, have not been incorporated into this entropic model, which could weaken the theoretical basis for its application. Nevertheless, it is worthy of noting that, besides the classic deterministic flocculation models, formulating a simple and accurate flocculation model to simulate the particle-particle interaction in a turbulent flow in a stochastic manner is receiving more attention from many researchers. This includes, for example, a stochastic Lagrangian flocculation model proposed by Maggi (2008), a new Monte Carlo-based flocculation model by considering the floc breakage coefficient as a random number having a log-normal distribution by Shin et al. (2015), and a quasi-Monte Carlo (QMC)-based 
PBM for simulating the sediment flocculation recently proposed by Shen et al. (2021). The proposed entropic model could provide a new stochastic manner to estimate the floc size variation, especially in a piecewise varied shear environment from a statistical perspective. This model could be promising, as an addition to existing flocculation models, to be coupled into present mature hydrodynamic models to model the cohesive sediment transport in estuarine and coastal regions. Adding more physical mechanism involvement into the entropic model and testing it with more experimental and/or observational results, especially in a complicated shear environment and for various flocculation processes (e.g., bio-flocculation [7,97-100], should be a focus in future research.

\section{Concluding Remarks}

In this study, an extended mathematical expression (Equation (11)) for the temporal evolution of a representative floc size (characterized by the median size of floc size distribution) of cohesive particles when the flocculation system is subject to a piecewise varied shear rate was derived by the probability methods based on the Shannon entropy theory following the work of Zhu (2018). This expression contains only the initial value and the steady-state values of floc size, as well as a parameter characterizing the maximum capacity for floc size increase (or decay) proposed in this study, and it can be adopted to track well a monotonic flow growth (or decay) pattern. Comparison with 13 flocculation experimental data from the cohesive sediment field, the wastewater treatment field, and the colloidal science field showed the validity of the proposed entropic model with a large correlation coefficient and few errors.

Furthermore, for the case of tapered shear flocculation, as presented in Spicer et al. (1998) [23], an empirically negative power function was found to fit the relation between the calculated capacity parameter and the shear rate well, which is similar to the dependence of the steady-state floc size on the shear rate. With these, the entropic model was further parameterized, and its sensitivity to all four parameters was tested: The model is more sensitive to two coefficients that have been incorporated into the capacity parameter than those in the steady-state floc size.

Compared with the classic Winterwerp model and PBM, as well as the single-step flocculation work of Zhu (2018), the entropic model contains fewer input parameters, has a simple mathematical form, and avoids large mathematical iteration works, especially when the flocculation system is frequently subject to multiple cycles of high and low shear rates as in river mouth, tidal estuary, and coastal waters. Although not many physical flocculation mechanisms were involved in this model, it makes a step toward formulating the flocculation dynamics in a stochastic and statistical manner, and it could be a potential as a good addition to existing flocculation models to be coupled into present mature hydrodynamic models to model the cohesive sediment transport in estuarine and coastal regions.

Author Contributions: Z.Z. conceived and wrote the manuscript and contributed to a discussion of the results and the revision of the manuscript. J.D. contributed to a discussion regarding the model and a revision of the manuscript. Both authors have read and agreed to the published version of the manuscript.

Funding: This work was supported by the Open Research Foundation of Key Laboratory of the Pearl River Estuary Regulation and Protection of Ministry of Water Resources, China (Grant number: 2021KJ02).

Institutional Review Board Statement: Not applicable.

Informed Consent Statement: Not applicable.

Data Availability Statement: Data is contained within the article.

Conflicts of Interest: The authors declare no conflict of interest. 


\section{References}

1. Fang, H.W.; Lai, H.J.; Cheng, W.; Huang, L.; He, G.J. Modeling sediment transport with an integrated view of the biofilm effects. Water Resour. Res. 2017, 53, 7536-7557. [CrossRef]

2. Son, M.; Hsu, T.J. Flocculation model of cohesive sediment using variable fractal dimension. Environ. Fluid Mech. 2008, 8, 55-71. [CrossRef]

3. Lai, H.; Fang, H.; Huang, L.; He, G.; Reible, D. A review on sediment bioflocculation: Dynamics, influencing factors and modeling. Sci. Total Environ. 2018, 642, 1184-1200. [CrossRef] [PubMed]

4. Maggi, F. The settling velocity of mineral, biomineral, and biological particles and aggregates in water. J. Geophys. Res. Ocean. 2013, 118, 2118-2132. [CrossRef]

5. Maggi, F.; Tang, F.H.M. Analysis of the effect of organic matter content on the architecture and sinking of sediment aggregates. Mar. Geol. 2015, 363, 102-111. [CrossRef]

6. Mietta, F.; Chassagne, C.; Manning, A.J.; Winterwerp, J.C. Influence of shear rate, organic matter content, pH and salinity on mud flocculation. Ocean Dyn. 2009, 59, 751-763. [CrossRef]

7. Tang, F.H.M.; Maggi, F. A mesocosm experiment of suspended particulate matter dynamics in nutrient- and biomass-affected waters. Water Res. 2016, 89, 76-86. [CrossRef]

8. Dyer, K.R. Sediment processes in estuaries: Future research requirements. J. Geophys. Res. 1989, 94, 14327-14339. [CrossRef]

9. Winterwerp, J.C. A simple model for turbulence induced flocculation of cohesive sediment. J. Hydraul. Res. 1998, 36, 309-326. [CrossRef]

10. $\mathrm{Xu}$, F.; Wang, D.P.; Riemer, N. Modeling flocculation processes of fine-grained particles using a size-resolved method: Comparison with published laboratory experiments. Cont. Shelf Res. 2008, 28, 2668-2677. [CrossRef]

11. Ahn, J.H. Size distribution and settling velocities of suspended particles in a tidal embayment. Water Res. 2012, 46, 3219-3228. [CrossRef]

12. Soulsby, R.L.; Manning, A.J.; Spearman, J.; Whitehouse, R.J.S. Settling velocity and mass settling flux of flocculated estuarine sediments. Mar. Geol. 2013, 339, 1-12. [CrossRef]

13. Guo, L.; Zhang, D.; Xu, D.; Chen, Y. An experimental study of low concentration sludge settling velocity under turbulent condition. Water Res. 2009, 43, 2383-2390. [CrossRef]

14. Boyd, P.W.; Trull, T.W. Understanding the export of biogenic particles in oceanic waters: Is there consensus? Prog. Oceanogr. 2007, 72, 276-312. [CrossRef]

15. Gratiot, N.; Bildstein, A.; Anh, T.T.; Thoss, H.; Denis, H.; Michallet, H.; Apel, H. Sediment flocculation in the Mekong River estuary, Vietnam, an important driver of geomorphological changes. Comptes Rendus Geosci. 2017, 349, 260-268. [CrossRef]

16. Herbert, R.A. Nitrogen cycling in coastal marine ecosystems. FEMS Microbiol. Rev. 1999, 23, 563-590. [CrossRef]

17. Hill, P.S.; Newgard, J.P.; Law, B.A.; Milligan, T.G. Flocculation on a muddy intertidal flat in Willapa Bay, Washington, Part II: Observations of suspended particle size in a secondary channel and adjacent flat. Cont. Shelf Res. 2013, 60, S145-S156. [CrossRef]

18. Biggs, C.; Lant, P.; Hounslow, M. Modelling the effect of shear history on activated sludge flocculation. Water Sci. Technol. 2003, 47, 251-257. [CrossRef]

19. Gregory, J. Monitoring floc formation and breakage. Water Sci. Technol. 2004, 50, 163-170. [CrossRef]

20. Nan, J.; Wang, Z.; Yao, M.; Yang, Y.; Zhang, X. Characterization of re-grown floc size and structure: Effect of mixing conditions during floc growth, breakage and re-growth process. Environ. Sci. Pollut. Res. 2016, 23, 23750-23757. [CrossRef]

21. Oles, V. Shear-induced aggregation and breakup of polystyrene latex particles. J. Colloid Interface Sci. 1992, 154, 351-358. [CrossRef]

22. Slavik, I.; Müller, S.; Mokosch, R.; Azongbilla, J.A.; Uhl, W. Impact of shear stress and pH changes on floc size and removal of dissolved organic matter (DOM). Water Res. 2012, 46, 6543-6553. [CrossRef]

23. Spicer, P.T.; Pratsinis, S.E.; Raper, J.; Amal, R.; Bushell, G.; Meesters, G. Effect of shear schedule on particle size, density, and structure during flocculation in stirred tanks. Powder Technol. 1998, 97, 26-34. [CrossRef]

24. Xu, W.; Gao, B.; Yue, Q.; Wang, Y. Effect of shear force and solution $\mathrm{pH}$ on flocs breakage and re-growth formed by nano-Al13 polymer. Water Res. 2010, 44, 1893-1899. [CrossRef]

25. Wu, M.R.; van de Ven, T.G.M. Flocculation and reflocculation: Interplay between the adsorption behavior of the components of a dual flocculant. Colloids Surfaces A Physicochem. Eng. Asp. 2009, 341, 40-45. [CrossRef]

26. Biggs, C.A.; Lant, P.A. Activated sludge flocculation: On-line determination of floc size and the effect of shear. Water Res. 2000, 34, 2542-2550. [CrossRef]

27. Chaignon, V.; Lartiges, B.S.; El Samrani, A.; Mustin, C. Evolution of size distribution and transfer of mineral particles between flocs in activated sludges: An insight into floc exchange dynamics. Water Res. 2002, 36, 676-684. [CrossRef]

28. Keyvani, A.; Strom, K. Influence of cycles of high and low turbulent shear on the growth rate and equilibrium size of mud flocs. Mar. Geol. 2014, 354, 1-14. [CrossRef]

29. Wu, M.; Yu, W.; Qu, J.; Gregory, J. The variation of flocs activity during floc breakage and aging, adsorbing phosphate, humic acid and clay particles. Water Res. 2019, 155, 131-141. [CrossRef]

30. Son, M.; Hsu, T.J. The effect of variable yield strength and variable fractal dimension on flocculation of cohesive sediment. Water Res. 2009, 43, 3582-3592. [CrossRef]

31. Xu, C.; Dong, P. A Dynamic Model for Coastal Mud Flocs with Distributed Fractal Dimension. J. Coast. Res. 2017, 33, 218-225. [CrossRef] 
32. Kuprenas, R.; Tran, D.; Strom, K. A Shear-Limited Flocculation Model for Dynamically. J. Geophys. Res. Oceans 2018, 123, 6736-6752. [CrossRef]

33. Kranenburg, C. Effects of floc strength on viscosity and deposition of cohesive sediment suspensions. Cont. Shelf Res. 1999, 19, 1665-1680. [CrossRef]

34. Li, D.; Li, Z.; Gao, Z. Quadrature-based moment methods for the population balance equation: An algorithm review. Chin. J. Chem. Eng. 2019, 27, 483-500. [CrossRef]

35. Maggi, F. Effect of variable fractal dimension on the floc size distribution of suspended cohesive sediment. J. Hydrol. 2007, 343, 43-55. [CrossRef]

36. Shen, X.; Maa, J.P.Y. Numerical simulations of particle size distributions: Comparison with analytical solutions and kaolinite flocculation experiments. Mar. Geol. 2016, 379, 84-99. [CrossRef]

37. Shen, X.; Maa, J.P.Y. Modeling floc size distribution of suspended cohesive sediments using quadrature method of moments. Mar. Geol. 2015, 359, 106-119. [CrossRef]

38. Shen, X.; Toorman, E.A.; Fettweis, M.; Lee, B.J.; He, Q. Simulating multimodal floc size distributions of suspended cohesive sediments with lognormal subordinates: Comparison with mixing jar and settling column experiments. Coast. Eng. 2019, 148, 36-48. [CrossRef]

39. Zhang, J.F.; Zhang, Q.H. Lattice boltzmann simulation of the flocculation process of cohesive sediment due to differential settling. Cont. Shelf Res. 2011, 31, S94-S105. [CrossRef]

40. Tran, D.; Kuprenas, R.; Strom, K. How do changes in suspended sediment concentration alone influence the size of mud flocs under steady turbulent shearing? Cont. Shelf Res. 2018, 158, 1-14. [CrossRef]

41. Vlieghe, M.; Coufort-Saudejaud, C.; Liné, A.; Frances, C. QMOM-based population balance model involving a fractal dimension for the flocculation of latex particles. Chem. Eng. Sci. 2016, 155, 65-82. [CrossRef]

42. Thomas, D.N.; Judd, S.J.; Fawcett, N. Flocculation modelling: A review. Water Res. 1999, 33, 1579-1592. [CrossRef]

43. Sporleder, F.; Borka, Z.; Solsvik, J.; Jakobsen, H.A. On the population balance equation. Rev. Chem. Eng. 2012, 28, 149-169. [CrossRef]

44. Su, J.; Gu, Z.; Xu, X.Y. Advances in numerical methods for the solution of population balance equations for disperse phase systems. Sci. China Ser. B Chem. 2009, 52, 1063-1079. [CrossRef]

45. Zhang, J.F.; Zhang, Q.H.; Maa, J.P.Y.; Qiao, G.Q. Lattice Boltzmann simulation of turbulence-induced flocculation of cohesive sediment Topical Collection on the 11th International Conference on Cohesive Sediment Transport. Ocean Dyn. 2013, 63, 1123-1135. [CrossRef]

46. Maggi, F. Stochastic flocculation of cohesive sediment: Analysis of floc mobility within the floc size spectrum. Water Resour. Res. 2008, 44, 1-10. [CrossRef]

47. Shin, H.J.; Son, M.; Lee, G.H. Stochastic flocculation model for cohesive sediment suspended in water. Water 2015, 7, 2527-2541. [CrossRef]

48. Shen, X.; Lin, M.; Zhu, Y.; Ha, H.K.; Fettweis, M.; Hou, T.; Toorman, E.A.; Maa, J.P.Y.; Zhang, J. A quasi-Monte Carlo based flocculation model for fine-grained cohesive sediments in aquatic environments. Water Res. 2021, 194, 116953. [CrossRef]

49. Bubakova, P.; Pivokonsky, M.; Filip, P. Effect of shear rate on aggregate size and structure in the process of aggregation and at steady state. Powder Technol. 2013, 235, 540-549. [CrossRef]

50. Burban, P.Y.; Lick, W.; Lick, J. The flocculation of fine-grained sediments in estuarine waters. J. Geophys. Res. 1989, 94, 8323-8330. [CrossRef]

51. Stone, M.; Krishnappan, B.G. Floc morphology and size distributions of cohesive sediment in steady-state flow. Water Res. 2003, 37, 2739-2747. [CrossRef]

52. Guo, C.; He, Q.; Guo, L.; Winterwerp, J.C. A study of in-situ sediment flocculation in the turbidity maxima of the Yangtze Estuary. Estuar. Coast. Shelf Sci. 2017, 191, 1-9. [CrossRef]

53. Guo, L.; He, Q. Freshwater flocculation of suspended sediments in the Yangtze River, China. Ocean Dyn. 2011, 61, 371-386. [CrossRef]

54. Lee, B.J.; Toorman, E.; Fettweis, M. Multimodal particle size distributions of fine-grained sediments: Mathematical modeling and field investigation. Ocean Dyn. 2014, 64, 429-441. [CrossRef]

55. Lefebvre, J.P.; Ouillon, S.; Vinh, V.D.; Arfi, R.; Panché, J.Y.; Mari, X.; van Thuoc, C.; Torréton, J.P. Seasonal variability of cohesive sediment aggregation in the Bach Dang-Cam Estuary, Haiphong (Vietnam). Geo-Marine Lett. 2012, 32, 103-121. [CrossRef]

56. Xiao, Y.; Wu, Z.; Cai, H.; Tang, H. Suspended sediment dynamics in a well-mixed estuary: The role of high suspended sediment concentration (SSC) from the adjacent sea area. Estuar. Coast. Shelf Sci. 2018, 209, 191-204. [CrossRef]

57. Li, B.G.; Eisma, D.; Xie, Q.C.; Kalf, J.; Li, Y.; Xia, X. Concentration, clay mineral composition and Coulter counter size distribution of suspended sediment in the turbidity maximum of the Jiaojiang river estuary, Zhejiang, China. J. Sea Res. 1999, 42, 105-116. [CrossRef]

58. Eisma, D.; Li, A. Changes in suspended-matter floc size during the tidal cycle in the Dollard estuary. Netherlands J. Sea Res. 1993, 31, 107-117. [CrossRef]

59. Braithwaite, K.M.; Bowers, D.G.; Nimmo Smith, W.A.M.; Graham, G.W. Controls on floc growth in an energetic tidal channel. J. Geophys. Res. Ocean. 2012, 117, 1-12. [CrossRef] 
60. Chang, T.S.; Joerdel, O.; Flemming, B.W.; Bartholomä, A. The role of particle aggregation/disaggregation in muddy sediment dynamics and seasonal sediment turnover in a back-barrier tidal basin, East Frisian Wadden Sea, southern North Sea. Mar. Geol. 2006, 235, 49-61. [CrossRef]

61. Singh, V.P.; Sivakumar, B.; Cui, H. Tsallis entropy theory for modeling in water engineering: A review. Entropy 2017, $19,641$. [CrossRef]

62. Chiu, C.L. Entropy and probability concepts in hydraulics. J. Hydraul. Eng. 1987, 113, 583-599. [CrossRef]

63. Luo, H.; Singh, V.; Schmidt, A. Comparative study of 1D entropy-based and conventional deterministic velocity distribution equations for open channel flows. J. Hydrol. 2018, 563, 679-693. [CrossRef]

64. Mihailović, D.; Mimić, G.; Gualtieri, P.; Arsenić, I.; Gualtieri, C. Randomness representation of turbulence in canopy flows using Kolmogorov complexity measures. Entropy 2017, 19, 519. [CrossRef]

65. Kundu, S. Derivation of different suspension equations in sediment-laden flow from Shannon entropy. Stoch. Environ. Res. Risk Assess. 2018, 32, 563-576. [CrossRef]

66. Khozani, Z.S.; Wan Mohtar, W.H.M. Investigation of new Tsallis-based equation to predict shear stress distribution in circular and trapezoidal channels. Entropy 2019, 21, 1046. [CrossRef]

67. Singh, V.P. Entropy theory for movement of moisture in soils. Water Resour. Res. 2010, 46, 1-12. [CrossRef]

68. Singh, V.P.; Byrd, A.; Cui, H. Flow Duration Curve Using Entropy Theory. J. Hydrol. Eng. 2014, 19, 1340-1348. [CrossRef]

69. Singh, V.P.; Cui, H.; Byrd, A. Sediment Graphs Based on Entropy Theory. J. Hydrol. Eng. 2015, 20, 1-10. [CrossRef]

70. Singh, V.P.; Cui, H.; Byrd, A.R. Derivation of rating curve by the Tsallis entropy. J. Hydrol. 2014, 513, 342-352. [CrossRef]

71. Zhu, Z.; Hei, P.; Dou, J.; Peng, D. Evaluating different methods for determining the velocity-dip position over the entire cross section and at the centerline of a rectangular open channel. Entropy 2020, 22, 605. [CrossRef] [PubMed]

72. Zhao, K.; Vowinckel, B.; Hsu, T.J.; Köllner, T.; Bai, B.; Meiburg, E. An efficient cellular flow model for cohesive particle flocculation in turbulence. J. Fluid Mech. 2020, 889, 1-11. [CrossRef]

73. Zhu, Z. A simple explicit expression for the flocculation dynamics modeling of cohesive sediment based on entropy considerations. Entropy 2018, 20, 845. [CrossRef] [PubMed]

74. Xu, W.; Gao, B. Effect of shear conditions on floc properties and membrane fouling in coagulation/ultrafiltration hybrid process-The significance of Al b species. J. Memb. Sci. 2012, 415-416, 153-160. [CrossRef]

75. Wu, B.; Zheng, S.; Thorne, C.R. A general framework for using the rate law to simulate morphological response to disturbance in the fluvial system. Prog. Phys. Geogr. 2012, 36, 575-597. [CrossRef]

76. Jing, H.; Zhong, D.; Zhang, H.; Shi, X.; Wang, Y. The accumulation phenomenon and stochastic model in fluvial processes. Acta Geogr. Sin. 2020, 75, 1079-1094. [CrossRef]

77. Tsai, C.H.; Iacobellis, S.; Lick, W. Flocculation of Fine-Grained Lake Sediments Due to a Uniform Shear Stress. J. Great Lakes Res. 1987, 13, 135-146. [CrossRef]

78. Colomer, J.; Peters, F.; Marrasé, C. Experimental analysis of coagulation of particles under low-shear flow. Water Res. 2005, 39, 2994-3000. [CrossRef]

79. Serra, T.; Casamitjana, X. Structure of the aggregates during the process of aggregation and breakup under a shear flow. J. Colloid Interface Sci. 1998, 206, 505-511. [CrossRef]

80. Serra, T.; Colomer, J.; Casamitjana, X. Aggregation and breakup of particles in a shear flow. J. Colloid Interface Sci. 1997, 187, 466-473. [CrossRef]

81. Zhu, Z.; Zhao, M.; Yang, T.S. Review on experimental research on effect of shear flow on flocculation of cohesive sediment. J. Sedi. Res. 2010, 4, 3-10. [CrossRef]

82. Rau, M.J.; Ackleson, S.G.; Smith, G.B. Effects of turbulent aggregation on clay floc breakup and implications for the oceanic environment. PLoS ONE 2018, 13, 1-28. [CrossRef]

83. Verney, R.; Lafite, R.; Brun-cottan, J.C.; Le, P. Behaviour of a floc population during a tidal cycle: Laboratory experiments and numerical modelling. Cont. Shelf Res. 2011, 31, S64-S83. [CrossRef]

84. Xu, F.; Wang, D.; Riemer, N. An idealized model study of flocculation on sediment trapping in an estuarine turbidity maximum. Cont. Shelf Res. 2010, 30, 1314-1323. [CrossRef]

85. Choi, S.M.; Seo, J.Y.; Ha, H.K.; Lee, G. hong Estimating effective density of cohesive sediment using shape factors from holographic images. Estuar. Coast. Shelf Sci. 2018, 215, 144-151. [CrossRef]

86. Li, W.; Yang, S.; Hu, J.; Fu, X.; Zhang, P. Field measurements of settling velocities of fine sediments in Three Gorges Reservoir using ADV. Int. J. Sediment Res. 2016, 31, 237-243. [CrossRef]

87. Liu, W.C. Modeling the influence of settling velocity on cohesive sediment transport in Tanshui River estuary. Environ. Geol. 2005, 47, 535-546. [CrossRef]

88. Sherwood, C.R.; Aretxabaleta, A.L.; Harris, C.K.; Rinehimer, J.P.; Verney, R.; Sherwood, C.C.R. Cohesive and mixed sediment in the Regional Ocean Modeling System (ROMS v3. 6) implemented in the Coupled Ocean-Atmosphere-Wave-Sediment Transport Modeling System (COAWST r1234). Geosci. Model Dev. 2018, 11, 1849-1871. [CrossRef]

89. Forsberg, P.L.; Skinnebach, K.H.; Becker, M.; Ernstsen, V.B.; Kroon, A.; Andersen, T.J. The influence of aggregation on cohesive sediment erosion and settling. Cont. Shelf Res. 2018, 171, 52-62. [CrossRef]

90. Manning, A.J.; Bass, S.J. Variability in cohesive sediment settling fluxes: Observations under different estuarine tidal conditions. Mar. Geol. 2006, 235, 177-192. [CrossRef] 
91. Shang, Q.Q.; Fang, H.W.; Zhao, H.M.; He, G.J.; Cui, Z.H. Biofilm effects on size gradation, drag coefficient and settling velocity of sediment particles. Int. J. Sediment Res. 2014, 29, 471-480. [CrossRef]

92. Strom, K.; Keyvani, A. An Explicit Full-Range Settling Velocity Equation for Mud Flocs. J. Sediment. Res. 2011, 81, 921-934. [CrossRef]

93. Maerz, J.; Verney, R.; Wirtz, K.; Feudel, U. Modeling flocculation processes: Intercomparison of a size class-based model and a distribution-based model. Cont. Shelf Res. 2011, 31, S84-S93. [CrossRef]

94. Mietta, F.; Chassagne, C.; Verney, R.; Winterwerp, J.C. On the behavior of mud floc size distribution: Model calibration and model behavior. Ocean Dyn. 2011, 61, 257-271. [CrossRef]

95. Shen, X.; Lee, B.J.; Fettweis, M.; Toorman, E.A. A tri-modal flocculation model coupled with TELEMAC for estuarine muds both in the laboratory and in the field. Water Res. 2018, 145, 473-486. [CrossRef]

96. Keyvani, A.; Strom, K. Flocculation in a decaying shear field and its applications for mud removal in near-field river mouth discharges. J. Geophys. Res. Ocean 2016, 121, 2142-2162. [CrossRef]

97. Badireddy, A.R.; Chellam, S.; Gassman, P.L.; Engelhard, M.H.; Lea, A.S.; Rosso, K.M. Role of extracellular polymeric substances in bioflocculation of activated sludge microorganisms under glucose-controlled conditions. Water Res. 2010, 44, 4505-4516. [CrossRef]

98. Deng, Z.; He, Q.; Safar, Z.; Chassagne, C. The role of algae in fine sediment flocculation: In-situ and laboratory measurements. Mar. Geol. 2019, 413, 71-84. [CrossRef]

99. Fang, H.; Chen, Y.; Huang, L.; He, G. Biofilm growth on cohesive sediment deposits: Laboratory experiment and model validation. Hydrobiologia 2017, 799, 261-274. [CrossRef]

100. Shen, X.; Toorman, E.A.; Lee, B.J.; Fettweis, M. Biophysical flocculation of suspended particulate matters in Belgian coastal zones. J. Hydrol. 2018, 567, 238-252. [CrossRef] 